University of Louisville

ThinkIR: The University of Louisville's Institutional Repository

Electronic Theses and Dissertations

$12-2011$

\title{
Annonacin in Asimina triloba fruit : implications for neurotoxicity.
}

Lisa Fryman Potts

University of Louisville

Follow this and additional works at: https://ir.library.louisville.edu/etd

\section{Recommended Citation}

Potts, Lisa Fryman, "Annonacin in Asimina triloba fruit : implications for neurotoxicity." (2011). Electronic Theses and Dissertations. Paper 1145.

https://doi.org/10.18297/etd/1145

This Doctoral Dissertation is brought to you for free and open access by ThinkIR: The University of Louisville's Institutional Repository. It has been accepted for inclusion in Electronic Theses and Dissertations by an authorized administrator of ThinkIR: The University of Louisville's Institutional Repository. This title appears here courtesy of the author, who has retained all other copyrights. For more information, please contact thinkir@louisville.edu. 


\title{
ANNONACIN IN ASIMINA TRILOBA FRUIT: IMPLICATIONS FOR NEUROTOXICITY
}

\author{
By \\ Lisa Fryman Potts \\ B.S. Centre College, 2005 \\ M.S. University of Louisville, 2010

\begin{abstract}
A Dissertation Submitted to the Faculty of the School of Medicine at the University of Louisville

Doctor of Philosophy

Department of Anatomical Sciences and Neurobiology University of Louisville School of Medicine Louisville, Kentucky
\end{abstract} \\ in Partial Fulfillment of the Requirements for the Degree of
}

December 2011 
Copyright 2011 by Lisa Fryman Potts

All rights reserved 
ANNONACIN IN ASIMINA TRILOBA FRUIT:

IMPLICATIONS FOR NEUROTOXICITY

\author{
By \\ Lisa Fryman Potts \\ B.S. Centre College, 2005 \\ M.S. University of Louisville, 2010
}

A Dissertation Approved on

July 21, 2011

by the following Dissertation Committee:

Irene Litvan, M.D.

Dissertation Director

Frederick Luzzio, Ph.D.

Michal Hetman, M.D., Ph.D.

David Hein, Ph.d.

Theo Hagg, Ph.D.

Martha Bickford, Ph.D. 


\section{DEDICATION}

This dissertation is dedicated to my parents

Mr. Harry Fryman

and

Mrs. Linda Fryman

and my husband

Mr. Joseph Potts

who have supported me throughout my academic career and life 


\section{ACKNOWLEDGEMENTS}

I would like to thank my mentor, Dr. Irene Litvan for her guidance and support. I would also like to thank Dr. Frederick Luzzio and Dr. Michal Hetman for their support and mentorship on specific aspects of this research. I also thank my other committee members, Dr. David Hein, Dr. Theo Hagg and Dr. Martha Bickford for their support and guidance during my graduate career at the University of Louisville. I would also like to thank Dr. Pierre Champy for sample donation and consultation, Ms. Juan Chen and Dr. Bogdan Bogdanov for their technical assistance, as well as Mr. Scott Smith for his technical assistance and moral support. I would also like to express my appreciation to Dr. Samuel Weakly and Ms. Lydia B. Miller for their generosity in donating research funds that supported this project. 


\title{
ABSTRACT
}

\section{ANNONACIN IN ASIMINA TRILOBA FRUIT: IMPLICATIONS FOR NEUROTOXICITY}

\author{
Lisa F. Potts
}

November 28, 2011

The acetogenin annonacin, from the tropical annonaceous plant Annona muricata, is a lipophilic, mitochondrial complex I inhibitor reported to be more toxic than rotenone to mesencephalic neurons. The temperate annonaceous plant Asimina triloba (pawpaw) is native to the Eastern United States and its products are available online. This study determined whether annonacin is in the pawpaw fruit pulp and whether it or the crude ethyl acetate (EtOAc) extract is toxic to cortical neurons and induces pathological changes in the microtubule associated protein tau.

Pawpaw extract was prepared by pulp extraction with methanol and liquidliquid partitioning with EtOAc. Annonacin was isolated from the crude EtOAc extract via column chromatography using a gradient solvent system of increasing polarity. Mass spectroscopy, nuclear magnetic resonance and infrared 
spectroscopy were used to compare isolated material with synthetic annonacin and a natural annonacin sample. Toxicity of isolated annonacin and the total EtOAc extract were determined in primary rat cortical neurons using the MTT (3(4,5-dimethylthiazol-2-yl)-2,5-diphenyltetrazolium bromide) assay. The effects of annonacin on tau phosphorylation were determined by immunocytochemistry and western blot analysis.

The average concentration of annonacin in the fruit pulp was $0.07 \pm 0.03$ $\mathrm{mg} / \mathrm{g}$. Purified annonacin $(30.07 \mu \mathrm{g} / \mathrm{ml})$ and crude EtOAc extract $(47.96 \mu \mathrm{g} / \mathrm{ml})$ reduced relative viability of cortical neurons by $50 \% \mathbf{4 8}$ hours post treatment. Annonacin toxicity was enhanced in the presence of crude extract. Annonacin treatment resulted in a decrease in the neuronal specific marker microtubule associated protein 2 (MAP2) and tau immunoreactivity, and tau expression was decreased on western blot.

In conclusion, Asimina triloba fruit contains a high concentration of annonacin, which is toxic to cortical neurons. Based on these results, annonacin acts to reduce overall levels of tau, though it remains elusive whether or not this is a direct or indirect effect of annonacin action. Crude fruit extract also induced neurotoxicity, highlighting the need for additional studies to determine the bioavailability after consumption and potential risks of neurodegeneration associated with chronic exposure to pawpaw products. 


\section{TABLE OF CONTENTS}

\section{PAGE}

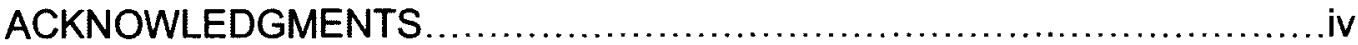

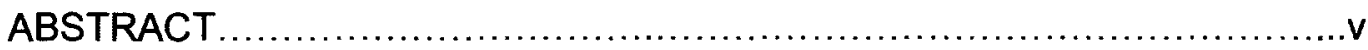

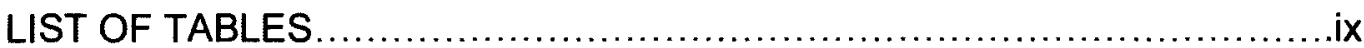

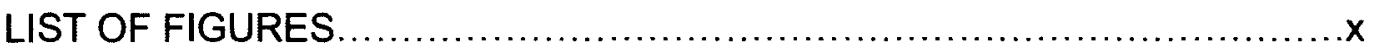

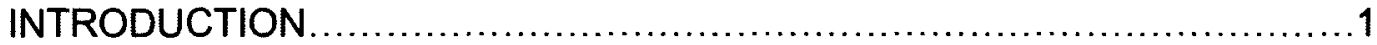

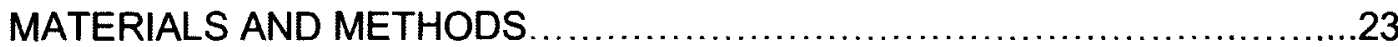

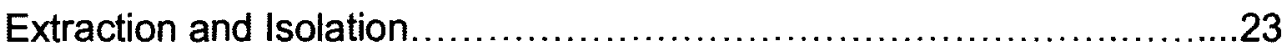

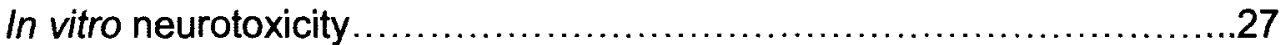

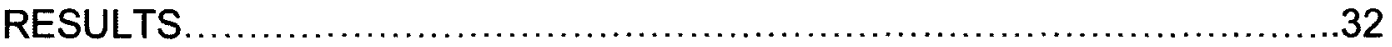

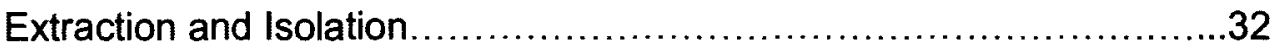

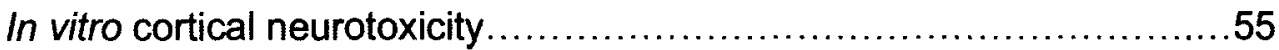

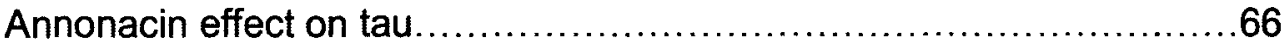

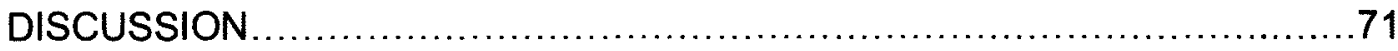

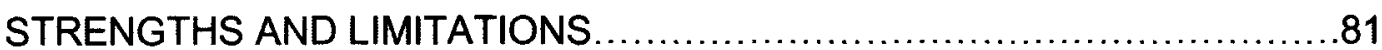


CONCLUSIONS AND FUTURE CONSIDERATIONS

.84

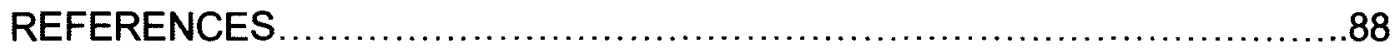

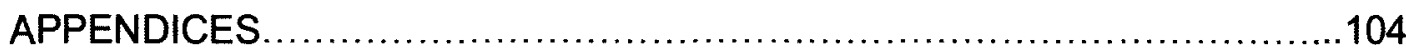

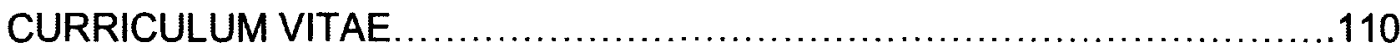




\section{LIST OF TABLES}

TABLE

PAGE

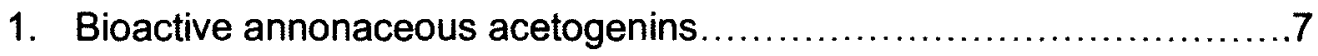

2. Neurotoxicity of relevant compounds ..................................... 19

3. Chemical structures and ${ }^{1} \mathrm{H}$ and ${ }^{13} \mathrm{C}$ NMR data for Annonacin and

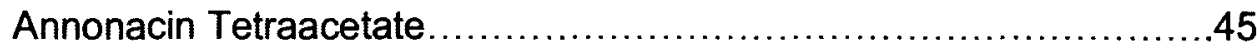

4. Annonacin content of Asimina triloba vs. Annona muricata..............54 


\section{LIST OF FIGURES}

1. Asimina triloba (pawpaw) tree .2

2. Distribution of As. triloba in North America 4

3. Annona muricata (soursop) tree .5

4. Soursop fruit. .9

5. Pawpaw fruit. . .9

6. Structure of Annonacin. .10

7. Relevant Complex-1 Inhibitors. 15

8. Annonacin TLC. .35

9. FTMS of annonacin .36

10. ${ }^{1} \mathrm{H}$ NMR of annonacin. 43

11. Conversion of annonacin to annonacin tetraacetate derivative 47

12. Annonacin and tetraacetate TLC. .48 
13. FTMS of annonacin and annonacin-tetraacetate.

14. ${ }^{1} \mathrm{H}$ NMR of annonacin and annonacin-tetraacetate.

15. FTIR of annonacin and annonacin-tetraacetate.

16. Cortical neurons $48 \mathrm{hrs}$ after AN treatment .56

17. Time-response of MAP2 immunoreactivity in cortical neurons after annonacin treatment.

18. Tau immunoreactivity in cortical neurons after annonacin treatment.....59

19. Solvent tolerance of cortical neurons after $48 \mathrm{hrs}$ 62

20. Cortical neurons $48 \mathrm{hrs}$ after pawpaw extract treatments. .64

21. Dose-responses of cortical neurons $48 \mathrm{hrs}$ after pawpaw extract treatments. 65

22. Tau expression $4 \mathrm{hrs}$. after annonacin treatment. 67

23. GSK-3ß expression 4 hrs. after annonacin treatment 69 


\section{CHAPTER I}

\section{INTRODUCTION}

Annonaceous acetogenins (ACGs), specifically annonacin, isolated from Annona muricata (An. muricata) fruit, bark and leaves are naturally occurring compounds exhibiting a range of biological activities related to inhibition of mitochondrial complex I of the electron transport chain. ${ }^{1-4}$ The annonaceous plants have been investigated for their potential as cancer treatments, ${ }^{5-8}$ but also for neurotoxicity due to their high content of acetogenins. ${ }^{9,10}$ The purpose of this project was to determine the presence and quantity of annonacin in Asimina triloba (As. triloba) fruit pulp and assess annonacin and crude extract toxicity in cultured cortical neurons, which are affected in a number of neurodegenerative diseases.

\section{Annonaceous Plants}

The Annonaceae, or custard-apple, family consists of many different genera including Annona and Asimina, each containing several species. The United States Department of Agriculture provides a complete list of the 205 Annonaceae genera on the Germplasm Resources Information Network (GRIN, 
http://www.ars-grin.gov/cgi-bin/npgs/html/exgnlist.pl) including Annona (89) and Asimina (12) individual species taxonomy. Most annonaceous plants are confined to tropical or sub-tropical climates; however, the Asimina species are also tolerant of temperate climates. ${ }^{8}$

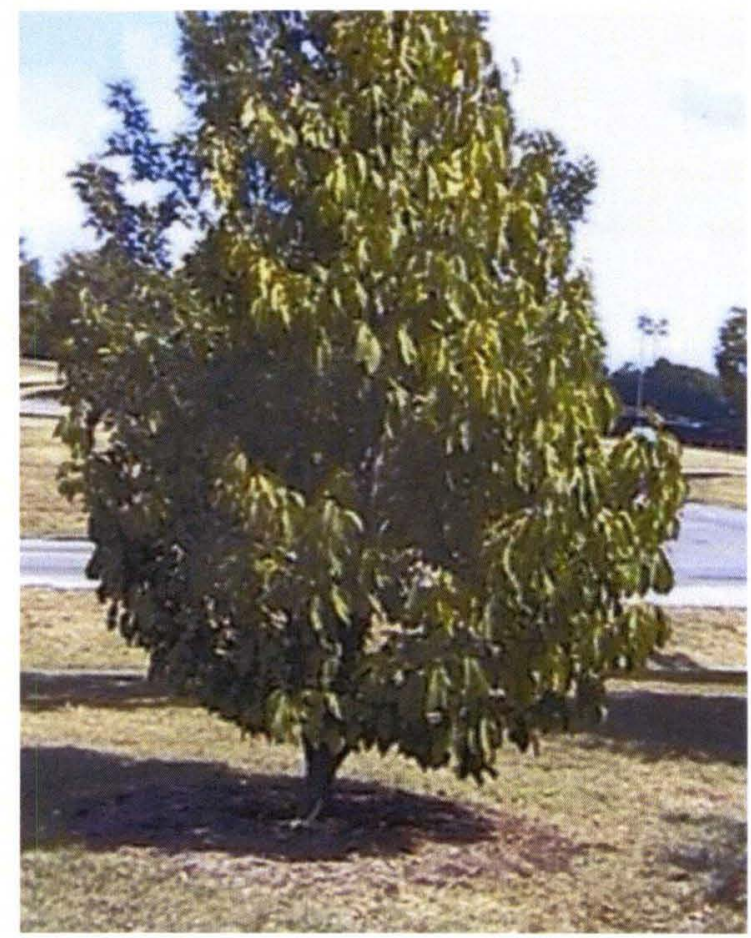

Figure 1. Asimina triloba (pawpaw) tree at the University of Kentucky Arboretum in Lexington, KY (2008). 
Specifically, As. triloba (Figure 1. pawpaw, papaw, prairie banana, poor man's banana, dog banana, Ozark banana, Banango, also commonly referred to as its native states "banana" e.g. Indiana/Hoosier banana, Kentucky banana) is native to the Eastern United States and even southern parts of Canada making it the only fruit-bearing annonaceous plant found abundantly throughout North America (Figure 2).

The Annonaceae are widely studied due to their high concentrations of cytotoxic alkaloids and acetogenins, which may be useful as anti-cancer, antifungal, anti-viral, and pesticidal agents. ${ }^{3,11-13}$ Annona muricata (Figure 3. An. muricata, soursop, graviola, guanabana, Brazilian pawpaw, prickly custard apple) is particularly well known for its medicinal use as an anti-cancer agent. ${ }^{7,14}$ Recently, graviola was even featured on the popular $\mathrm{Dr}$. Oz show for its immunity-boosting properties http://www.doctoroz.com/videos/rainforestremedies-pt-2, May 23, 2011). As. triloba is also growing in popularity for its potential use in alternative medicine and is being promoted for development as an alternative cash crop to tobacco in some states. ${ }^{15,16}$ 


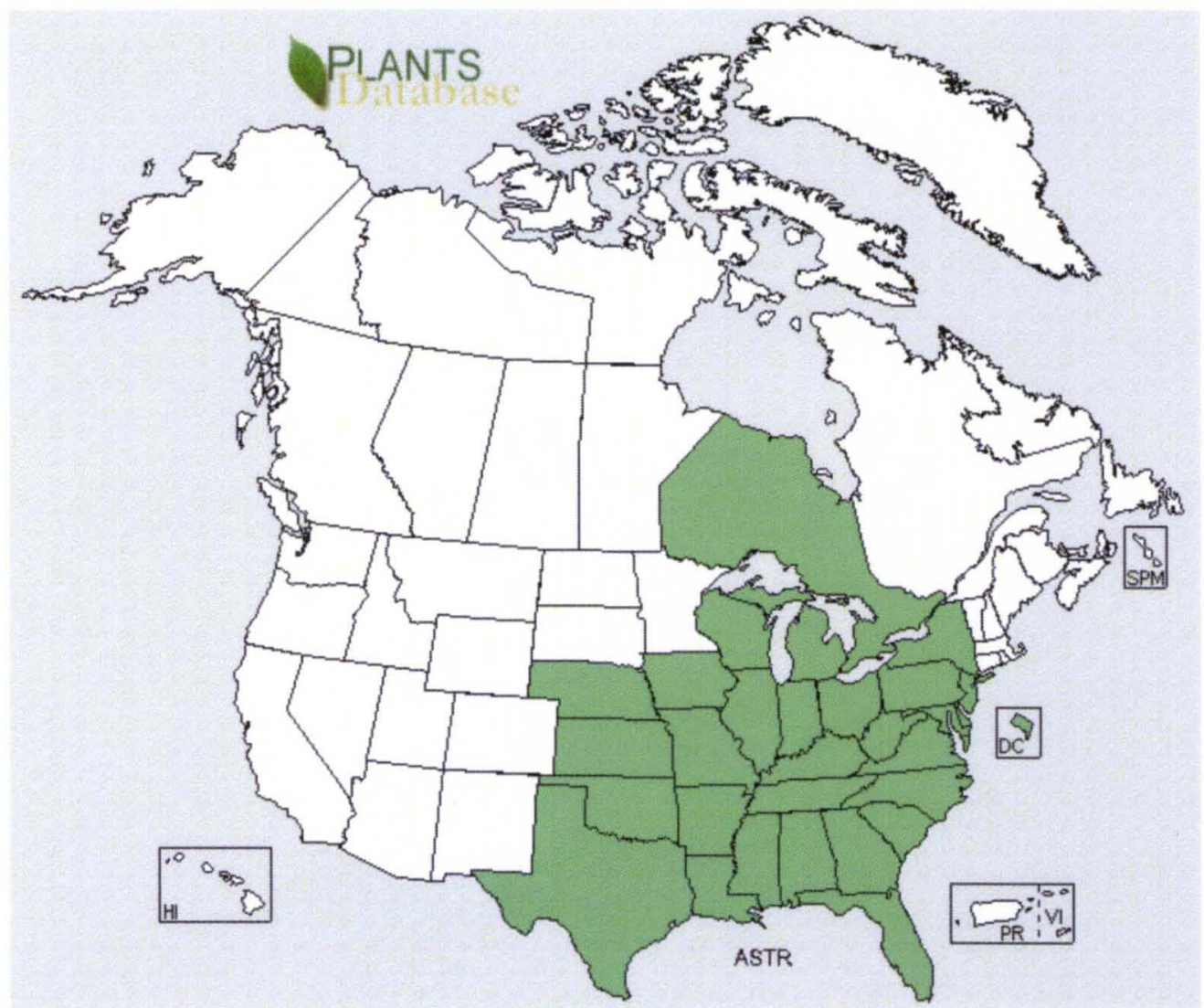

Figure 2. Distribution of As. triloba in North America. Map and related information from the United States department of agriculture natural resources conservation services is available online at http://plants.usda.gov. 


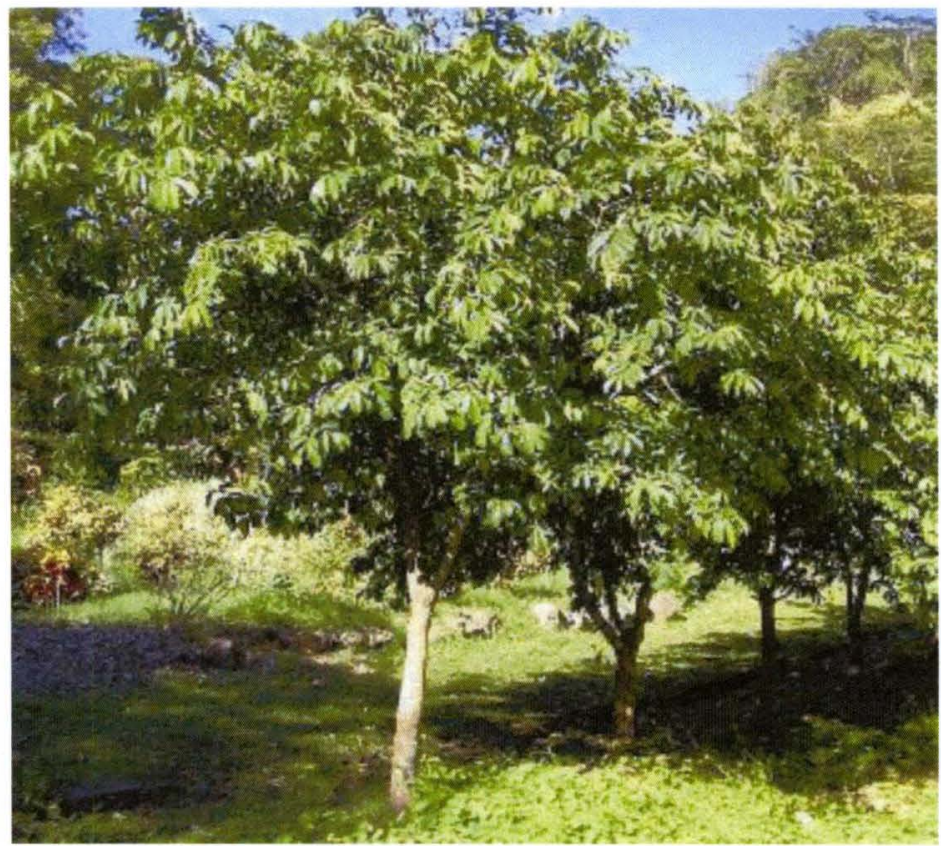

Figure 3. Annona muricata (soursop) tree. (image from http://www.fruitipedia.com/soursop\%20Annona\%20muri cata.htm)

\section{Acetogenins}

ACGs are a class of polyketide compounds containing, in most cases, a long hydrocarbon chain and a terminal y-lactone moiety (i.e. butenolide). Most ACGs contain one or more tetrahydrofuran (THF) rings, (see Table 1 for a brief list of bioactive annonaceous acetogenins). However, there are some without a THF ring that may contain tetrahydropyran (THP) or epoxy rings or that are linear. ${ }^{1}$ They are reported to be cytotoxic via mitochondrial complex-1 inhibition 
and adenosine triphosphate (ATP) depletion. ${ }^{8}$ Acetogenins can be found in various organs of annonaceous plants, with seeds and bark having historically been the most commonly studied. However, recent research on ACG content of the Annonaceae has investigated the fruit with reports of acetogenins in both soursop (Figure 4) and pawpaw (Figure 5) fruit pulp. 9, 17 
Table 1. Bioactive annonaceous acetogenins

\begin{tabular}{|c|c|c|c|c|c|c|}
\hline ACG name ${ }^{a}$ (MW) & Species & Organ & $\begin{array}{l}\text { Mol. } \\
\text { Formula }\end{array}$ & THF profile & $\begin{array}{l}\text { THF } \\
\text { Stereo- } \\
\text { chemistry }\end{array}$ & References \\
\hline Asimicin (622) & $\begin{array}{l}\text { As. triloba, } \\
\text { An. comifolia }\end{array}$ & $\begin{array}{l}\text { Bark, roots, seeds, pulp. } \\
\text { Seeds. }\end{array}$ & $\mathrm{C}_{37} \mathrm{H}_{66} \mathrm{O}_{7}$ & Adjacent bis- & th/th/thth & $T 1-20$ \\
\hline $\begin{array}{l}\text { Bullatacin (a.k.a. } \\
\text { rolliniastatin-2) } \\
(622)\end{array}$ & $\begin{array}{l}\text { As. triloba, } \\
\text { An. bullata, } \\
\text { An. comifolia, } \\
\text { R. mucosa }\end{array}$ & $\begin{array}{l}\text { Bark, pulp. } \\
\text { Bark. } \\
\text { Seeds. } \\
\text { Seeds. } \\
\end{array}$ & $\mathrm{C}_{37} \mathrm{H}_{66} \mathrm{O}_{7}$ & Adjacent bis- & th/th/t/ter & $11,18,19,21,22$ \\
\hline Trilobacin (622) & As. triloba & Bark & $\mathrm{C}_{37} \mathrm{H}_{66} \mathrm{O}_{7}$ & Adjacent bis & th/ter/c/th & 71,18 \\
\hline $\begin{array}{l}\text { Bullatalicin (a.k.a. } \\
\text { cherimolin-1) } \\
(638)\end{array}$ & $\begin{array}{l}\text { As. triloba } \\
\text { An. cherimolia, } \\
\text { An bullata }\end{array}$ & $\begin{array}{l}\text { Pulp. } \\
\text { Seeds. } \\
\text { Bark. }\end{array}$ & $\mathrm{C}_{37} \mathrm{H}_{66} \mathrm{O}_{8}$ & Non-adjacent bis & t/th-th/t/er & $73,17,21,23,24$ \\
\hline Asitrocin (596) & As. triloba & Seeds & $\mathrm{C}_{35} \mathrm{H}_{64} \mathrm{O}_{7}$ & Mono & ertth & 25 \\
\hline Annonacin (596) & $\begin{array}{l}\text { As. triloba } \\
\text { An. muricata } \\
\text { An. densicoma }\end{array}$ & $\begin{array}{l}\text { Bark, seeds. } \\
\text { Pulp, bark, leaves } \\
\text { Seeds }\end{array}$ & $\mathrm{C}_{35} \mathrm{H}_{64} \mathrm{O}_{7}$ & Mono & th/t/th & $0,18,26-29$ \\
\hline $\begin{array}{l}\text { Gigantetrocin-A } \\
\text { (596) }\end{array}$ & G.giganteus & Bark & $\mathrm{C}_{35} \mathrm{H}_{64} \mathrm{O}_{7}$ & Mono & tth-th & 30 \\
\hline $\begin{array}{l}\text { Asitrilobin-C and } \\
\text { D (624) }\end{array}$ & As. triloba & Seeds & $\mathrm{C}_{37} \mathrm{H}_{68} \mathrm{O}_{7}$ & Mono & th/thth & 31 \\
\hline Squadiolin A (640) & An. squamosa & Seeds & $\mathrm{C}_{37} \mathrm{H}_{68} \mathrm{O}_{8}$ & Mono & er/tth & 32 \\
\hline $\begin{array}{l}\text { Diepomuricanin-A } \\
\text { (546) }\end{array}$ & An. muricata & Seeds & $\mathrm{C}_{35} \mathrm{H}_{62} \mathrm{O}_{4}$ & $\begin{array}{l}\text { No THFs, rather bis- } \\
\text { epoxy rings }\end{array}$ & - & 33 \\
\hline $\begin{array}{l}\text { Butyrolactone-1 } \\
\text { (390) }\end{array}$ & P. macrocarpa & Seeds & $\mathrm{C}_{25} \mathrm{H}_{42} \mathrm{O}_{3}$ & $\begin{array}{l}\text { Linear ACG with no } \\
\text { THFs }\end{array}$ & - & \\
\hline
\end{tabular}




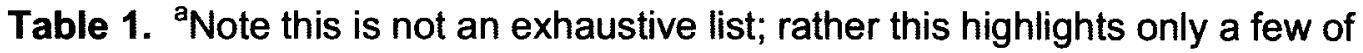
the numerous annonaceous acetogenins with reported bioactivity. See references 1,7 and 8 for thorough reviews of acetogenins and their bioactivities. THF stereochemistry refers to the stereochemistry of the bonds between the hydroxyl groups and the THF ring(s) and between the THF rings. Abbreviations: As. $=$ Asimina, An. = Annona, $R .=$ Rollinia, $G .=$ Goniothalamus, $P .=$ Phaleria; th $=$ threo, $t=$ trans, er = erythro, $c=$ cis. 


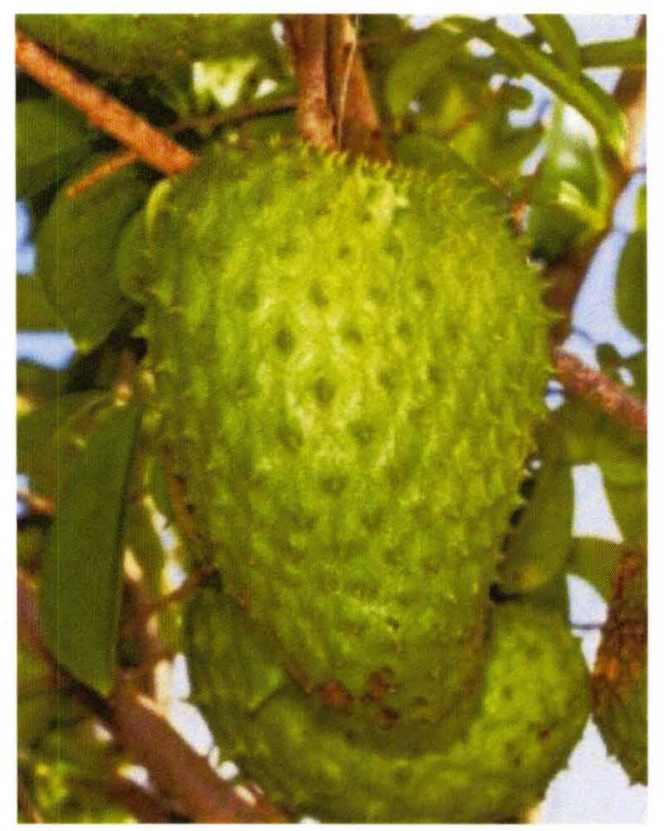

Figure 4. Soursop fruit on tree.

(http://www.fruitipedia.com/soursop $\% 20$

Annona\%20muricata.htm

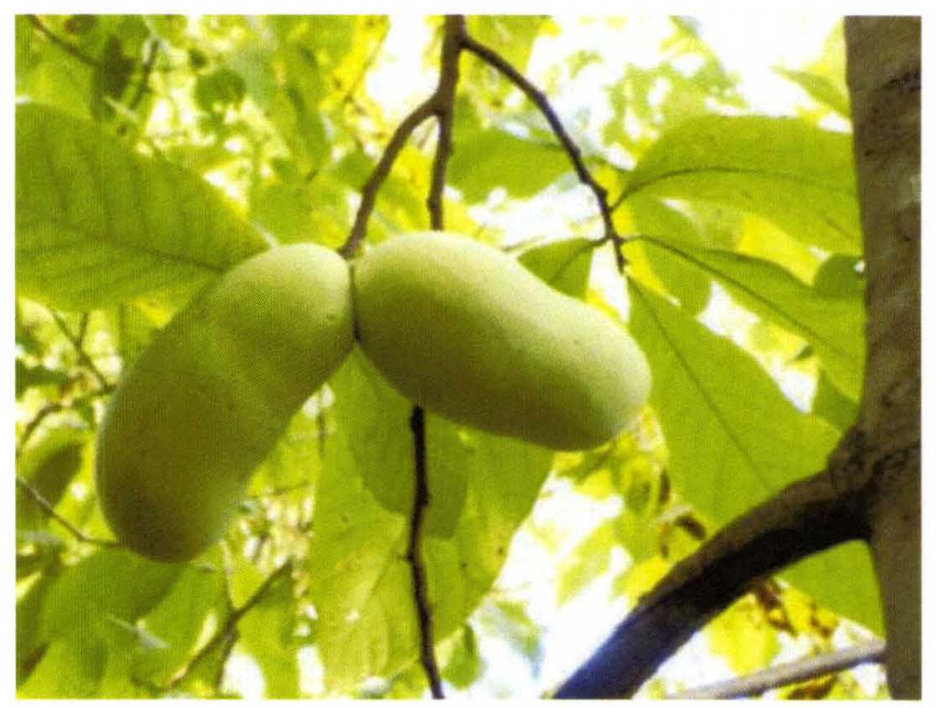

Figure 5. Pawpaw fruit on tree.

(http://www.meridian.k12.il.us/middle\%20school/st udent work/rricker native trees/Pawpaw.html) 
Current research on the acetogenin content of As. triloba is focused on bis-THFs indicating they are more cytotoxic than mono-THFs and therefore more relevant to cancer research $4,8,11,12,17,35$. Annonacin (Figure 6) is a mono-THF acetogenin found in the fruit, twigs, bark and leaves of An. muricata, and it is reported to be neurotoxic ${ }^{10}$.

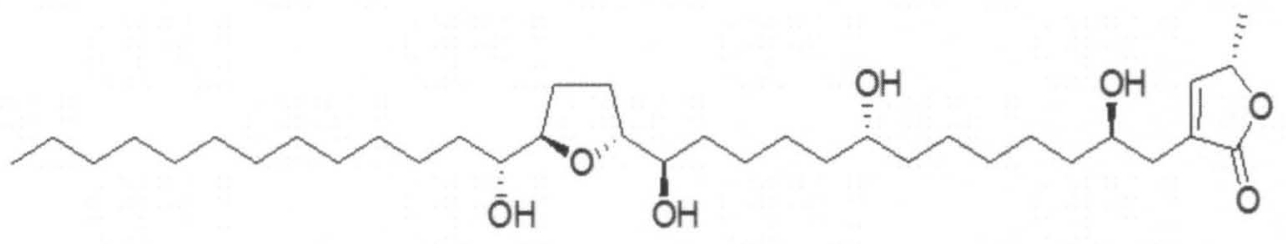

Figure 6. Structure of Annonacin: $\mathrm{C}_{35} \mathrm{H}_{64} \mathrm{O}_{7}$.

Though annonacin has also been found in As. triloba, these studies focused on parts of the plant that provided the most easily accessible extracts, such as twig bark or seeds, rather than fruit. ${ }^{18,27,28,36}$ Annonacin has also been detected in Paw-Paw Cell Reg ${ }^{\mathrm{TM}}$, a natural supplement prepared from As. triloba twig extracts. $^{8,26}$

\section{Public Health Significance}

As noted above, the annonaceous plants As. triloba and An. muricata are growing in popularity for various reasons including their potential use in the treatment of cancer. ${ }^{7,8}$ Products from each of these plants are widely available online for purchase year-round. The push to increase market awareness of As. triloba products as well as the potential medicinal uses for acetogenins is evident 
online and when reviewing the academic literature. ${ }^{7,8,15-17,26}$ For example, in a recent review of annonaceous acetogenins, Dr. Liaw notes the importance of considering these compounds in drug development: ${ }^{7}$

In 27 years, more than 500 acetogenins were isolated from various parts of the plants of this [Annonaceae] family. These bioactive acetogenins became more important, particularly in pharmaceutical research. A great interest in investigating the mechanisms of action of a series of acetogenins emerged from the leaps in knowledge about the processes involved in tumour cell death. Members of this class of natural compounds are regarded as "potential" candidates for future generations of anti-cancer drugs. Acetogenins have become one of the most interesting classes of natural products at present.

Such reports highlight the significance of determining the acetogenin content of the pawpaw fruit and other plant products. This is especially crucial considering reports of neurotoxicity associated with An. muricata, which has been traced to the presence of annonacin. ${ }^{10,37}$ Specifically, regular consumption of fruit and tea from tropical annonaceous plants was reported in two epidemiologic studies to be higher in patients with progressive supranuclear palsy (PSP) and with an unclassifiable atypical parkinsonian disorder than controls in the French West Indies. ${ }^{38-41}$

To date, neurotoxicity studies of the Annonaceae have focused either on specific extracts from fruits other than pawpaw (e.g. soursop) or on pure annonacin rather than on extracts from As. triloba. ${ }^{5,6}$ Recent toxicity studies on 
As. triloba have examined extracts other than annonacin and only considered their usefulness as pesticides or cancer-preventing therapies without considering potential neurotoxic effects. ${ }^{3,11,12,42}$ Again, the focus of these studies has been on extracts from those parts of the tree that potentially contain the highest concentrations and most easily accessible extracts. The design and/or outcome measures of these studies were not appropriate for assessing the risks of chronic exposure to extracts or consumption of the fruit. Specifically, potentially neurotoxic side effects could not be captured by these studies as safety/toxicity was determined based strictly on weight loss or other behavioral changes. ${ }^{8,42-44}$ However, as noted in Dr. Champy's studies, no behavioral abnormalities or systemic effects could be detected in rats chronically exposed to annonacin at concentrations high enough to produce widespread neurodegeneration. ${ }^{5}$ Hence, the toxicity studies on As. triloba extracts in cancer cells and tumors did not consider the possible presence of neuropathology that may have resulted in response to their treatment paradigms. Therefore, the acetogenin content of pawpaw fruit and elucidation of its neurotoxic potential is an important public health issue that should be investigated before pawpaw products become more widely used in alternative medicine.

\section{Relevance to Neurodegeneration}

Though Parkinson's (PD) and Alzheimer's (AD) diseases represent the most common neurodegenerative disorders affecting over 1.5 and 5 million Americans respectively, there are a number of atypical parkinsonian disorders 
(APDs) that are less common and not as widely researched including tauopathies such as progressive supranuclear palsy (PSP), fronto-temporal dementia with parkinsonism associated with chromosome 17 (FTDP-17) and cortical basal degeneration (CBD). The distribution of degeneration and tau pathology varies between tauopathies affecting brainstem and basal ganglia nuclei as in PSP and CBD as well as cortical areas as seen in AD, CBD and Pick's disease. ${ }^{45-48}$ Understanding mechanisms of pathogenesis of these diseases may provide useful information that can be translated to their representative class of disorders (e.g. tauopathies, parkinsonian disorders) or more broadly to the process of neurodegeneration.

Typical symptoms of PSP include early postural instability and falls, vertical supranuclear gaze palsy and L-3,4-dihydroxyphenylalanine (L-DOPA) unresponsive parkinsonism, therefore classifying it as an APD. ${ }^{49-51}$ Additionally, while there is loss of dopaminergic neurons in the substantia nigra, similar to PD, the pathological hallmarks of PSP, which include the presence of hyperphosphorylated tau aggregates deposited in tufted astrocytes, and neurofibrillary tangles (NFTs), more closely resembles $A D$ and categorize it as a tauopathy. ${ }^{52,53}$ Risk factors associated with the development of PSP are therefore of interest as elucidation of PSP pathological mechanisms may provide insight into the underlying pathologies of both $P D$ and $A D$.

An. muricata is reported to be neurotoxic due to its high content of acetogenins and tetrahydroisoquinolones (TIQs), which are toxic to nigrostriatal neurons by inhibiting mitochondrial complex-1., 4,54-56 This mechanism is similar 
to that following rotenone and 1-methyl 4-phenyl 1,2,3,6-tetrahydropyridine (MPTP) exposure, which induce parkinsonism in humans and animal models and are considered model neurotoxins (see Figure 7 for structures of relevant compounds). ${ }^{57-60}$ MPTP toxicity is due to the production of the toxic metabolite 1-methyl-4-phenylpyridinium $\left(\mathrm{MPP}^{+}\right)$, which requires active transport into the cell via the dopamine transporter in order to induce mitochondrial inhibition and cell death therefore rendering it a dopaminergic specific toxin. ${ }^{61}$ Annonacin, the major acetogenin of An. muricata, is more potent than MPTP and as effective as rotenone at killing nigrostriatal neurons. ${ }^{5,62,63}$ Unlike MPTP, annonacin toxicity is not dependent upon the dopamine transporter and its toxicity is not specific to dopaminergic cells as it also causes cell death in $\mathrm{y}$-aminobutyric acid containing(GABA) and cholinergic neurons., 37,56 To date, studies investigating the neurotoxicity of annonacin were tested in cultured striatal or mesencephalic neurons $5,6,37,55,63$. This is an important distinction considering that cortical and other non-dopaminergic neurons are widely affected in tauopathies. ${ }^{45,46,52}$ Exposure of mesencephalic dopaminergic neurons to the total extract of alkaloids from An. muricata root bark and two of its most abundant sub-fractions (coreximine and reticuline) resulted in degeneration of $50 \%$ of the dopaminergic neurons one day later and this toxicity was also not dependent upon the dopamine transporter. ${ }^{55,56}$ Annonacin is much more potent than these alkaloids at killing dopaminergic neurons. ${ }^{6}$ Furthermore, recent reports suggest that pawpaw extracts may be more toxic than extracts from soursop or cherimoya (Annona cherimolia). ${ }^{17}$ 


\section{Relevant Complex-1 Inhibitors}

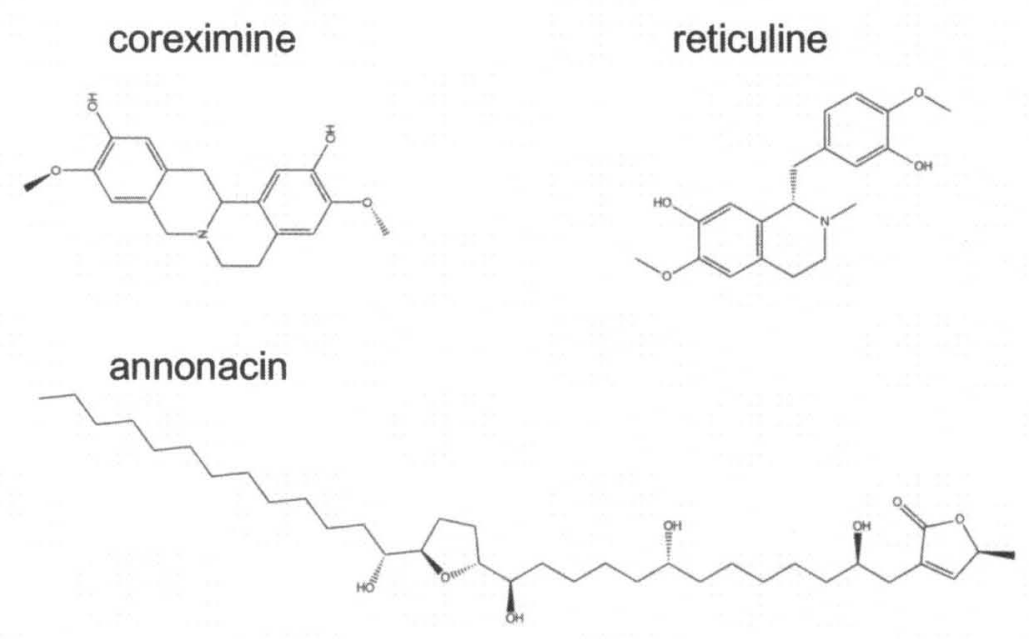

bullatacin

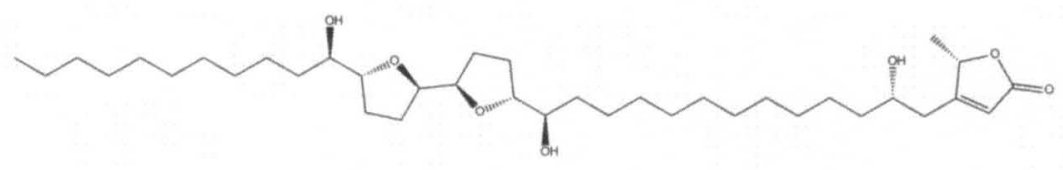

rotenone

MPP $^{+}$
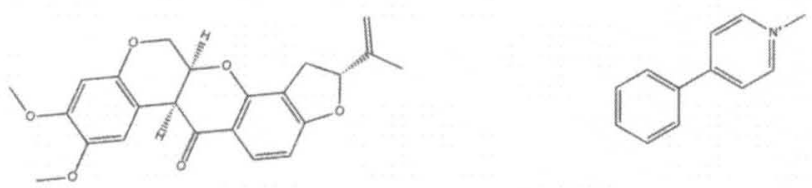

Figure 7. Structures of some of the complex-1 inhibitors noted throughout the text. Coreximine and reticuline are two alkaloids found in An. muricata that have been tested for neurotoxicity. ${ }^{55}$ Annonacin and bullatacin are two acetogenins with reported toxicity in various models. ${ }^{37,42}$ Rotenone and MPP ${ }^{+}$are model neurotoxins included for comparison. 


\section{Annonacin and Tau Pathology}

Located on chromosome $17 \mathrm{q} 21$, the tau gene encodes the important microtubule associated protein (MAP) tau, which is vital to microtubule dynamics including assembly and stability. ${ }^{64-66}$ In the human adult there are six different tau isoforms expressed as a result of alternative splicing of exons 2, 3 and 10. Depending on Exon 10 splicing, tau is expressed with either 3 or 4 repeats (3R or $4 R$ ) of microtubule binding domains (exon 10 inclusion $=4 R$ ). ${ }^{67}$ The ratio of $3 R$ to $4 R$ is important in normal neuronal functioning and is disrupted in human tauopathies. ${ }^{68,69}$ Additionally, pathological tau is sufficient for inducing neurodegeneration as evident by the association of mutations in chromosome 17 with fronto-temporal dementia with parkinsonism. ${ }^{70}$ Furthermore, the MAPT H1 haploptype is associated with increased risk for PSP. ${ }^{67,71}$ Therefore, understanding the cause and effects of tau pathology is important for elucidating the mechanisms of neurodegeneration in diseases with pathological tau deposition.

Annonacin isolated from An. muricata has been reported to cause cell death and tau pathology in mesencephalic cultures, ${ }^{37}$ and neurodegeneration of the basal ganglia and brainstem after its chronic, intravenous administration to rats ${ }^{5}$. Nigrostriatal pathology, mitochondrial impairment and/or tau pathology are seen in numerous neurodegenerative disorders including PD, AD and PSP. ${ }^{45,72}$ ${ }^{73}$ Accumulation of tau in the cell body is also seen in a number of tauopathies including $A D$ and PSP. ${ }^{45,50,52,53,72,74,75}$ It is reported that, along with cell death, low concentration of annonacin results in the migration of the protein tau from the 
axon to the cell body, increased tau protein levels, disruption of microtubules, mitochondrial complex-1 inhibition and ATP depletion, which have all been shown to occur in the aforementioned diseases. ${ }^{37,45,50,52,53,72,74,75}$ These studies support the hypothesis that annonacin and other acetogenins in As. triloba are neurotoxic and may cause neurodegeneration.

Model neurotoxins are commonly used in vitro to gain a better understanding of the role processes such as mitochondrial impairment, ATP depletion, alterations in tau and microtubule disruption play in the development of neuropathology. ${ }^{76}$ Rotenone and MPTP are both model "parkinsonian" neurotoxins that have been shown to inhibit mitochondrial complex-1 and induce protein aggregation and parkinsonism in vivo (see Table 2 for a brief list of neurotoxins) ${ }^{57,58,63,77-81}$ Eskobar-Khondiker et al. reported that annonacin's inhibition of mitochondrial complex-1 is responsible for the redistribution of tau. However, they also showed microtubule damage in response to annonacin treatment, and prevention of complex-1 inhibition only partially protected mesencephalic cultures from annonacin induced cell death. ${ }^{37}$ It was also recently suggested that complex- 1 inhibition may not be the primary mechanism of neuronal cell death induced by rotenone, which has long been considered a classical complex-1 inhibitor. ${ }^{82}$ Furthermore, studies have demonstrated that neurotoxins may adversely affect microtubule dynamics as a primary mechanism of action in addition to inhibiting complex-1. ${ }^{83,84}$

Tau may be phosphorylated at a number of serine and threonine residues, some of which are found within the microtubule binding domains with many other 
phosphorylation sites flanking this region (see reference 67 for review of tau phosphorylation sites). Tau is hyperphosphorylated in paired helical filaments (PHFs) and neurofibrillary tangles (NFTs). Glycogen synthase kinase (GSK)-3 $\beta$ is an intriguing target of study in tau pathogenesis since it is known to phosphorylate tau at sites in and around the microtubule binding domain ${ }^{85-87}$ GSK-3 $\beta$ may play a role in tau pathology as there is increased GSK-3 $\beta$ expression in tau inclusions of tauopathy patients compared to controls. ${ }^{88}$ Additionally, rotenone is reported to activate GSK-3 $\beta$ and induce tau hyperphosphorylation. ${ }^{89}$ The effect of annonacin on kinase activation has not been previously considered and may provide a better understanding of its mechanism of action. While GSK-3 $\beta$ may play a role in the effects of annonacin on complex-1 and consequent changes in tau, annonacin may also directly affect it, which in turn may affect the phosphorylation state of tau and/or signal cell death independently of complex-1 inhibition.

Sharing similarities with rotenone and MPTP as well as inducing pathological changes in tau makes annonacin a compound of interest for neurotoxicity studies. ${ }^{37,55,62}$ Human exposure to MPTP is currently uncommon as it is a byproduct in the production of a synthetic narcotic. ${ }^{59}$ Therefore, while it may be a useful tool for mechanistic studies, it does not represent a probable risk factor for idiopathic PD since widespread exposure is highly unlikely. 
Table 2. Neurotoxicity of relevant compounds

\begin{tabular}{|c|c|c|c|}
\hline Toxin & Bioactivity & Experimental Model & Ref. \\
\hline ROT & $\mathrm{LC}_{50}=100 \mathrm{nmol} / \mathrm{L}$ Complex-1 inhibition req'd. & SK-N-MC & \\
\hline ROT & $\begin{array}{l}2.5 \mathrm{mg} / \mathrm{kg} / \mathrm{day}=\text { parkinsomism and widespread ND. Nigrostriatal cell death and tau } \\
\text { pathology. }\end{array}$ & chronic IV infusion to rats for 28 days & 62,77 \\
\hline ROT & 100nM ROT activated GSK3 $\beta$. Toxicity required GSK3 $\beta$ & SK-N-MC & 89 \\
\hline $\begin{array}{l}\text { ROT, PQ, } \\
\text { MPP }^{+}\end{array}$ & $\begin{array}{l}\text { Wild type: } 10 \mathrm{nM} \text { ROT }=75 \% \text { DAergic death and } 33 \% \text { complex-1 inhibition. } \\
\text { Complex-1 inhibition not required for toxicity of ROT, MPP or PQ }\end{array}$ & $\begin{array}{l}\text { Wild type and Ndufs } 4 \text { knockout } \\
\text { midbrain E14 mouse cultures }\end{array}$ & 82 \\
\hline Soursop & $\begin{array}{l}\text { OR for PSP }=20 . \text { PSP Symptoms improved after stopping annonaceous } \\
\text { consumption }\end{array}$ & human consumption & 38,39 \\
\hline Soursop & $\begin{array}{l}\text { Gd-PSP and -PDC consumed more soursop (150g/life or } 2 \mathrm{~g} / \mathrm{kg} \mathrm{AN} \text { ) than controls or } \\
\text { PD (25g/life or } 0.4 \mathrm{~g} / \mathrm{kg} \text { ) (cummulative) }\end{array}$ & $\begin{array}{l}\text { human consumption and brain imaging } \\
\text { on controls and PD, Gd-PSP and } \\
\text { GdPDC patients }\end{array}$ & 40 \\
\hline $\begin{array}{l}\text { Soursop } \\
\text { (alkaloids) }\end{array}$ & $\begin{array}{l}\text { EC50 alkaloid totum }=18 \mathrm{ug} / \mathrm{ml}, \text { apoptotic cell death, inhibition DA uptake that was } \\
\text { not required for toxicity }\end{array}$ & E 16.5 rat mesencephalic culture & 55 \\
\hline TIQs & Decrease in striatal DA ipsi- and contralateral to lesion & $\begin{array}{l}7 \text { day unilateral infusion into rat } \\
\text { striatum }\end{array}$ & 34 \\
\hline $\begin{array}{l}\text { Complex-1 } \\
\text { inhibitors }\end{array}$ & $\begin{array}{l}\text { AN } I C_{50} \text { complex-1 }=55 \mathrm{nM}, E_{50} \text { ATP depletion= } 134 \mathrm{nM}, \mathrm{EC}_{50} \text { death=60nM. MPP+ } \\
\mathrm{IC}_{50}=2.6 \mathrm{mM}, \mathrm{EC}_{50} \text { ATP \& death }=54 \mu \mathrm{M} \text {. ROT } \mathrm{IC}_{50}, \mathrm{EC}_{50} \text { ATP \& death all }=7 \mathrm{nM} \text {. }\end{array}$ & E 16.5 rat striatal culture & 63 \\
\hline AN & $\begin{array}{l}\text { AN ( } 3.8 \text { or } 7.6 \mathrm{mg} / \mathrm{kg} / \text { day) crosses BBB, inhibits complex-1, decreases ATP, and } \\
\text { causes nigro-striatal cell death }\end{array}$ & chronic IV infusion to rats for 28 days & 5 \\
\hline$\overline{A N}$ & $\begin{array}{l}\mathrm{LC}_{50}=50 \mathrm{nM} \text { after } 48 \mathrm{hrs} \text {. ATP depletion, increased tau phosphorylation, somatic } \\
\text { redistribution of tau, retrograde transport of mitochondria and MT disruption. }\end{array}$ & E 16.5 rat striatal culture & 37 \\
\hline $\mathbf{A N}$ & 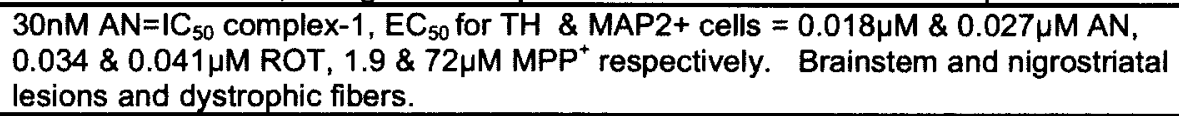 & $\begin{array}{l}\text { E } 15.5 \text { rat mesencephalic culture and } \\
\text { IV infusion of } A N \text { for } 28 \text { days }\end{array}$ & 6,56 \\
\hline
\end{tabular}

For thorough review of complex-1 inhibiting neurotoxins see references 63 and 76 . AN = annonacin, ROT = rotenone,

$P Q=$ paraquat, $T I Q=$ tetrahydroisoquinolone, $S K-N-M C=$ human neuroblastoma cell line,$D A=$ dopamine,$O R=$ odds

ratio, $I C=$ inhibitory concentration, $E C=$ effective concentration, $M T=$ microtubule, $\mathrm{Gd}=$ Guadeloupian, $\mathrm{PDC}=$

Parkinson-dementia complex, BBB = blood-brain barrier, $\mathrm{TH}=$ tyrosine hydroxylase. 
Rotenone is still approved for use as a pesticide in the United States and therefore represents a public health concern; however, though it does induce tau aggregation, its toxic effects are not protein specific and therefore its usefulness as a model compound translates more generally to neurodegeneration rather than a particular disease or set of diseases as is the case with MPTP and PD. ${ }^{37}$. $58,76,79$ To date, annonacin has been shown to specifically induce tau pathology and may therefore represent a novel model neurotoxin that is more etiologically relevant to tauopathies than MPTP. ${ }^{37}$ For these reasons, elucidation of annonacin toxicity may provide valuable insight into to the pathogenesis of tauopathies including those that present as APDs.

\section{Research Aims}

Considering that annonacin is present in other (e.g. An. muricata) annonaceous fruits and is present in As. triloba bark, it was hypothesized that it would also be present in the fruit pulp As. triloba (i.e. pawpaw). Additionally, while the toxic effects of extracts, including annonacin, from An. muricata have been reported in striatal and midbrain cultures, it has not been determined whether the extracts or annonacin from As. triloba share this toxicity in cortical neurons, which are also affected in a number of the diseases noted above. Considering the information discussed above regarding the presence of toxic acetogenins in As. triloba and related plants, it was hypothesized that As. triloba fruit would contain the neurotoxic acetogenin annonacin and that it would be toxic 
to cortical neurons. Furthermore, crude acetogenin-containing extract was expected to be more toxic than annonacin due to the presence of multiple bioactive acetogenins. Finally, it was hypothesized that annonacin would induce changes in the tau protein as previously reported. The long-term goal of this research is to provide insight into the mechanisms of pathogenesis of neurodegenerative diseases to develop better treatment strategies for them. The specific aims of this project were as follows:

\section{AlM I: To determine the presence and concentration of annonacin in pawpaw fruit pulp.}

*/s the toxic acetogenin, specifically annonacin, present in fruit pulp of Asimina triloba?

*Is annonacin present in the pawpaw fruit in high enough concentration to induce neurotoxicity?

\section{AIM II: To determine the toxicity of pawpaw fruit extracts in primary cortical neurons.}

*/s treatment with annonacin isolated from the pawpaw fruit toxic to rat cortical cultures?

*/s treatment with total acetogenin-containing extracts more toxic than pure annonacin? 
AIM III: To confirm the effect of annonacin on tau phosphorylation.

*Does treatment with annonacin isolated from pawpaw fruit result in tau hyperphosphorylation or accumulation?

*Does annonacin activate glycogen synthase kinase (GSK)-3 $\beta$ as shown in most tauopathies?

The following chapters detail the methods used to investigate these questions and discuss the results in relation to the current literature. 


\section{CHAPTER II}

\section{MATERIALS AND METHODS}

\section{Extraction and isolation of annonacin from Asimina triloba fruit pulp}

Frozen pawpaw pulp was purchased from Integration Acres, Ltd. Fresh pawpaws were purchased from A Little Piece of Paradise Farm, Kings Mountain, Kentucky. A sample of annonacin isolated from An. muricata was kindly donated by Dr. Pierre Champy, Faculté de Pharmacie, Chatenay-Malabry, France, as a sample for purposes of comparison with As. triloba extracts. Solvents and reagents were American Chemical Society (ACS) grade and used as commercially supplied (VWR). Analytical thin-layer chromatography (TLC) utilized $0.25 \mathrm{~mm}$ pre-cut glass-backed plates (Merck, Silica Gel $60 \mathrm{~F}_{254}$ ). Thinlayer chromatograms were visualized during chromatographic and extraction runs by rapidly dipping the plates in anisaldehyde/ethanol/sulfuric acid stain and heating (hot plate). A second technique involved dipping the plates in 3,5dintrobenzoic acid/methanol (2\%) and heating followed by dipping in $\mathrm{KOH} /$ methanol (Kedde reagent). The Kedde reagent specifically stains acetogenins due to its butenolide reactivity; however, it is far less sensitive than anisaldehyde staining, which is not acetogenin specific. Therefore, anisaldehyde 
stain was preferentially used to analyze fractions as they were eluted. Gravitycolumn chromatography was carried out using silica gel 60 (E. Merck 9385, 235400 mesh) or silica gel 62 (Mallinckrodt 6551, 60-200 mesh). Extracts and chromatographic fractions were concentrated with a Büchi rotavapor under water aspirator vacuum. High Resolution Mass Spectral (HRMS, specifically FTMS using ESI) data were measured with a Thermo Electron Corporation LTQ-FT. Nuclear magnetic resonance $\left(500 \mathrm{MHz}{ }^{1} \mathrm{H}\right.$ and ${ }^{13} \mathrm{C}$ NMR) spectra were recorded with Varian INOVA 500 or VNMRS 400 instruments using deuterated dicholormethane $\left(\mathrm{CDCl}_{3}\right)$ as a solvent and internal standard. Infrared spectra (Fourier-transform infrared spectroscopy, FTIR) were recorded with a PerkinElmer Spectrum 100 instrument. Optical rotations were recorded with a JASCO Dip-370 polarimeter.

(5S)-5-Methyl-3-[(2R,8R,13R)-2,8,13-trihydroxy-13-[(2R,5R)-5-[(1R)-1hydroxytridecyl]-2-tetrahydrofuranyl] tridecyl]-5H-furan-2-one. Annonacin (AN): Fresh (peeled and seeded fruit) or frozen fruit pulp (1000 g) was homogenized in methanol $(800 \mathrm{~mL})$ using a commercial blender. The yellowgreen methanolic homogenate was stored overnight under refrigeration. The homogenate was then vacuum-filtered with a $150 \mathrm{~mm}$ diameter Buchner funnel and the filter cake was washed with $50 \%$ aqueous methanol in portions $(600 \mathrm{~mL}$, total) and the application of vacuum was continued after the washing process until the sturdy filter cake was slightly damp. The resulting yellow-orange filtrate was then poured into a separatory funnel $(2000 \mathrm{~mL})$ and extracted with ethyl acetate (EtOAc, $3 \times 200 \mathrm{~mL}$ ) whereupon brine was added as needed to enhance 
the separation of aqueous methanol and organic EtOAc layers. The crude ethyl acetate extracts were combined and the yellow solution was dried over anhydrous sodium sulfate $(30 \mathrm{~g})$ overnight $\left(10^{\circ} \mathrm{C}\right)$. The drying agent was removed by vacuum filtration directly into a $1000 \mathrm{~mL}$ recovery flask while washing with fresh ethyl acetate $(100 \mathrm{~mL})$. The clear, deep yellow filtrate was concentrated by rotary evaporation in vacuo at room temperature $(\mathrm{rt})$. During the concentration process, a white precipitate, presumably carbohydrate components of the crude extract due to its water solubility, was evident and was removed by vacuum filtration while washing with ethyl acetate. The resultant filtrate (crude ethyl acetate extract, $\mathrm{CEX}$ ) was concentrated under vacuum pressure and the odorous orange-yellow oil $(500 \mathrm{mg})$ was kept under refrigeration until submission to column chromatography. The concentrated oily cEX was applied to a $25 \times 500$ $\mathrm{mm}$ glass column packed with silica gel $(250 \mathrm{~mm})$ and eluted sequentially with hexane/ethyl acetate $(5: 1,500 \mathrm{~mL})$, hexane/ethyl acetate $(2: 1,200 \mathrm{~mL})$, hexane/ethyl acetate $(1: 2,200 \mathrm{~mL})$, ethyl acetate $(100 \%, 100 \mathrm{~mL})$ and ethyl acetate/methanol $(95: 5,500 \mathrm{~mL})$. Elution analysis of the individual fractions was conducted by TLC with visualization by anisaldehyde stain. The fractions bearing annonacin, a less-mobile component and two more mobile components were combined and concentrated under vacuum. The combined oily, chromatographed concentrate was submitted to a second column chromatography using the same volume of silica gel and eluted with hexane/ethyl acetate $(1: 1,200 \mathrm{~mL})$, hexane/ethyl acetate $(1: 2,300 \mathrm{~mL})$ and ethyl acetate/methanol $(95: 5,300 \mathrm{~mL})$ again testing each fraction by TLC. The 
occurrence of a persistent higher-running component necessitated a third chromatographic run using the same conditions as the second. Final annonacin and acetogenin containing fractions were identified by TLC visualized with anisaldehyde and Kedde staining and weight determined following solvent removal in vacuo. FTMS and NMR were used to compare the isolated annonacin to an annonacin sample from An. muricata and synthetic annonacin data. $^{90}$

(5S)-5-Methyl-3-[(2R,8R,13R)-2,8,13-triacetoxy-13-[(2R,5R)-5-[(1R)-1acetoxytridecyl]-2-tetrahydrofuranyl] tridecyl]-5H-furan-2-one. Annonacin tetraacetate (AN-Ac): Crude annonacin (79 mg, $0.13 \mathrm{mmol}$ ) was dissolved in pyridine $(200 \mu \mathrm{L}, 2.5 \mathrm{mmol})$ and then acetic anhydride $(100 \mu \mathrm{L}, 1.0 \mathrm{mmol})$ was added by syringe. The reaction mixture was stirred $(48 \mathrm{~h}, \mathrm{rt})$ whereupon TLC (hexanes/ethyl acetate, 2:1) indicated complete consumption of starting material and formation of a higher-running spot. The reactants were removed under high vacuum and the viscous residue was dissolved in dichloromethane and applied to a gravity silica gel column. Elution of the column with hexanes/ethyl acetate, 2:1 followed by combination and concentration of the fractions yielded the annonacin tetraacetate derivative. The spectral data was compared to that of isolated annonacin. Optical rotations and infrared spectra (FTIR) were also recorded for samples of annonacin and annonacin tetraacetate. 
In vitro toxicity of annonacin and Asimina triloba organic fruit extract and effects on microtubule associated protein tau

Known amounts of purified annonacin and CEX were dissolved in dimethyl sulfoxide (DMSO) or ethyl acetate (EtOAc) to make $50 \mathrm{mM}$ and $75 \mathrm{mg} / \mathrm{mL}$ stock solutions respectively, which were stored at $-80^{\circ} \mathrm{C}$. Acetogenin-free fractions (ACG-free) isolated from CEX alongside annonacin were diluted in DMSO to 22 $\mathrm{mg} / \mathrm{mL}$ and stored at $-80^{\circ} \mathrm{C}$. Stock solutions of $1 \mathrm{mM}$ rotenone (Sigma R8875) were prepared in DMSO or EtOAc prior to each experiment. Serial dilutions of drugs were prepared in basal medium Eagle (BME, Sigma) immediately before each experiment. Reagents used for neuronal cultures and analytical techniques were used as commercially supplied or prepared fresh according to manufacturer protocols and $\mathrm{pH}$ adjusted to 7.4 with sodium hydroxide.

Cell Cultures. Cortical neurons were cultured from newborn SpragueDawley rat pups on postnatal day $0(\mathrm{PO})$ according to previously published methods. ${ }^{91}$ The handling of animals followed Institutional Animal Care and Use Committee approved procedures. For viability assays, cultured neurons were plated in 96-well culture plates coated with poly-D-lysine (PDL, $5 \%$ ) at a density of 4.8-6.4 $\times 10^{4}$ cells/ well. For immunocytochemistry, cells were plated at a density of $0.5 \times 10^{6}$ cells/ well in 24-well plates with PDL and laminin coated glass coverslips. For western blotting, cells were plated in 35 or $60 \mathrm{~mm}$ culture dishes coated with PDL at densities of 2.0 or $4.0 \times 10^{6}$ cells/ well respectively. 1- 
( $\beta$-D-Arabinofuranosyl) cytosine (Ara-C, $2.5 \mu \mathrm{M}$ ) was added to all wells on day 2 in vitro (DIV 2) to inhibit proliferation of non-neuronal cells.

Cells were treated with annonacin, cEX, ACG-free extract, rotenone or vehicle (DMSO or EtOAC) on DIV 5. The amount of DMSO in control cultures did not exceed $0.5 \%$ unless otherwise noted. The toxicity of EtOAc, as well as $\mathrm{MeOH}$ and ethanol (EtOH), was tested against the typical vehicle control, DMSO, prior to performing experimental treatments with EtOAc. ACG-free extract served as a negative control for the extraction process. These fractions were considered to be ACG free due to the fact that they lacked Kedde positive staining when heavily spotted on TLC. In addition to being Kedde negative, these fractions were chosen as negative controls because they eluted closely with the annonacin containing fractions therefore representing the most similarly processed extracts.

Rotenone toxicity in cortical and midbrain neurons varies depending on the experimental paradigm, with reported toxicity ranging from low nanomolar to micromolar concentrations. ${ }^{63,77,92-97}$ Considering these varying reports, and that high concentrations of rotenone may induce cell death via different mechanisms, ${ }^{96} 1 \mu \mathrm{M}$ rotenone was used as a positive control for neurotoxicity.

Viability Assay. MTT (3-(4,5-dimethylthiazol-2-yl)-2,5diphenyltetrazolium bromide) is converted to a formazan product by mitochondrial dehydrogenase in live cells. As the rate of conversion is proportional to the number of surviving cells, it provides a convenient measure of 
cell viability. ${ }^{98,99}$ Therefore, the MTT assay was used as previously described to assess the toxicity of each treatment relativeto vehicle-treated controls. ${ }^{100}$ Fortyeight hours post-treatment MTT was added to 96 -well plates and incubated for 2 hours followed by overnight solubilization in 1:1 N,N-dimethylformamide and sodium dodecyl sulfate (SDS, $20 \%$ in di- $\mathrm{H}_{2} \mathrm{O}$ ). Absorbance was determined at $570 \mathrm{~nm}$ with a Spectra Max spectrophotometer and analyzed with Soft-max pro.

Immunocytochemistry. Cells were fixed with $4 \%$ paraformaldehyde at 0 , 8,24 , and 48 hours and immunostained following standard procedures ${ }^{91}$ with rabbit anti-MAP2 (microtubule associated protein 2) polyclonal antibody (Cell Signaling Technologies \#4542, 1:200), mouse anti-total tau (DA9, 1:500), anti-tau phosphorylated at serines 396 and 404 (PHF-1, 1:500), anti-tau phosphorylated at serine 202 (CP-13, 1:500) or anti-tau conformational epitope MC-1 (recognizes amino acids $7-9$ and $326-333,1: 100$ ) monoclonal antibodies (all tau antibodies were kindly provided by Dr. Peter Davies, Albert Einstein College of Medicine). IGg, secondary antibodies used included goat anti-mouse Texas Red (Calbiochem \#401218), AlexaFluor \#488 goat anti-mouse or goat anti-rabbit (Invitrogen \#A11029 and A11034, respectively). Nuclear chromatin was costained with Hoechst 33258 (Sigma). Images were captured on a Zeiss AxioObserver A.1 inverted light microscope with a Zeiss AxioCam MRM canon camera using AxioVision 4 software.

Western Blot Analysis. At 1, 4, 8, and 24 hours after treatment, cells were lysed with SDS lysis buffer and stored at $-20^{\circ} \mathrm{C}$. Equal amounts of cell lysates were run on $10 \%$ acrylamide gels according to standard laboratory 
procedures. 91,101 The tau antibodies noted above were used to probe for total and phospho-tau epitopes. Anti-GSK-3 $\beta$ total (cell signaling \#9332, rabbit 1:1000) and -phospho-serine 9 (Biosource \#44-600G, rabbit 1:1000) were used to probe for total and inactive GSK-3ß. Anti- $\beta$-actin (Sigma \#A5316, mouse 1:2000) was used as a loading control for each probe. Secondary horseradish peroxidase conjugated mouse and rabbit antibodies were used according to manufacturer's protocol (CalBiochem \#402335 and \#401315, respectively, $1: 10,000)$. Protein expression was quantified by illuminescence on a Kodak Image Station 4000R using GE software and normalized to loading controls.

Statistical Analysis. Absorbance of treated cells was normalized to controls for each 96 -well plate. The raw values normalized to vehicle-treated controls were used to determine relative viability of treated cells. Annonacin toxicity was determined from a total of 13 independent experiments ( 22 total 96 well plates). CEX and ACG-free treatments were tested in a total of 3 independent experiments ( 3 and 5 total 96 -well plates respectively). In some instances multiple 96-well plates were used as replicates within that experiment, hence the above indication of the total number of plates. On each 96-well plate, 6 replicate wells (or sister cultures) were used per treatment. Rotenone was included as a positive control on each plate. The mean, $95 \%$ confidence intervals, and p-values were determined for each treatment using Graph-Pad prism software. One-way analysis of variance (ANOVA) followed by Dunnette's post-hoc test was used to determine significance, and non-linear regression analysis to calculate the $\mathrm{LD}_{50}$ of annonacin. 
Lysates from a total of 4 independent experiments were analyzed via Western blot. Background was subtracted from each lane and all lanes normalized to their corresponding loading control (Beta actin). Relative phosphorylation was determined by also normalizing each phospho-epitope to its respective total antibody expression. For example, after being normalized to loading control, GSK-3 $\beta$ phospho-serine 9 values were also normalized to total GSK-3ß. All treatment wells were normalized to controls and one-way ANOVA with Dunnette's post-hoc test was used to determine differences in protein expression between control and annonacin treated cells. P-values $<0.05$ were considered to be significant. 


\section{CHAPTER III}

\section{RESULTS}

\section{Extraction and isolation of annonacin from Asimina triloba fruit pulp}

Extraction and Isolation. TLC, FTMS, ${ }^{1} \mathrm{H}$ - and ${ }^{13} \mathrm{C}-\mathrm{NMR}$, FTIR spectroscopic analyses and polarimetry (optical rotation) revealed the presence of annonacin in extracts isolated from pawpaw fruit pulp. When examined by TLC in multiple solvent systems, isolated annonacin co-spotted with the An. muricata sample (Figure 8). FTMS and NMR spectra corresponded with that of the annonacin sample (Figures 9-10), and NMR shifts were consistent with those previously reported for synthetic annonacin ${ }^{90}$ (Table 3).

(5S)-5-Methyl-3-[(2R,8R,13R)-2,8,13-trihydroxy-13-[(2R,5R)-5-[(1R)-1hydroxytridecyl]-2-tetrahydrofuranyl] tridecyl]-5H-furan-2-one. Annonacin: $R_{f}=0.35$. HRMS calculated for $\mathrm{C}_{35} \mathrm{H}_{64} \mathrm{O}_{7} \mathrm{~m} / 2$ [m $\left.+\mathrm{Na}\right]^{+}:$619.4543; Found: $619.4546 \pm 0.6$ ppm. ${ }^{1} \mathrm{H}$ NMR $\delta\left(400 \mathrm{MHz}, \mathrm{CDCl}_{3}\right): 7.18(\mathrm{~s}, 1 \mathrm{H}), 5.06(\mathrm{q}$ $J=6.8 \mathrm{~Hz}, 1 \mathrm{H}), 3.85(\mathrm{~m}, 1 \mathrm{H}), 3.81(\mathrm{dt}, \mathrm{J}=6.8 \mathrm{~Hz}, 12 \mathrm{~Hz}, 2 \mathrm{H}), 3.59(\mathrm{~m}, 1 \mathrm{H}), 3.41(\mathrm{dt}$, $J=6.8 H z, 12 H z, 2 H), 2.52(d, J=14 H z, 1 H), 2.40(d d, J=15.2 H z, 8 H z, 1 H), 2.06$ $(\mathrm{m}, 4 \mathrm{OH}), 1.98(\mathrm{~m}, 2 \mathrm{H}), 1.65(\mathrm{~m}, 2 \mathrm{H}), 1.62-1.25(\mathrm{~m}, 40 \mathrm{H}), 1.43(\mathrm{~d}, \mathrm{~J}=6.8 \mathrm{~Hz})$, 
$0.88(\mathrm{t}, \mathrm{J}=6.8 \mathrm{~Hz}, 3 \mathrm{H}) ;{ }^{13} \mathrm{C}$ NMR $\left(400 \mathrm{MHz}, \mathrm{CDCl}_{3}\right)$ ס: 174.51, 151.85, 131.14, $82.66,82.58,77.98,74.08,73.97,71.72,69.88,37.32,37.25,33.42,33.35$, $31.90,29.70,29.65-29.62$ signal overlap, $29.44,29.33,28.74,25.63,25.57$, $25.47,22.66,19.08,14.09$. FTIR $3416,2922,2852,1744,1075 \mathrm{~cm}^{-1} .[\alpha]_{D}{ }^{20}$ : $+20.4^{\circ}\left(\mathrm{c}=0.51, \mathrm{CHCl}_{3}\right)$.

Isolation Optimization. The extraction and isolation process described here represents a high-yield, reliable method for both preparing and purifying extracts of the acetogenins from frozen fruit pulp and isolating annonacin. The aforementioned procedure yielded pure annonacin $(\sim 90 \%)$ as determined by HRMS (FTMS), high-field NMR, FTIR and optical rotation. The fruit of the Eastern pawpaw tree, As. triloba is commercially available from health food stores or local farms (See Materials and Methods). A kilogram of the raw peeled fruit or commercially available frozen pulp may be conveniently processed on a laboratory scale using a blender. Although extracting freeze-dried pulp with organic solvents was considered for the initial stages of the process, the solventsolvent extraction of filtered homogenate derived from fresh or frozen pulp was the best expedient in terms of time and mass transfer. Although classed as a lipid, annonacin possesses four hydroxyl groups and is relatively polar as compared to many other classes of small-molecule lipids. When choosing solvents for the extraction-partitioning steps, methanol and ethyl acetate, respectively, were found to be optimal and the sequence repeatedly delivered $\sim 500 \mathrm{mg}$ of crude extract per kilogram of pulp. On initial concentration of the crude syrupy extract, a granular white water-soluble/ethyl acetate insoluble 
precipitate was observed, which was presumably the carbohydrate portion of the extract and easily removed by vacuum filtration. At first a portion of the crude isolate was submitted to flash chromatography $(F-C)^{102}$ on silica gel using combinations of chloroform-methanol, since the chloroform methanol system was optimal for separation of the suspected acetogenin components on analytical TLC. However, the F-C system was not optimal since many of the less-polar compounds, presumably terpenes or terpene-like compounds were carried through before separation was effected. The most effective separation system was a gravity silica gel column which utilized combinations of hexanes/ethyl acetate and ethyl acetate/methanol with gradually increasing polarity of the solvent mixtures. While previous work on natural products bearing the butenolide ( $\alpha, \beta$-unsaturated-y-lactone) subunit utilized the two-step Kedde reagent for detection during chromatography, ${ }^{103}$ the o-anisaldehyde TLC stain for the individual fractions was the best expedient. While the Kedde reagent system confirmed the presence of the desired acetogenin, the o-anisaldehyde TLC stain was superior in terms of time and sensitivity for routine separations. Separation and ${ }^{1} \mathrm{H}$ NMR $(500 \mathrm{MHz})$ analysis of the intermediate fractions eluted with the ethyl acetate/methanol solvent sequence revealed the presence of annonacin on comparison with spectral data published by $\mathrm{Wu}$ and co-workers through their enantioselective total synthesis of annonacin. ${ }^{90}$ 


\section{Annonacin TLC}

\section{9:1 C:M \\ Anis- \\ Kedde aldehyde}

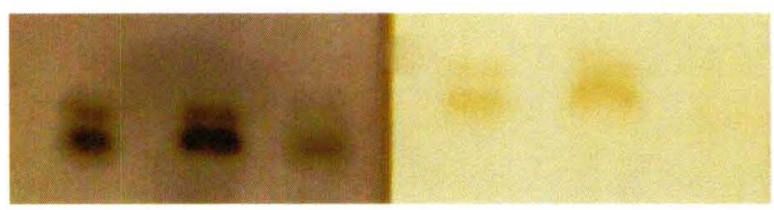

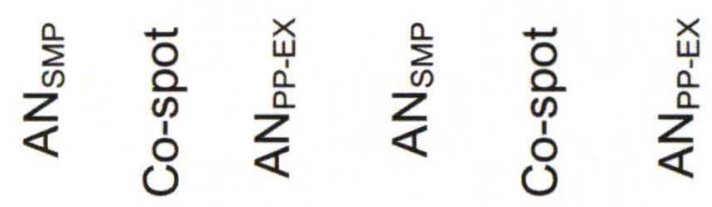

Figure 8. TLC of annonacin isolated from Asimina triloba co-spotted with an annonacin sample from Annona muricata. TLC mobile phase:

chloroform/methanol (9:1), stained with anisaldehyde and Kedde reagent. $R_{f}=$ 0.35. $\mathrm{AN}_{\mathrm{SMP}}=$ annonacin sample derived from $A n$. muricata, $\mathrm{AN}_{\mathrm{PP}-\mathrm{EX}}=$ pure annoncin isolated from As. triloba fruit. 
A

LP sample 2 FT 100000 pos_090619152911 \#1

T: FTMS + p ESI Full ms [100.00-1000.00]

๙

\section{FTMS of annonacin}

1 AV: 1 NL: 1.03E7

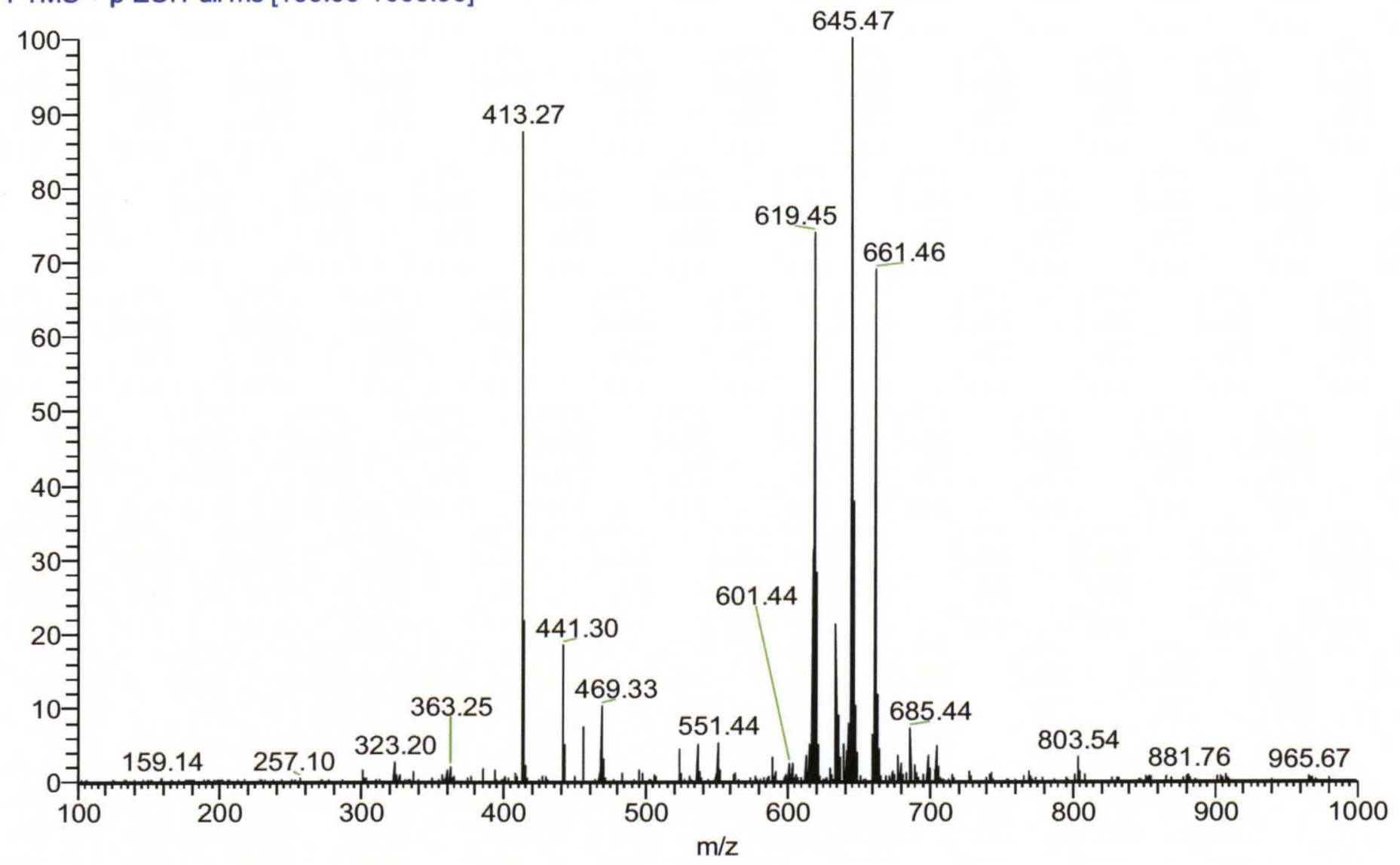


B

LP 152_3 FT MS \#1 RT: 0.01 AV: 1 NL: 1.401

T: FTMS + p ESIFull ms [100.00-1000.00]

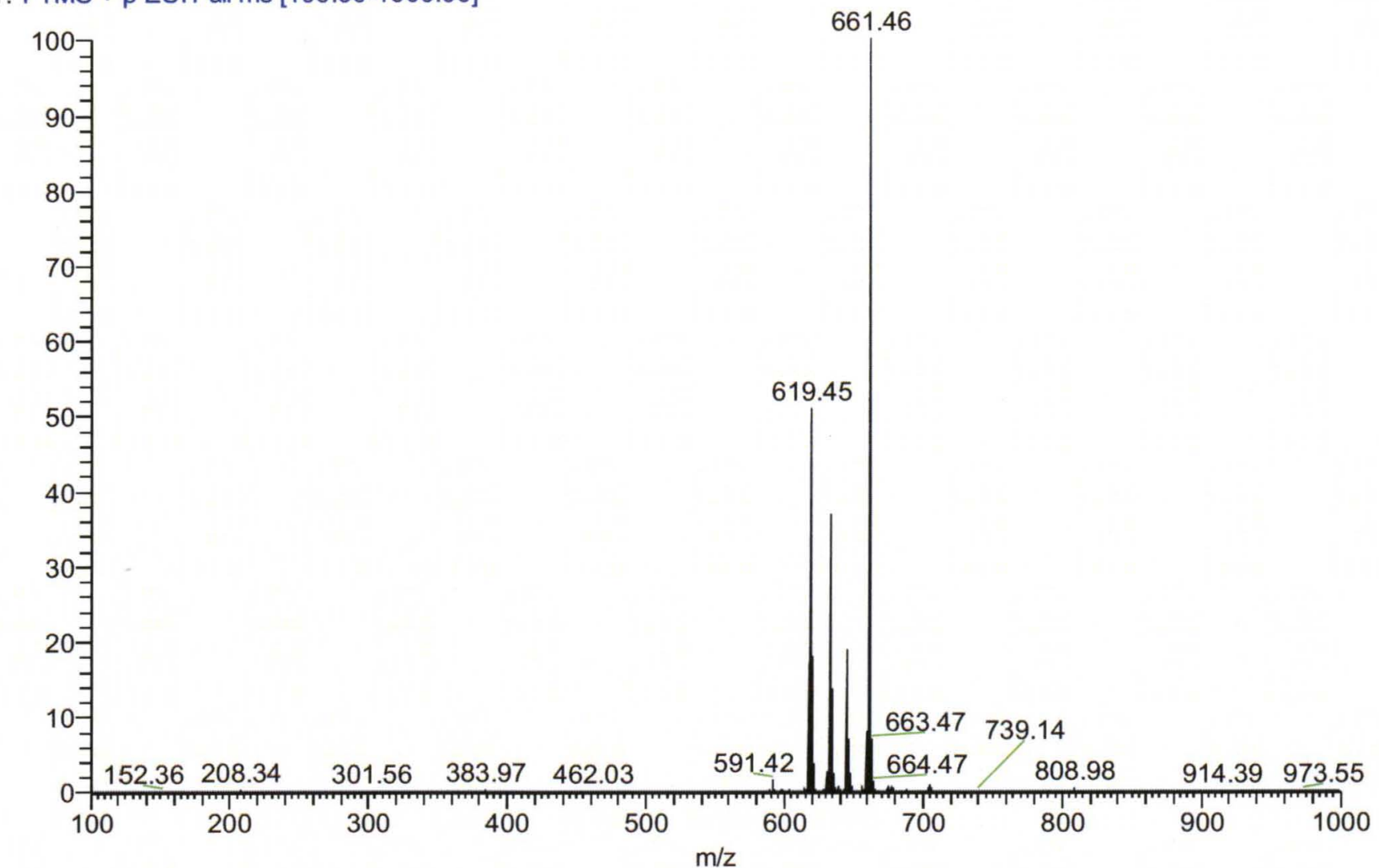


LP 154_3 FT MS \#1 RT: 0.02 AV: 1 NL: 1 .ouco

T: FTMS + p ESI Full ms [50.00-1000.00]

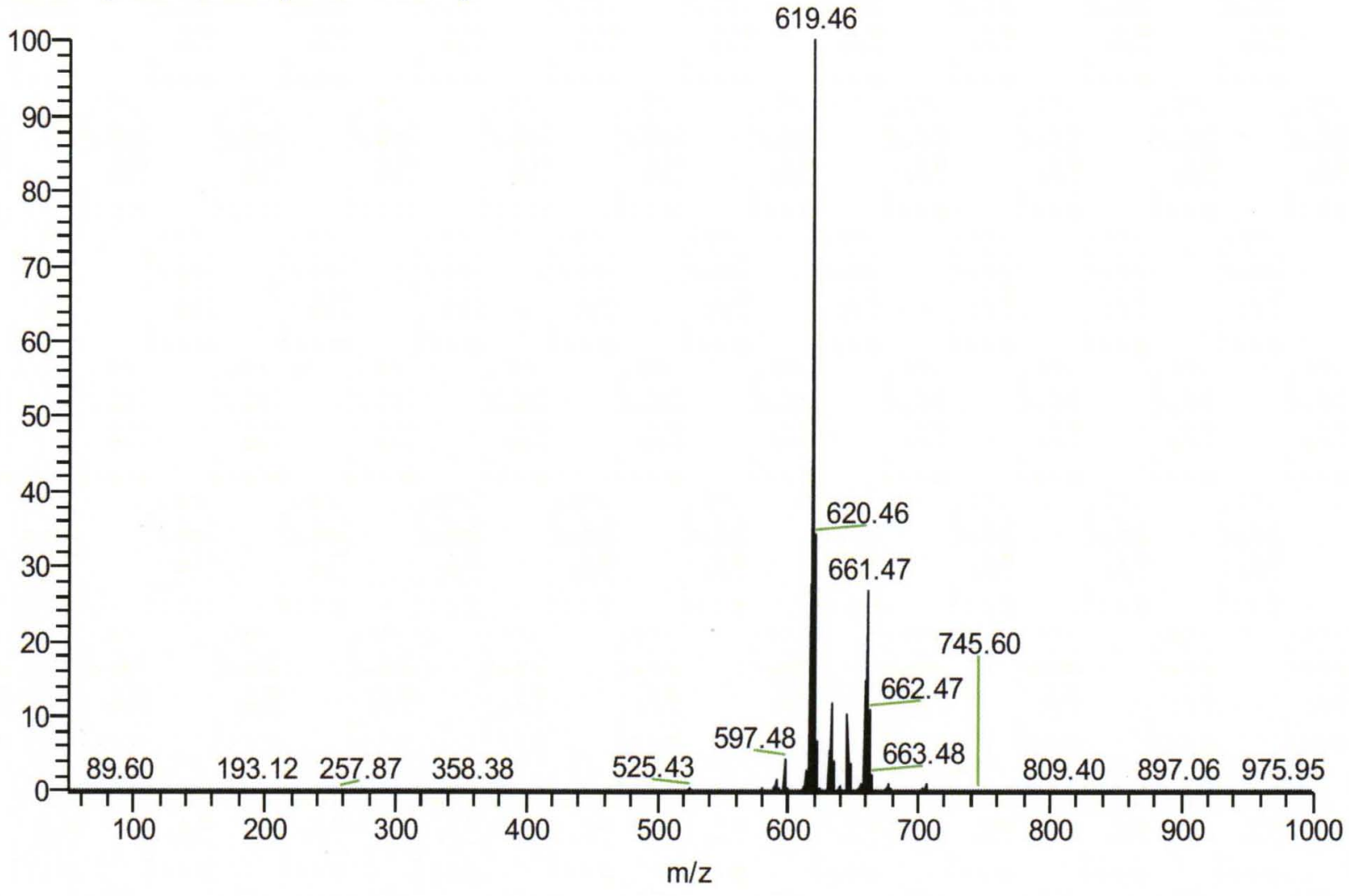




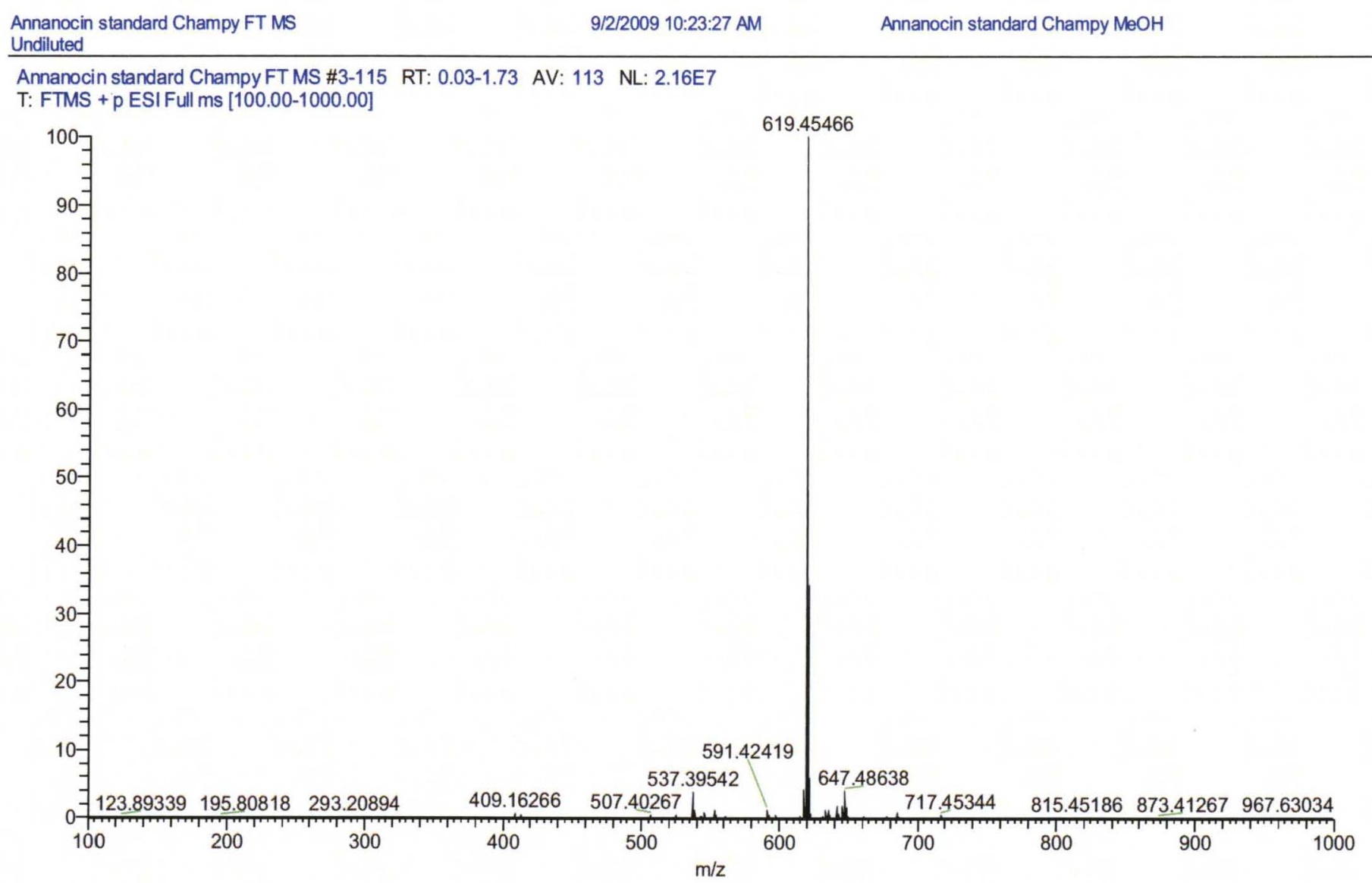




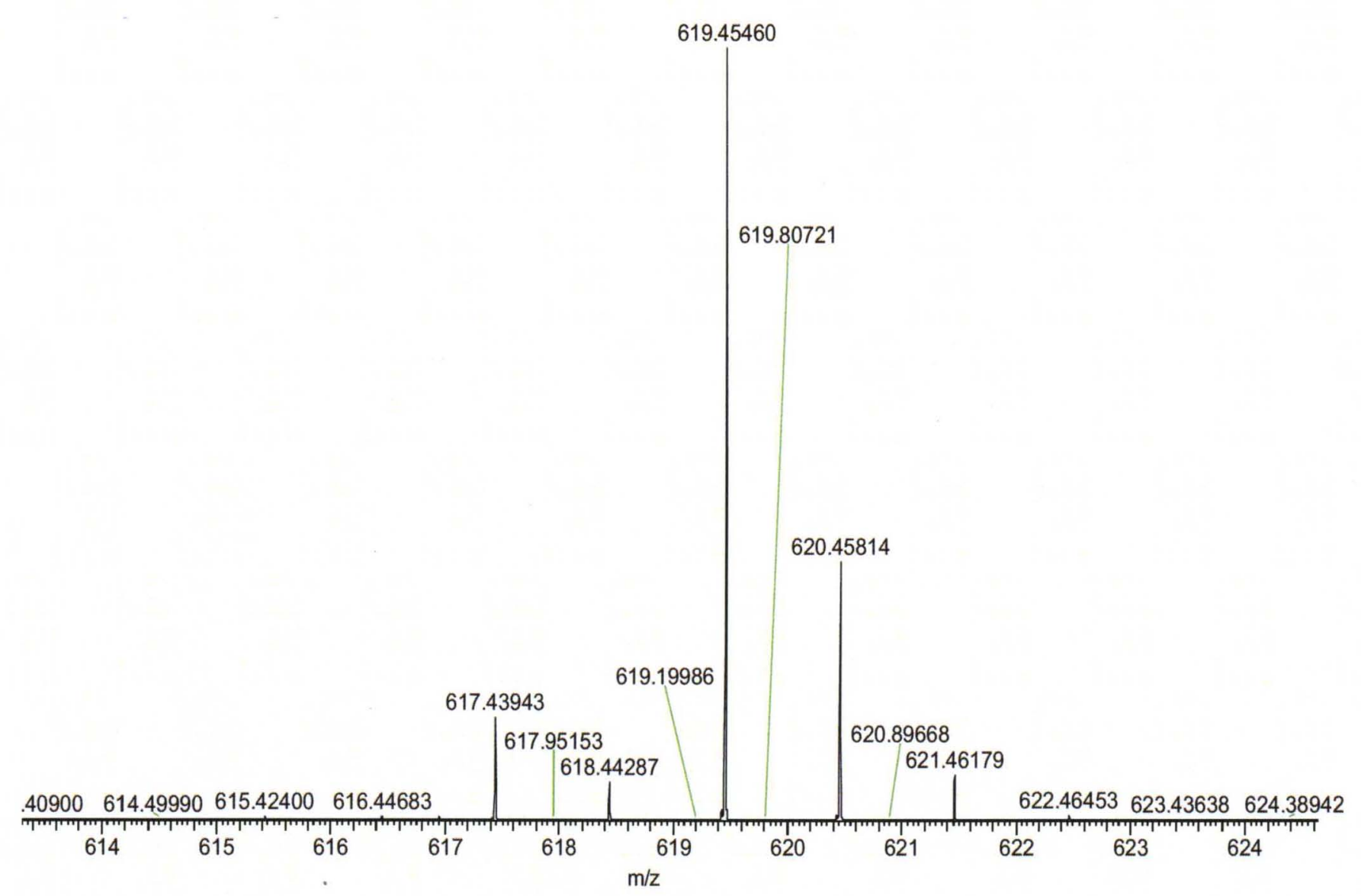




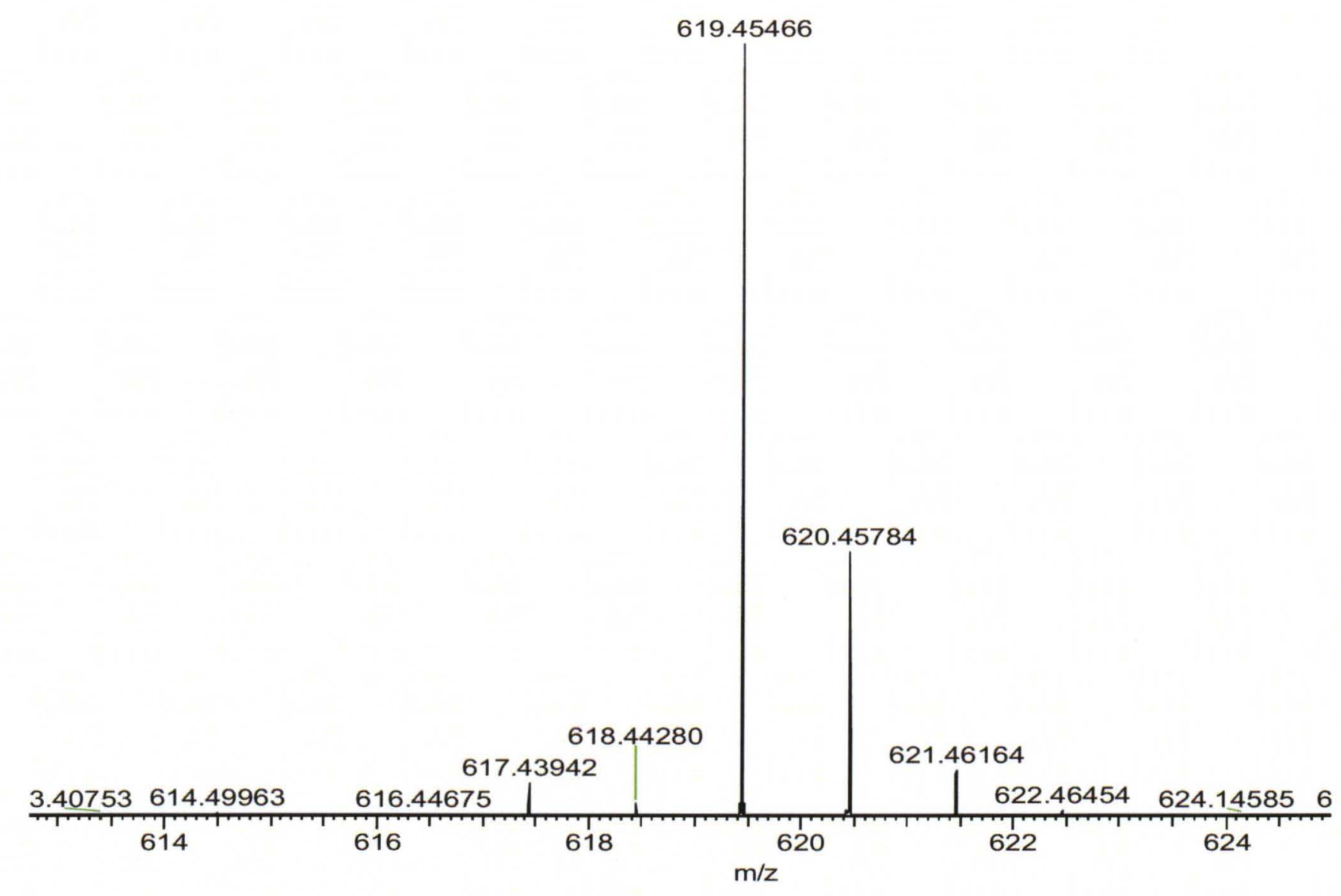


Figure 9. Fourier transform mass spectrometry (FTMS) spectra of crude ethyl acetate extracts of As. triloba fruit pulp (cEX) reveals presence of annonacin among other acetogenins (A). Spectra of annonacin-containing fractions after the second $(B)$ and third $(C)$ chromatographic runs. Spectra of annonacin sample derived from An. muricata (D). Comparison of As. triloba isolated annonacin $(E)$ with the An. muricata sample $(F)$ showing a more narrow range of spectra surrounding the annonacin peaks from $C$ and D. High Resolution Mass Spectrometry (HRMS) calculated for annonacin, $\mathrm{C}_{35} \mathrm{H}_{64} \mathrm{O}_{7} \mathrm{~m} / 2$ [m $\left.+\mathrm{Na}\right]^{+}$:

619.4543; Found: $619.4546 \pm 0.5 \mathrm{ppm}$. 
${ }^{1} \mathrm{H}$ NMR of annonacin

A

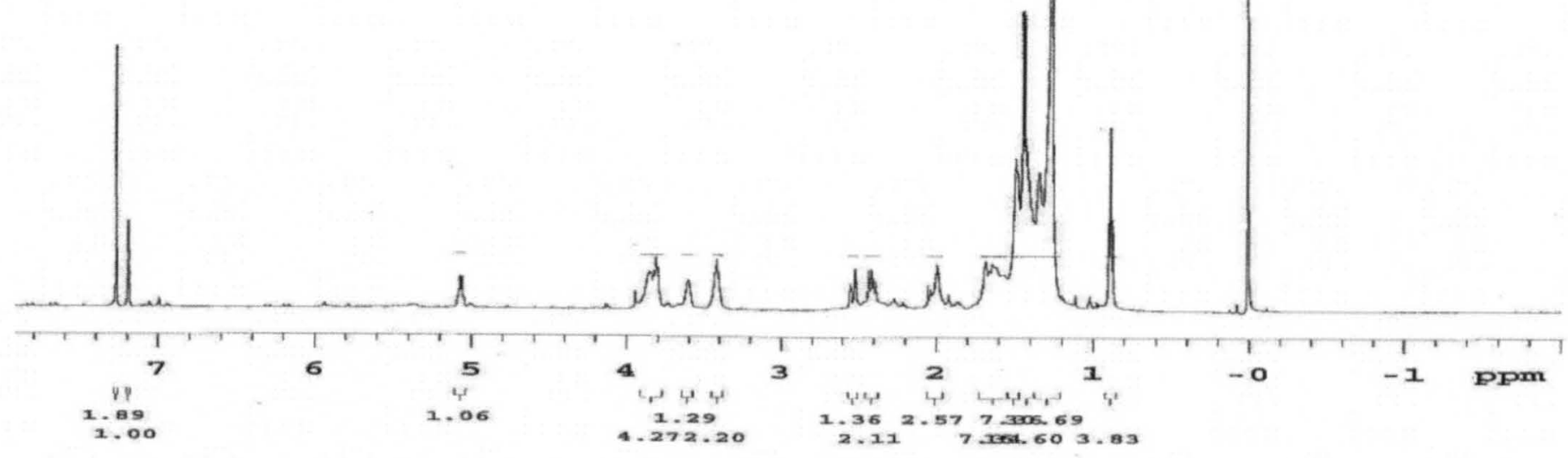




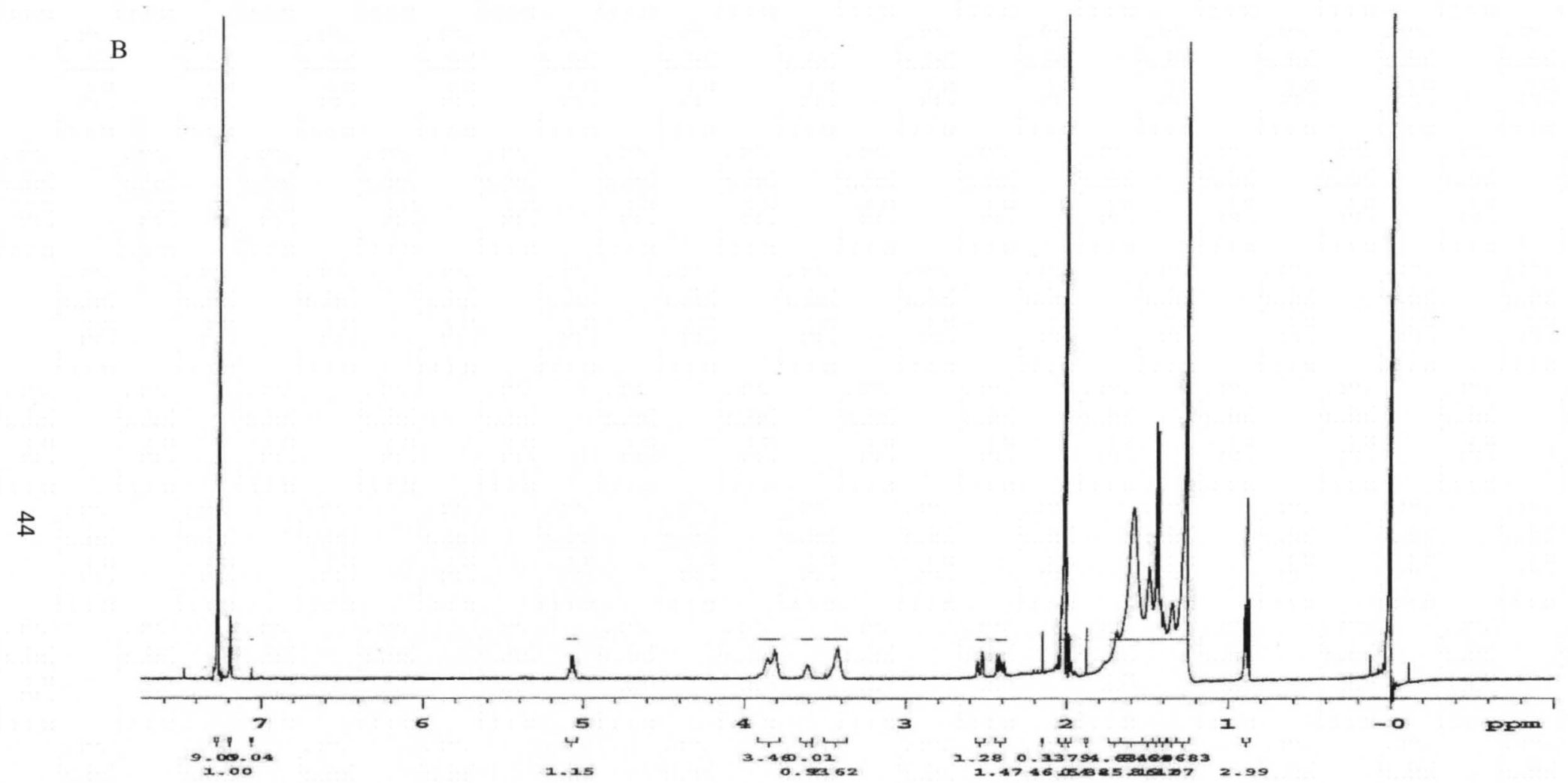

Figure 10. Proton nuclear magnetic resonance $\left({ }^{1} \mathrm{H}\right.$ NMR) spectra of annonacin from As. triloba fruit pulp (A) and An. muricata (B). Spectra obtained with VNMRS $400 \mathrm{MHz}$ instrument using $\mathrm{CDCl}_{3}$ as solvent and internal standard. 
Table 3. Chemical structures and ${ }^{1} \mathrm{H}$ and ${ }^{13} \mathrm{C}$ NMR Data for Annonacin $(\mathrm{R}=\mathrm{H})$ and Annonacin Tetraacetate $(\mathrm{R}=\mathrm{Ac})$

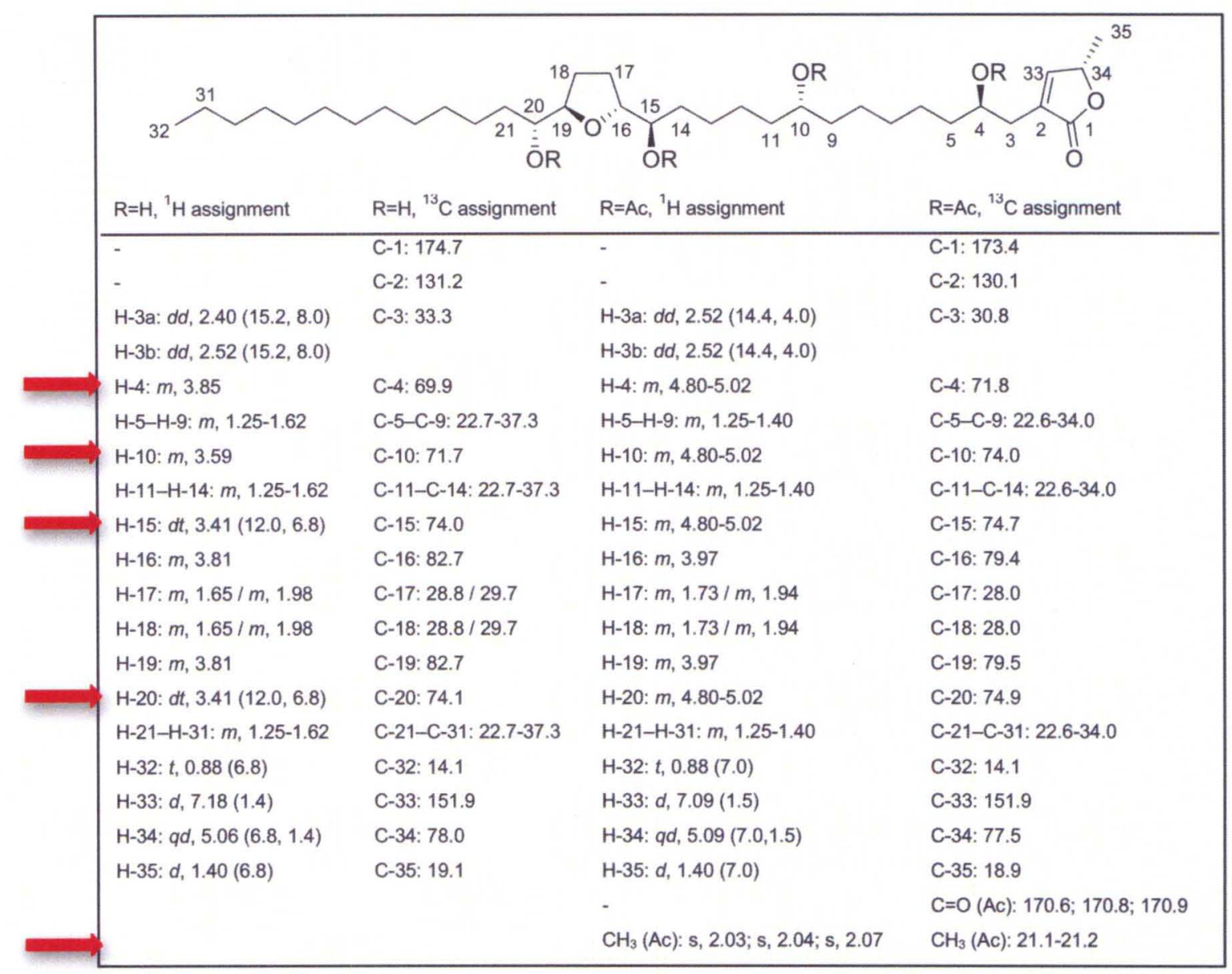

Isolated and purified materials were dried and dissolved in $\mathrm{CDCl}_{3}$ (chemical shifts $\delta$ in ppm; coupling constants $J$ in Hz; 100 and $400 \mathrm{MHz}$ ). Arrows highlight positions where assignments differ between isolated and acetylated annonacin, confirming the presence of reactive hydroxyl groups. 
Annonacin tetraacetate. The derivatization of polyol natural products by conversion to the less polar acetate or even benzoate ester is a common practice which facilitates smooth chromatographic purification of the parent compound or may provide additional data for its thorough characterization. ${ }^{104,105} 106$ Crude annonacin was treated with acetic anhydride and pyridine $(48 \mathrm{~h} / \mathrm{rt})$ producing the chromatographically more mobile and solvent-soluble annonacin tetraacetate (Figure 11) after purification by silica gel column chromatography $(40.2 \mathrm{mg}$, 40\%). TLC revealed complete consumption of the starting material (Figure 12) and increased silica gel mobility. The tetraacetate was characterized and confirmed by HRMS, ${ }^{1} \mathrm{H},{ }^{13} \mathrm{C}$ NMR, FTIR, and optical rotation (Figures 13-15). 

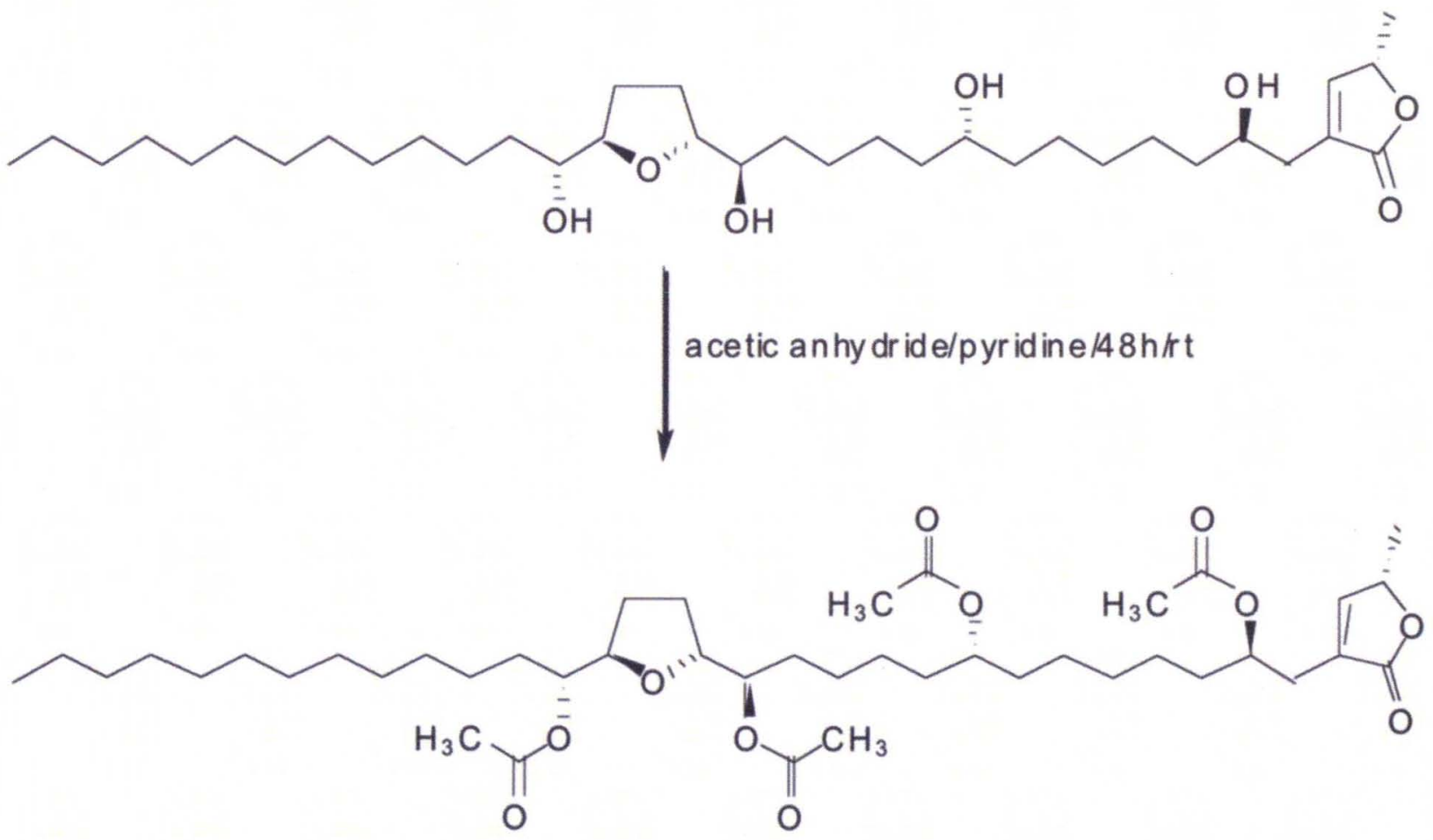

Figure 11. Conversion of annonacin to the tetraacetate derivative. 


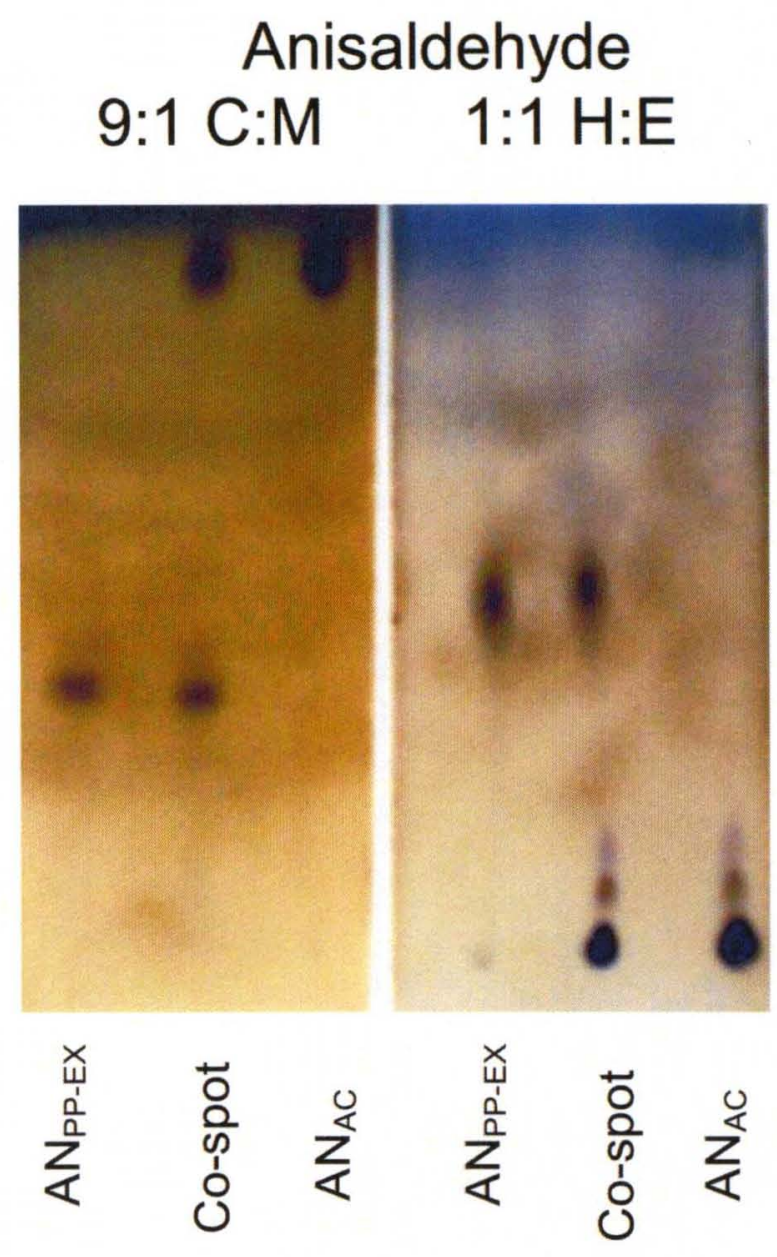

Figure 12. TLC of annonacin co-spotted with the annonacin tetraacetate derivative shows complete consumption of starting material and evidence of increased mobility on silica gel of the tetraacetate. TLC mobile phase:

chloroform/methanol (9:1) and hexane/ethyl acetate (1:1), stained with anisaldehyde. $\mathrm{AN}_{\mathrm{PP}-\mathrm{EX}}=$ pure annoncin isolated from As. triloba fruit, $\mathrm{AN}_{\mathrm{AC}}=$ acetylated annonacin. 
(5S)-5-Methyl-3-[(2R,8R,13R)-2,8,13-triacetoxy-13-[(2R,5R)-5-[(1R)-1acetoxytridecyl]-2-tetrahydrofuranyl] tridecyl]-5H-furan-2-one. Annonacin tetraacetate: $R_{f}=0.40$. HRMS calculated for $\mathrm{C}_{43} \mathrm{H}_{72} \mathrm{O}_{11} \mathrm{~m} / 2[\mathrm{~m}+\mathrm{Na}]^{+}$: 787.4966. Found: 787.4963. ${ }^{1} \mathrm{H}$ NMR $\left(500 \mathrm{MHz}, \mathrm{CDCl}_{3}\right)$ d: 7.09 (s, $\left.1 \mathrm{H}\right), 5.10$ $(m, 1 H), 5.01(J=7 H z, 13.5 H z), 4.85(m, 3 H), 3.97(m, 2 H), 2.55(q, J=4 H z$, $14 \mathrm{~Hz}$ ), $2.52(\mathrm{q}, \mathrm{J}=4 \mathrm{~Hz}, 14 \mathrm{~Hz}), 2.07(\mathrm{~s}, 6 \mathrm{H})$ signal overlap, $2.04(\mathrm{~s}, 3 \mathrm{H}), 2.03(\mathrm{~s}$, $3 \mathrm{H}), 1.94(\mathrm{~m}, 2 \mathrm{H}), 1.5-1.59(\mathrm{~m}, 12 \mathrm{H}), 1.40(\mathrm{~d}, \mathrm{~J}=6.5 \mathrm{~Hz}), 1.25-1.4(\mathrm{~m}, 30 \mathrm{H}), 0.88$ (t, J=7Hz, 3H). ${ }^{13} \mathrm{C} \mathrm{NMR}\left(100 \mathrm{MHz}, \mathrm{CDCl}_{3}\right) \delta: 173.44,170.87,170.85,170.59$, $150.90,130.14,79.54,79.43,77.50,74.92,74.73,74.00,71.84,34.01,33.99$, $31.87,30.82$. 30.75. 29.84, 29.62, 29.65-29.59 signal overlap, 29.52, 29.44, $29.30,29.20,28.03,28.02,25.29,22.64,21.22,21.10,21.08,18.89,14.07$. $[\alpha]_{\mathrm{D}}^{20}+7.45^{\circ}\left(\mathrm{c}=0.51, \mathrm{CHCl}_{3}\right)$. FTIR 2927, 2856, 1744, 1737, $1241 \mathrm{~cm}^{-1}$.

The successful formation of annonacin tetraacetate provided additional confirmation that our isolated material was annonacin as noted by shifts in FTMS, NMR and FTIR absorptions where expected (Figures 13-15). Arrows in Table 3 highlight where chemical shifts differ between annonacin and the tetraacetate. These shifts confirm the conversion of hydroxyl groups to acetates, as expected. Specifically the loss of $\mathrm{OH}$ bending in the FTIR tetraacetate spectra indicated disappearance of the 4 hydroxyl groups that were evidenced by a broad absorption band at $3416.74 \mathrm{~cm}^{-1}$ in the annonacin spectra. Furthermore, the optical rotation $\left([a]_{D}^{20}=+20.4^{\circ}\right)$ of our purified material corresponds to that of annonacin prepared by stereoselective synthesis $\left([\alpha]_{D}{ }^{20}=+21\right),{ }^{107}$ which confirms that it possesses the same stereochemistry as annonacin. 
FTMS of annonacin and annonacin-tetraacetate

A LP 154 3 ACFTMS \#1 RT: 0.02 AV: 1 NL. L.JजË8

T: FTMS + p ESI Full ms [50.00-1000.00]

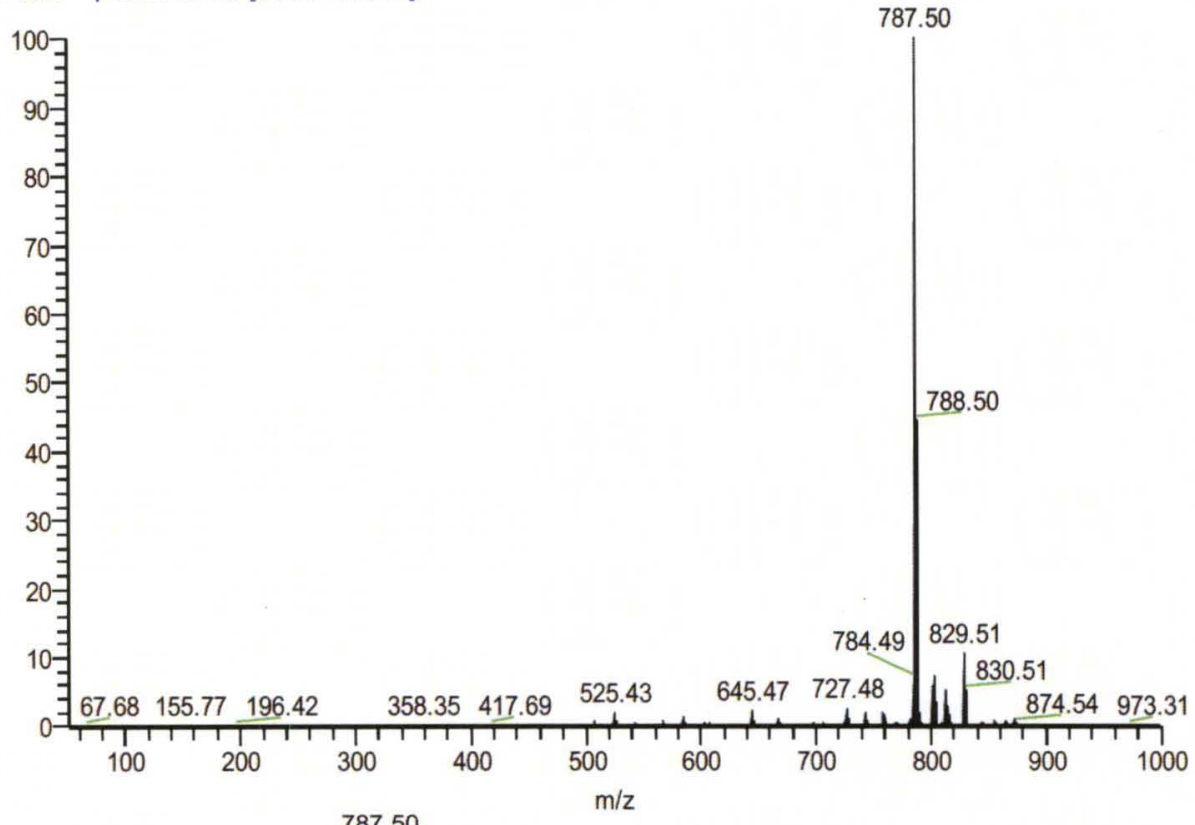

B

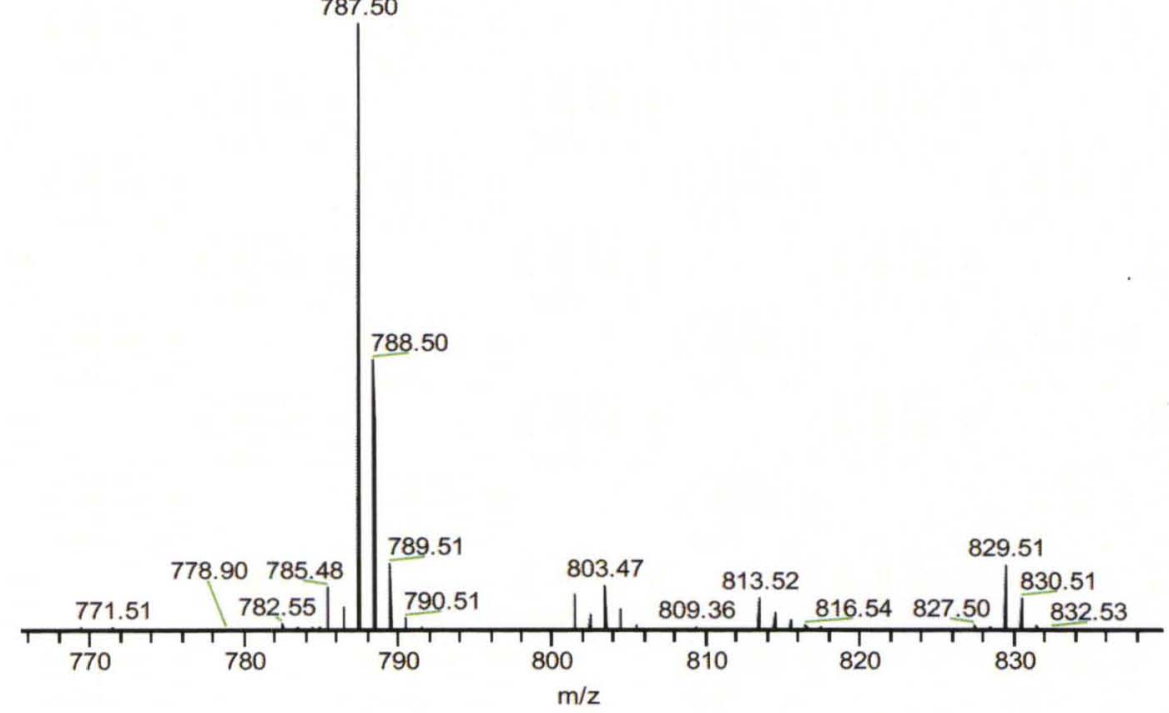

Figure 13. FTMS spectra for tetraacetate derivative of isolated annonacin (A).

Panel B shows a more narrow range of the spectra around the tetraacetate peak.

HRMS calculated for annonacin tetraacetate, $\mathrm{C}_{43} \mathrm{H}_{72} \mathrm{O}_{11} \mathrm{~m} / \mathrm{z}[\mathrm{m}+\mathrm{Na}]^{+}:$787.4966;

Found: $787.4963 \pm 0.4 \mathrm{ppm}$. 


\section{${ }^{1} \mathrm{H}$ NMR of annonacin and annonacin-tetraacetate}
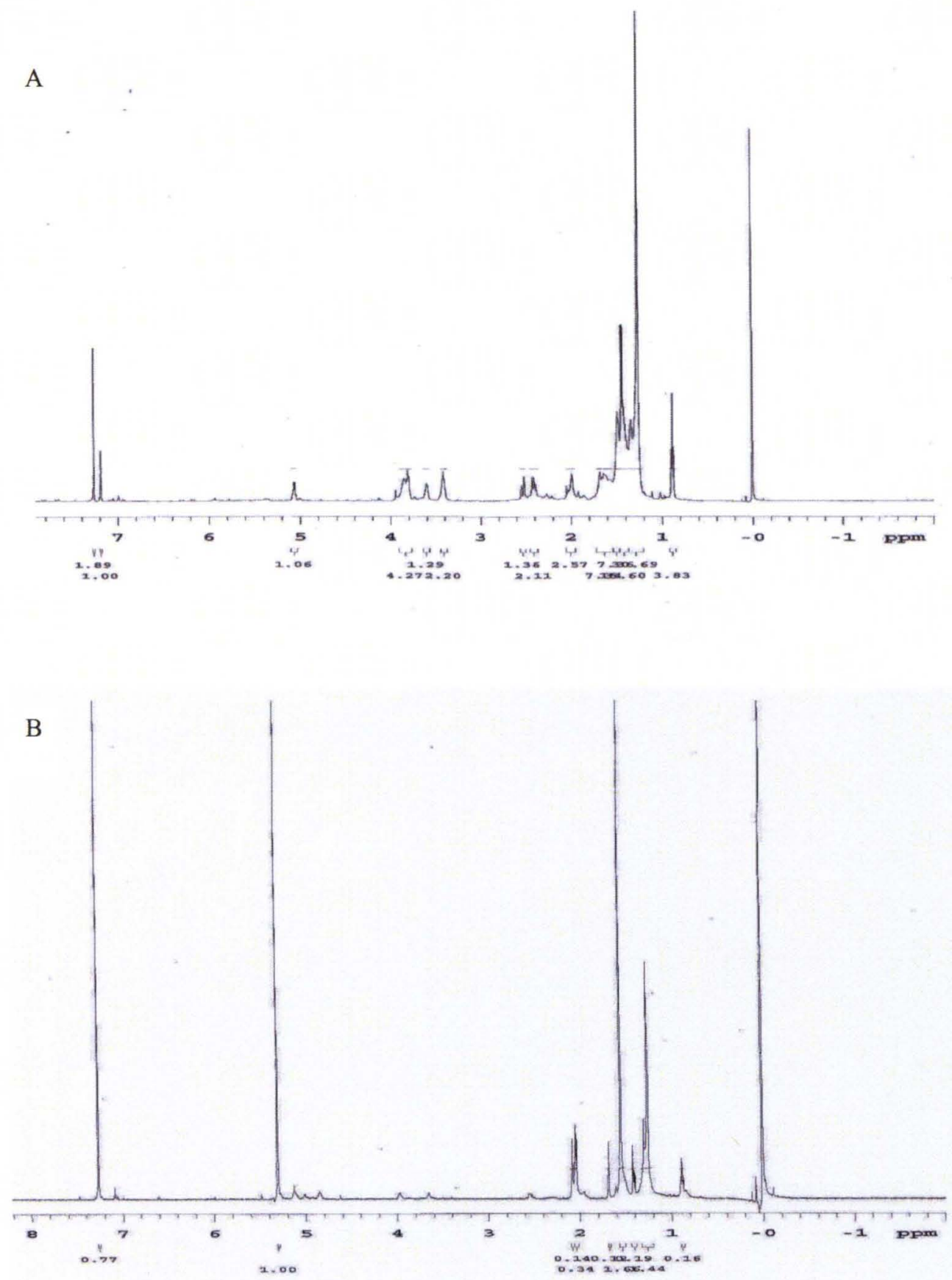

Figure 14. Comparing ${ }^{1} \mathrm{H}$ NMR spectra for annonacin $(\mathrm{A})$ and annonacin tetraacetate $(B)$ shows shift in peaks where expected. Spectra obtained with VNMRS $400 \mathrm{MHz}$ instrument using $\mathrm{CDCl}_{3}$ as solvent and internal standard. 
FTIR of annonacin and annonacin-tetraacetate

A

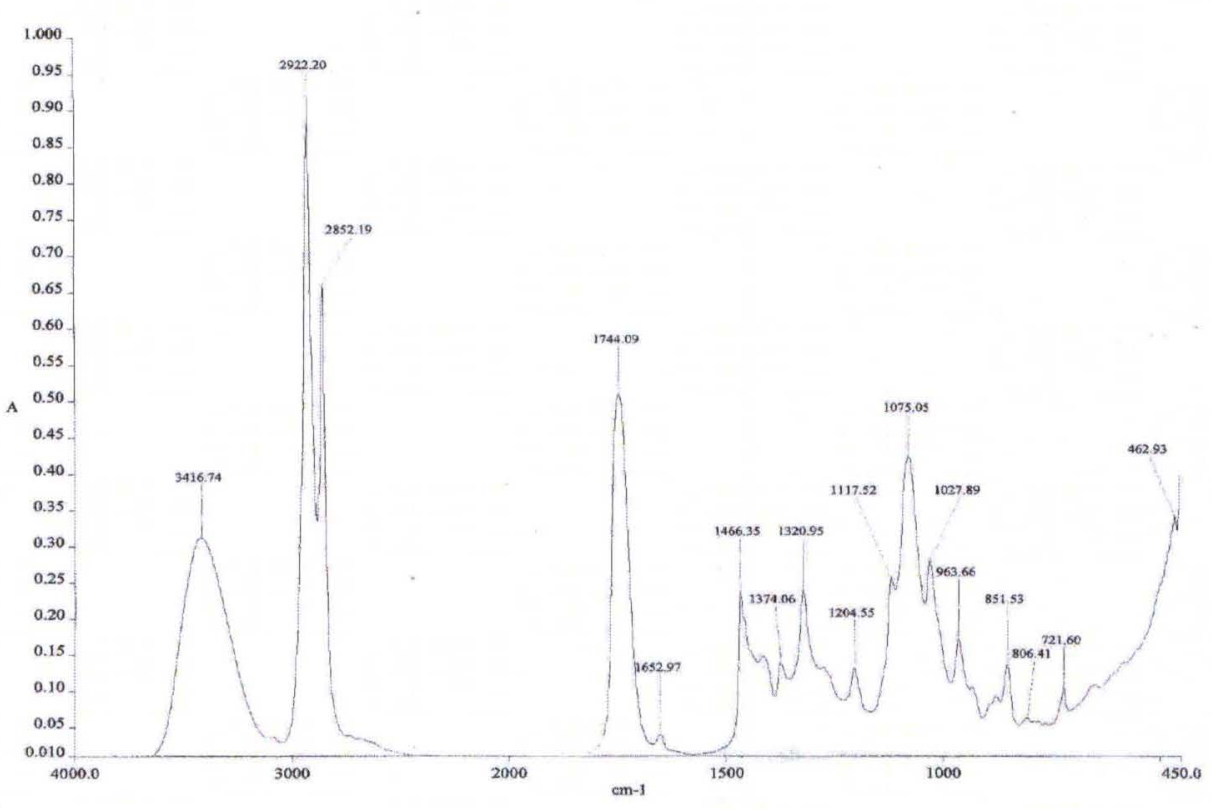

B

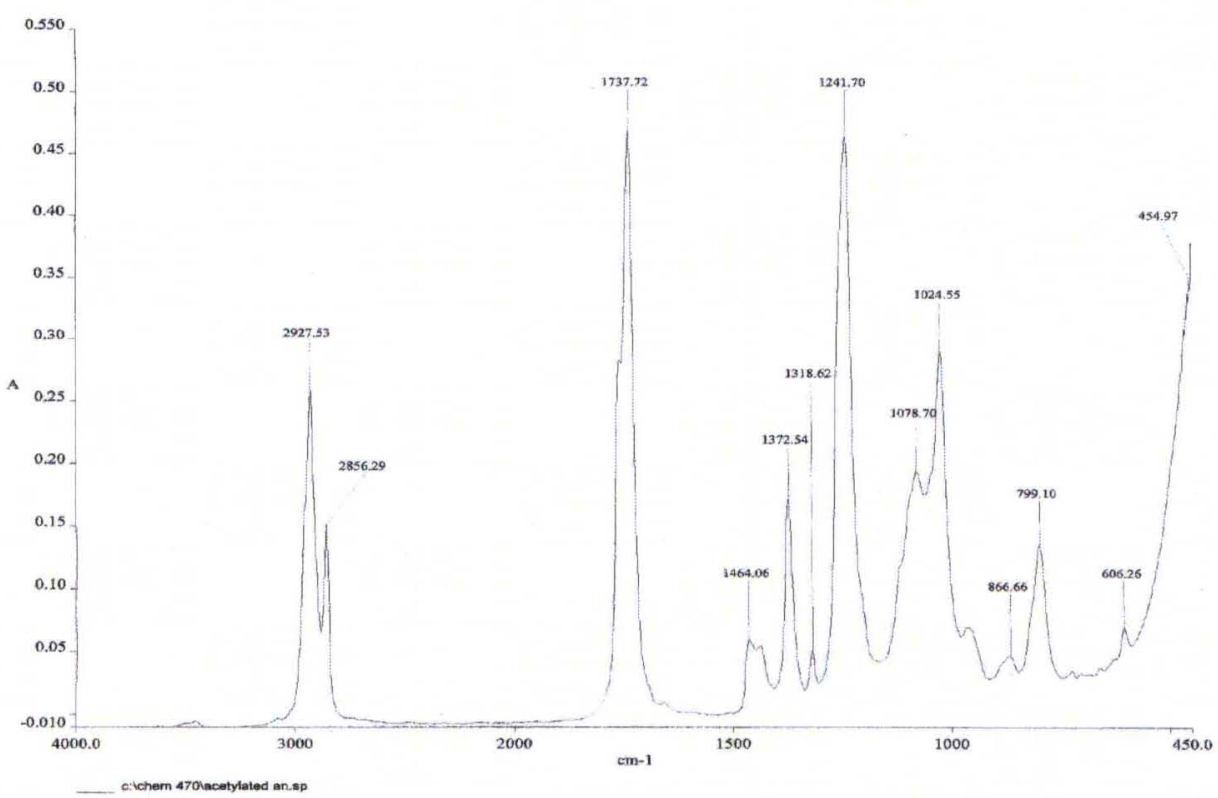


Figure 15. Fourier transform infrared (FTIR) spectra of annonacin isolated from Asimina triloba: $3416.74 \mathrm{~cm}^{-1}=\mathrm{OH}$ groups, $2922.2 \mathrm{~cm}^{-1}=\mathrm{CH}_{2}$ 's, $2852.19 \mathrm{~cm}^{-1}=$ THF ring, $1744.09 \mathrm{~cm}^{-1}=$ butenolide $(A)$ compared to spectra of the tetraacetate derivative $2927.53 \mathrm{~cm}^{-1}=\mathrm{CH}_{2}$ 's, $2856.29 \mathrm{~cm}^{-1}=$ THF ring, $1737.72 \mathrm{~cm}^{-1}=$ acetates with butenolide shoulder (B). Note, as expected, in B there is no longer a peak corresponding to the $\mathrm{OH}$ groups confirming complete consumption of starting material and tetraacetate formation. Purified samples dissolved in $\mathrm{CHCl}_{3}$ and spotted on salt plates for spectral acquisition using Perkin-Elmer Spectrum 100 instrument. 
Quantification. The amount of annonacin isolated per gram of frozen fruit pulp was $0.07 \pm 0.03 \mathrm{mg}$ as determined by average weight from extractions on 5 separate batches (Table 4). Based on repeated extractions it was determined that annonacin represents $0.01 \%$ of pawpaw pulp by weight determination. On average, annonacin made up ten percent of the total crude EtOAc extract (CEX). One additional extraction was done on locally harvested fresh fruit, which gave an annonacin yield of $0.12 \mathrm{mg}$ per gram of pulp.

Table 4. Annonacin content of Asimina triloba vs. Annona muricata

\begin{tabular}{|l|l|l|l|}
\hline & $\begin{array}{l}\text { Average } \\
\text { total fruit } \\
\text { weight }^{1}(\mathrm{~g})\end{array}$ & $\begin{array}{l}\text { Amount } \\
\text { annonacin } \\
\text { per fruit } \\
\text { (mg) }\end{array}$ & $\begin{array}{l}\text { Amount } \\
\text { annonacin per } \\
\text { gram of fruit } \\
\text { pulp }^{2}(\mathrm{mg} / \mathrm{g})\end{array}$ \\
\hline $\begin{array}{l}\text { Asimina triloba } \\
\begin{array}{l}\text { Frozen fruit } \\
\text { pulp } \\
\text { Fresh fruit pulp }\end{array}\end{array}$ & $\sim 300$ & 7.0 & 0.07 \\
\hline $\begin{array}{l}\text { Annona } \\
\text { muricata }\end{array}$ & $\sim 800$ & 12.3 & 0.12 \\
\hline
\end{tabular}

'Note these values reflect weight of the whole fruit (i.e. including skin, seeds and pulp). ${ }^{2}$ The amount of annonacin per gram of fruit pulp is based on the amount of pulp used in the extraction, not the weight of the whole fruit. ${ }^{10}{ }^{3}$ Quantities in fresh fruit are based on data from one extraction; one pawpaw fruit yielded 100 grams of pulp on average. 
$\underline{\text { In vitro toxicity of annonacin and Asimina triloba organic fruit extract }}$

Annonacin treatment reduced the number of viable cells remaining in the culture 48 hours after treatment at concentrations as low as $10 \mu \mathrm{M}(p<0.001$, Figure 16) as determined by MTT assay. Immunocytochemistry confirmed neuronal toxicity as shown by a decrease in MAP2 immunoreactivity and changes in neuronal morphology indicative of neurodegeneration, prior to cell death (Figure 17). Similar to MAP2 staining, images reveal an overall decrease in total tau (DA9) immunoreactivity in response to annonacin treatment (Figure 18) confirming annonacin toxicity in neuronal cells. 
Cortical neurons $\mathbf{4 8 h r s ~ a f t e r ~ t r e a t m e n t ~}$

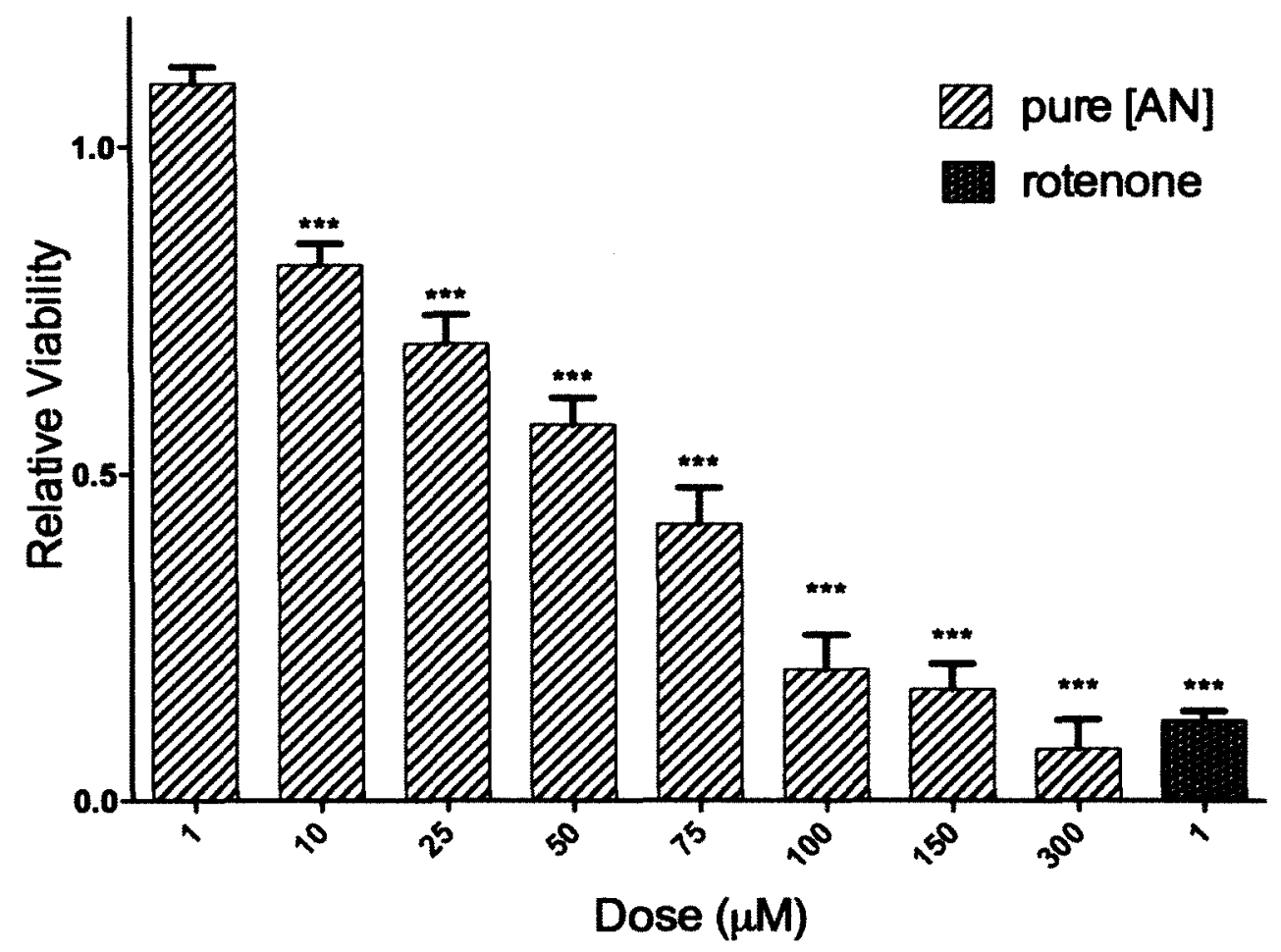

Figure 16. MTT assay of cortical neurons 48 hours after treatment with purified annonacin isolated from Asimina triloba fruit pulp. $\mathrm{LD}_{50}$ for annonacin $=50.45$ $\mu M$ (ie. ) \pm 1.07 . Bars represent mean ( \pm SEM) viability relative to vehicle control-treated cultures. Diagonal lines $=$ annonacin $(\mu \mathrm{M})$, checkered fill $=$ rotenone $(\mu \mathrm{M}), \mathrm{p}$-value $<0.001\left(^{(* *)}\right)$.

56 
Time-response of MAP2 immunoreactivity in cortical neurons after annonacin treatment
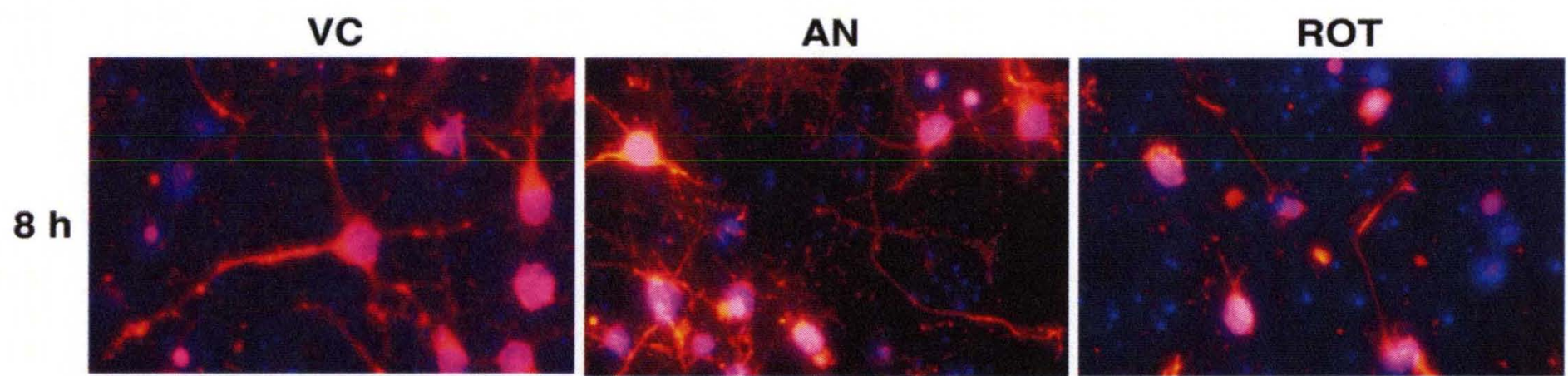

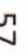
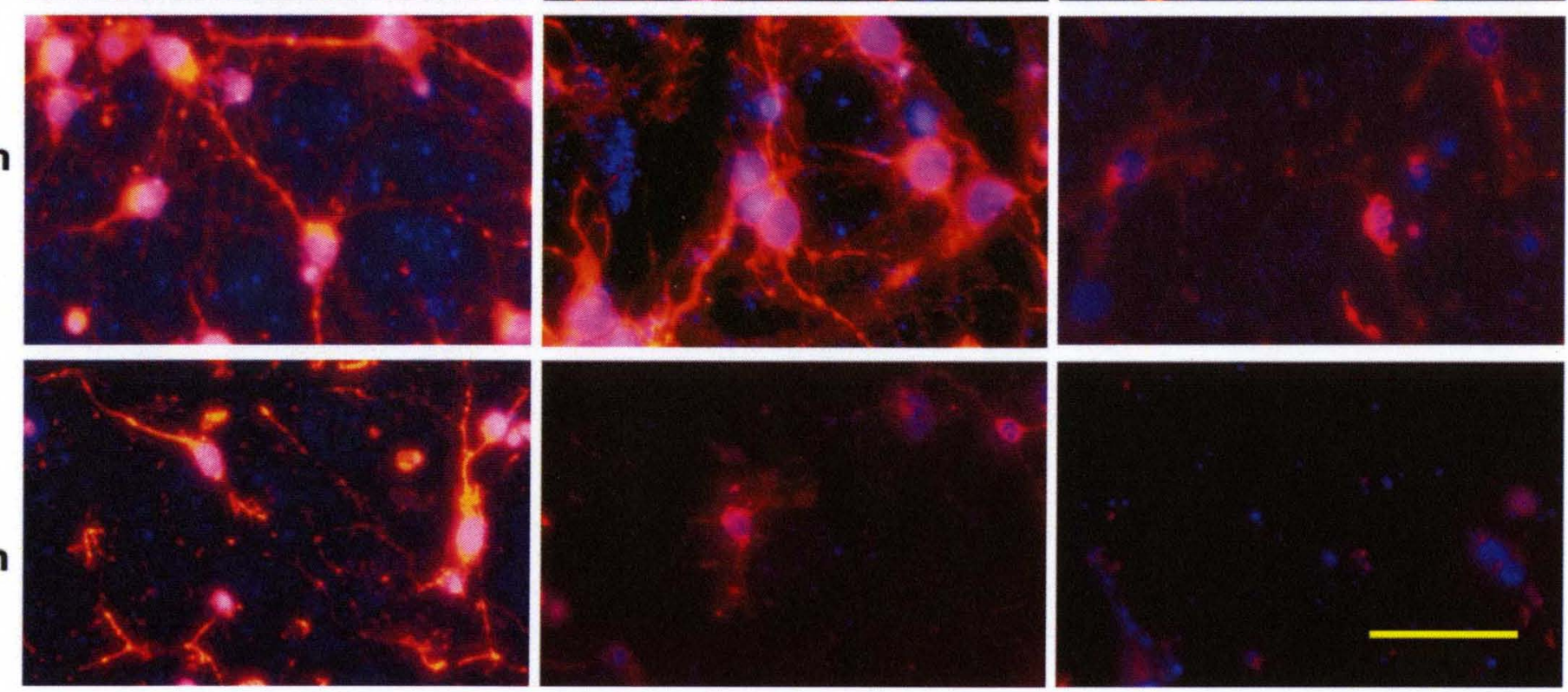
Figure 17. Cells were fixed as noted in the text at 8,24 , and 48 hours after treatment and visualized with anti-MAP2 immunotstaining (red). Nuclear chromatin was co-stained with Hoechst (blue). Merged images are shown. VC = vehicle $(\mathrm{DMSO})$ control; $\mathrm{AN}=75 \mu \mathrm{M}$ annonacin; $\mathrm{ROT}=1 \mu \mathrm{M}$ rotenone. $\mathrm{A}$ decrease in MAP2 immunoreactivity in response to annonacin treatment confirms neuronal toxicity. All images taken with $20 x$ objective; scale bar $=100 \mu \mathrm{m}$. 
Tau immunoreactivity in cortical neurons after annonacin treatment
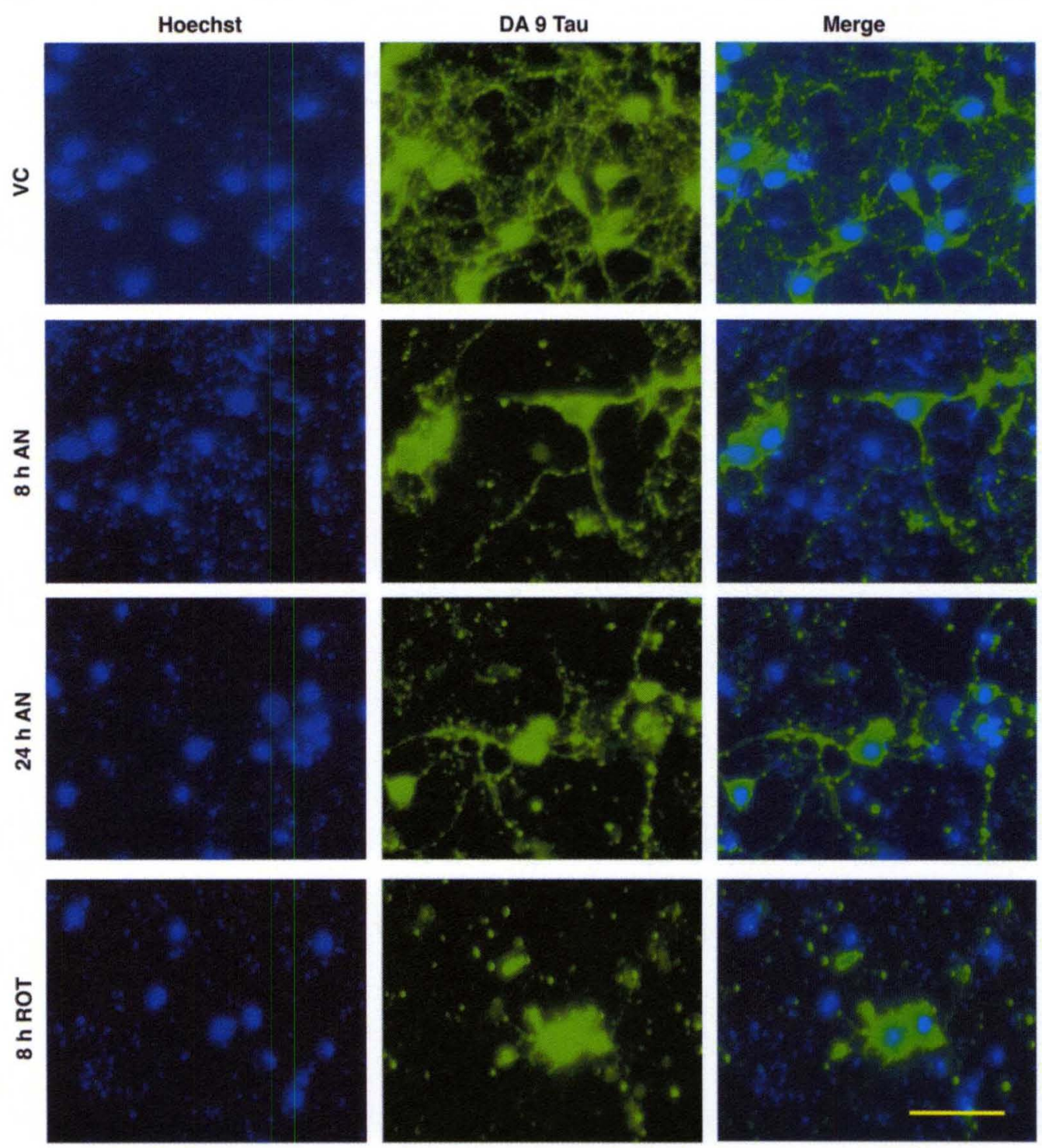
Figure 18. Cells were fixed as noted in the text at 8 and 24 hours after treatment with either $75 \mu \mathrm{M}$ annonacin (AN) or $1 \mu \mathrm{M}$ rotenone (ROT). Immunostaining with anti-total tau antibody DA9 (green) suggests an overall reduction in tau in response to annonacin treatment. Nuclear chromatin was co-stained with Hoechst (blue) $. \mathrm{VC}=$ vehicle $(\mathrm{DMSO})$ control. All images taken with $20 \mathrm{x}$ objective; scale bar $=50 \mu \mathrm{m}$. 
During initial treatments with cEX, an oily precipitate was noticeable in the culture media, indicating that CEX was not completely dissolving and therefore likely not reaching the cells to have an effect. Therefore, experiments were conducted to determine the most appropriate solvent for cEX that would also be tolerated by the cultured neurons. Data showed that EtOAc was well tolerated by the cells (Figure 19). As expected considering the extract procurement process, EtOAc was also the most effective of the solvents considered (DMSO, MeOH, $\mathrm{EtOH}, \mathrm{EtOAc}$ ) at dissolving cEX. ACG-free treatment did not result in cell death indicating that the processing of extract components per se is not sufficient for procuring toxic material (Figure 20). The $L D_{50}$ values for purified annonacin and CEX 48 hours after treatment were $30.07 \mu \mathrm{g} / \mathrm{ml}$ (i.e. $50.45 \mu \mathrm{M})$ and $(47.96 \mu \mathrm{g} / \mathrm{ml}$ ) respectively, as determined by non-linear regression analysis of MTT viability data. Comparison of $L D_{50}$ values between pure annonacin and the amount of annonacin present in $\operatorname{CEX}\left(\mathrm{LD}_{50}=4.80 \mu \mathrm{g} / \mathrm{ml}\right)$ confirmed that $\mathrm{CEX}$ has more toxic potential than annonacin by itself $(p<0.0001$, Figure 21). Though the lack of significant difference between pure annonacin and total CEX suggest that the presence of other compounds in cEX may affect annonacin toxicity. 
Solvent tolerance of cortical neurons after $\mathbf{4 8} \mathrm{hrs}$.

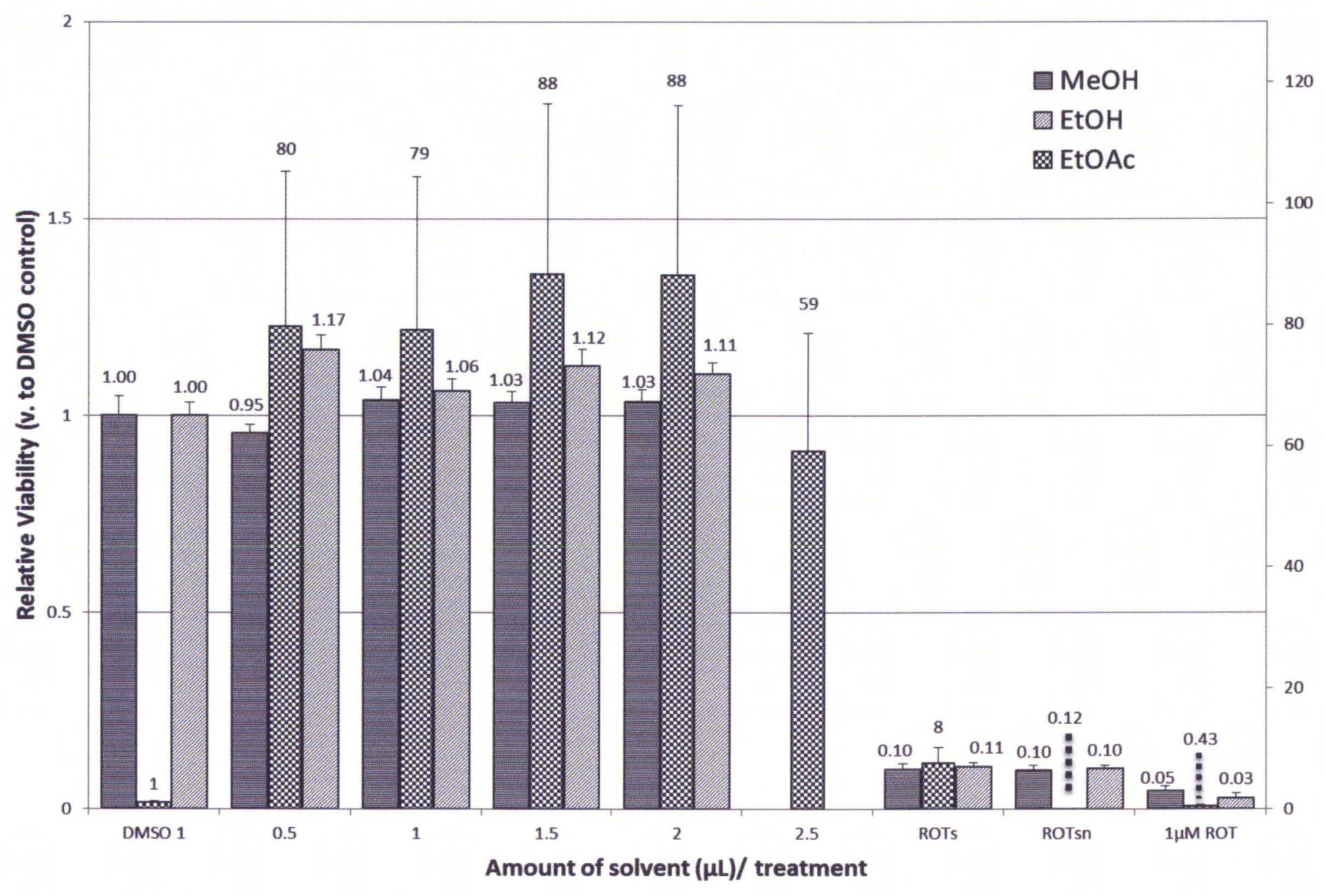


Figure 19. Relative viability of primary cortical neurons 48 hours after treatment with one of three solvents $(\mathrm{MeOH}, \mathrm{EtOH}$, and EtOAc) as determined by MTT assay. Values for each solvent were normalized to the standard DMSO control. EtOAc consistently resulted in high levels of viability compared to DMSO treated controls. Due to the dramatic difference in relative viabilities between solvent groups, $\mathrm{MeOH}$ and $\mathrm{EtOH}$ relative viabilities are plotted on left $\mathrm{Y}$-axis whereas EtOAc relative viability is plotted on right $Y$-axis. $X$-axis is the amount of solvent added (i.e. $0.5-2.5 \mu \mathrm{l}$ ) per well on a 96-well plate (total volume $=200 \mu \mathrm{l} /$ well). Rotenone treatments were included as positive controls for achieving toxicity in each solvent. ROTs $=1 \mu \mathrm{M}$ rotenone added in respective solvent but normalized to DMSO control. ROTsn $=1 \mu \mathrm{M}$ rotenone added in respective solvent and normalized to respective solvent. $1 \mu \mathrm{M} \mathrm{ROT}=1 \mu \mathrm{M}$ rotenone added in DMSO and normalized to DMSO. Bars represent average of wells from one (MeOH and EtOH) or three $(E t O A c)$ independent experiments. Error bars = SEM. Numbers above columns are the actual values of relative viability for the respective treatment. 


\section{Cortical neurons $48 \mathrm{hrs}$ after pawpaw extract treatments}

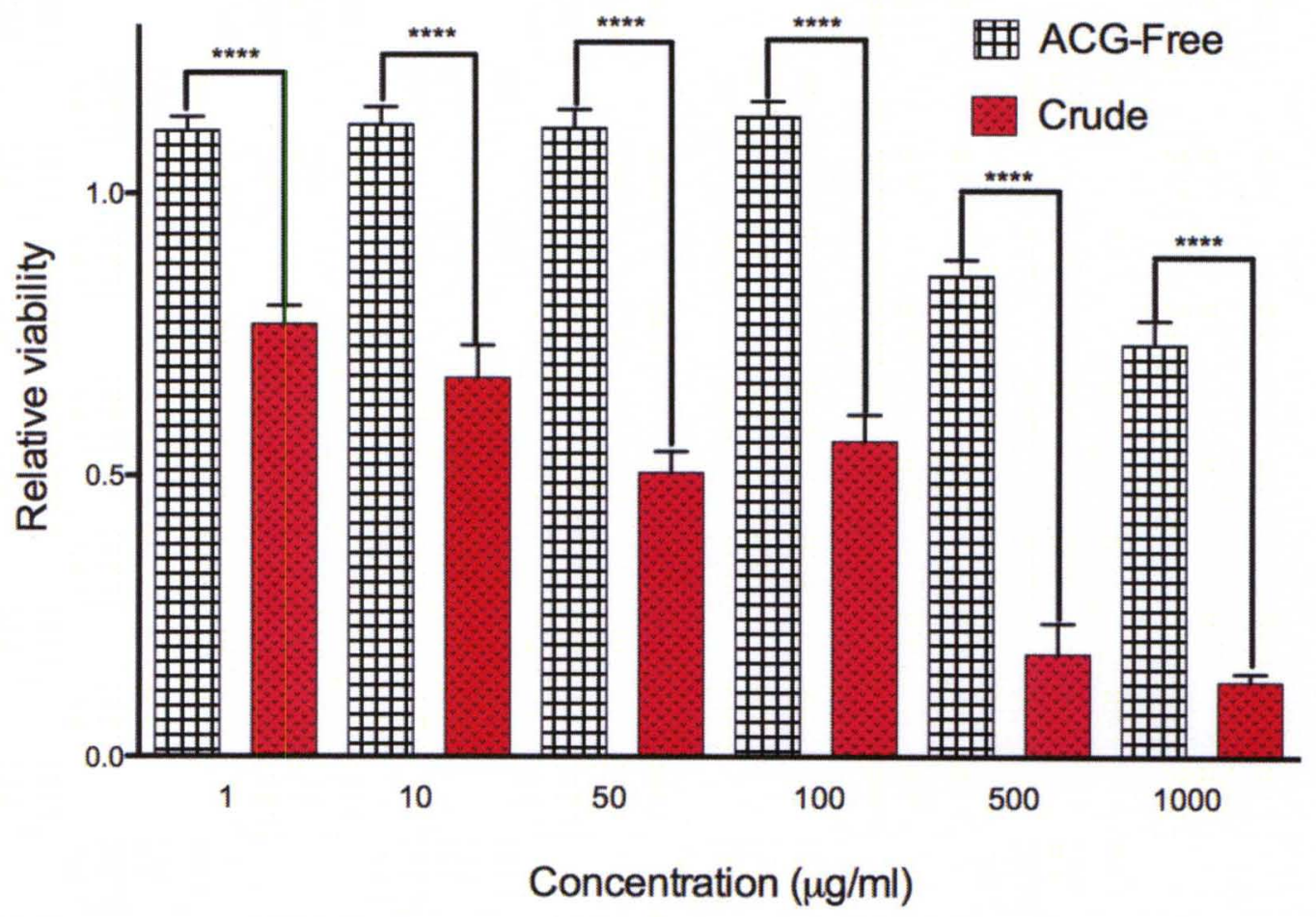

Figure 20. Relative viability of $\mathrm{cEX}$ (crude, red bars) was significantly lower at each dose than ACG-free (plaid bars) treatment $\left.p<0.0001{ }^{* * * *}\right)$. All doses of cEX significantly reduced cell viability compared to vehicle-treated controls $(p<$ 0.001). ACG-free treatment only significantly reduced viability at high concentrations (i.e. $\geq 500 \mu \mathrm{g} / \mathrm{ml}, \mathrm{p}<0.01$ ). Bars represent relative viability, normalized to controls (mean \pm SEM). P-values determined by one-way ANOVA with Dunnett's post hoc comparison. 


\section{Dose-responses of cortical neurons $48 \mathrm{hrs}$ after \\ pawpaw extract treatments}

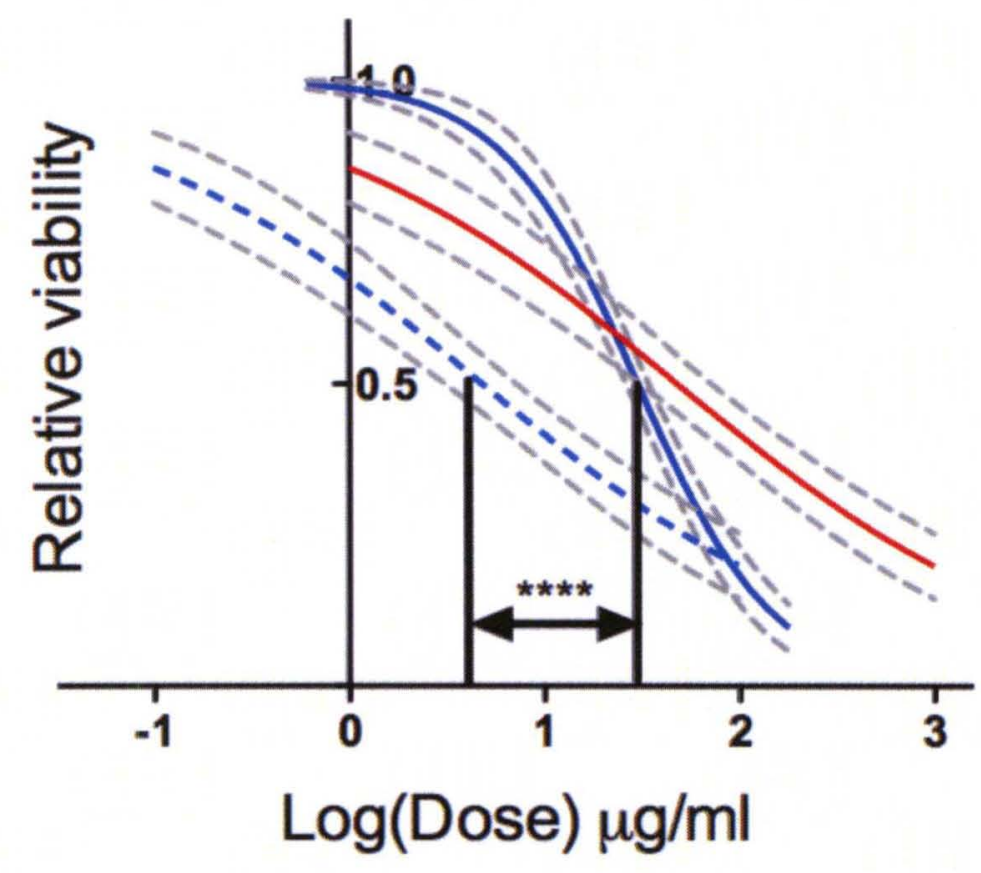

Figure 21. Dose-response curves for cEX (crude, red line, $L_{50}=47.96 \mu \mathrm{g} / \mathrm{ml}$ ) and for pure annonacin $(\mu \mathrm{g} / \mathrm{ml}$ ) (solid blue line) compared to amount of annonacin $(\mu \mathrm{g} / \mathrm{ml})$ in the crude extracts (dashed blue line) 48 hours posttreatment. $\mathrm{LD}_{50}$ of pure annonacin alone $(30.07 \mu \mathrm{g} / \mathrm{ml}$, i.e. $50.45 \mu \mathrm{M})$ is significantly higher than that of annonacin in the presence of crude extracts $(4.80$ $\left.\left.\mu \mathrm{g} / \mathrm{ml}, \mathrm{p}<0.0001{ }^{(\star * \star *}\right)\right) . \mathrm{LD}_{50}$ values determined by nonlinear regression of $\log ($ dose) v. relative viability. Gray dashed lines represent $95 \%$ confidence intervals for dose-response data. 
$\underline{\text { In vitro effects of annonacin on microtubule associated protein tau }}$

Considering the changes in neuronal morphology noted above by MAP2 and tau staining, the effect of annonacin on tau in cortical neurons was assessed at early time-points. To further assess annonacin's effect on tau, Western blotting was utilized to determine changes in the levels of tau expression 4 hours after treatment (Figure 22). Contrary to previous reports, ${ }^{37}$ but consistent with the above noted patterns of tau-immunostaining, annonacin resulted in a decrease in total tau (DA9, $p<0.01$ ). Statistical analysis of western blot data revealed that neither annonacin nor rotenone resulted in any changes in tau phosphorylation. Originally it was hypothesized that annonacin would induce tau phosphorylation. Since GSK-3ß is known to phosphorylate tau, it was also hypothesized that annonacin treatment would activate GSK-3 $\beta$, therefore

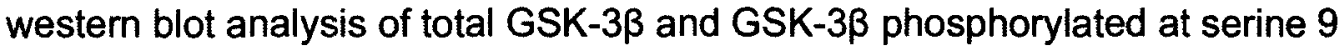
(inactive form) was performed. In contrast to the initial hypothesis but consistent with the above noted changes in tau, annonacin did not induce any changes in GSK-3 $\beta$ expression (Figure 23). 
Tau expression $4 \mathrm{hrs}$. after annonacin treatment

A

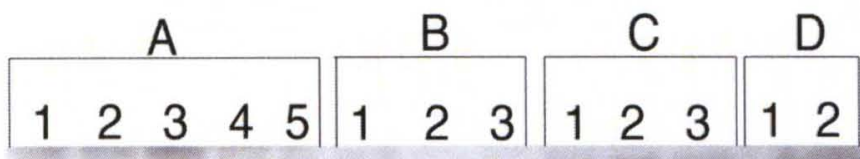

MC-1

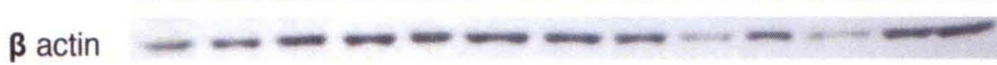

CP-13

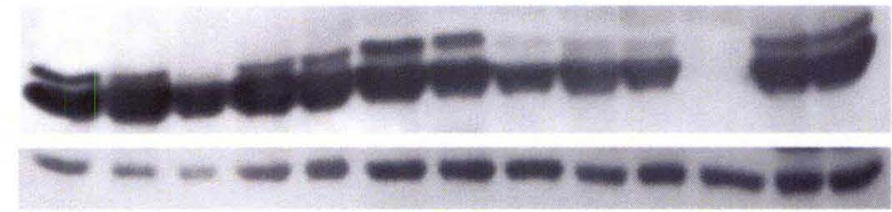

PHF-1

$\beta$ actin

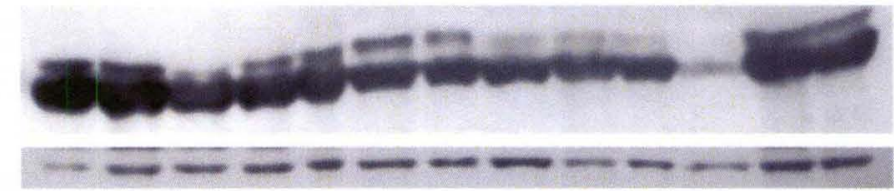

DA 9

$\boldsymbol{\beta}$ actin

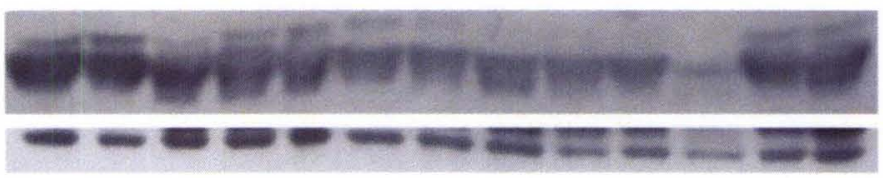

B

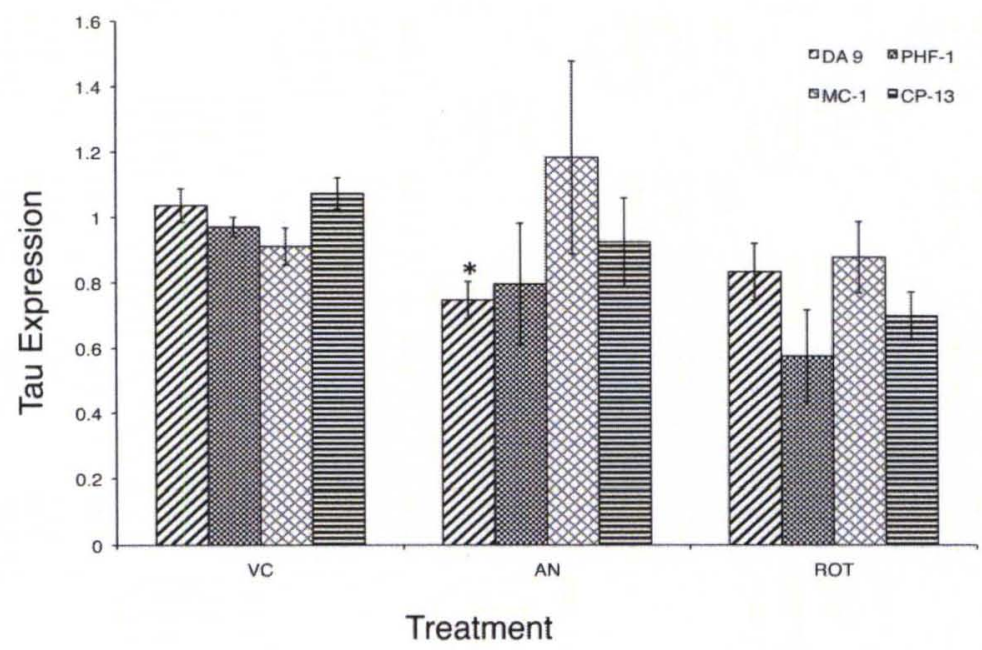


Figure 22. Western blot analysis of tau protein expression was performed as described in the text. $\beta$-actin was used as loading control. Lysates from 4 different experiments were run on the same blot $(A)$ with letters $A-D$ representing a different experiment. In A, lanes 1-5 are VC, VC, AN, AN, R. In B lanes 1-3 are VC, AN, R. In C, lanes1-3 are VC, VC, AN. In D, lanes 1-2 are VC, AN. VC $=$ vehicle (DMSO) control, $\mathrm{AN}=75 \mu \mathrm{M}$ annonacin, $\mathrm{ROT}=1 \mu \mathrm{M}$ rotenone. Quantitative analysis of relative abundance is graphically represented in panel B. One-way analysis of variance (ANOVA) with Dunnett's post-hoc test revealed a significant decrease in the amount of total tau (DA9, p-value $\left.=0.01\left(^{*}\right)\right) 4$ hours after annonacin treatment. Bars represent relative expression from 4 independent experiments (mean \pm SEM) as determined by normalizing absorbance values for each blot to its respective beta-actin blot and then to vehicle control. Phospho-tau epitopes were also normalized to total tau in order to determine relative phosphorylation. Diagonal lines $=\mathrm{DA} 9$, small checks $=$ PHF-1, diamond $=$ MC-1, horizontal lines $=\mathrm{CP}-13$. 
GSK-3 $\beta$ expression $4 \mathrm{hrs}$. after annonacin treatment

A

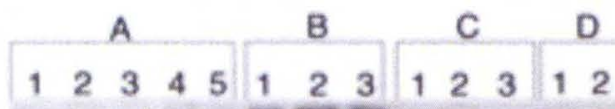

GSK 3 B PS9

GSK $3 \beta$ Total

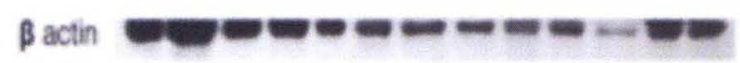

B
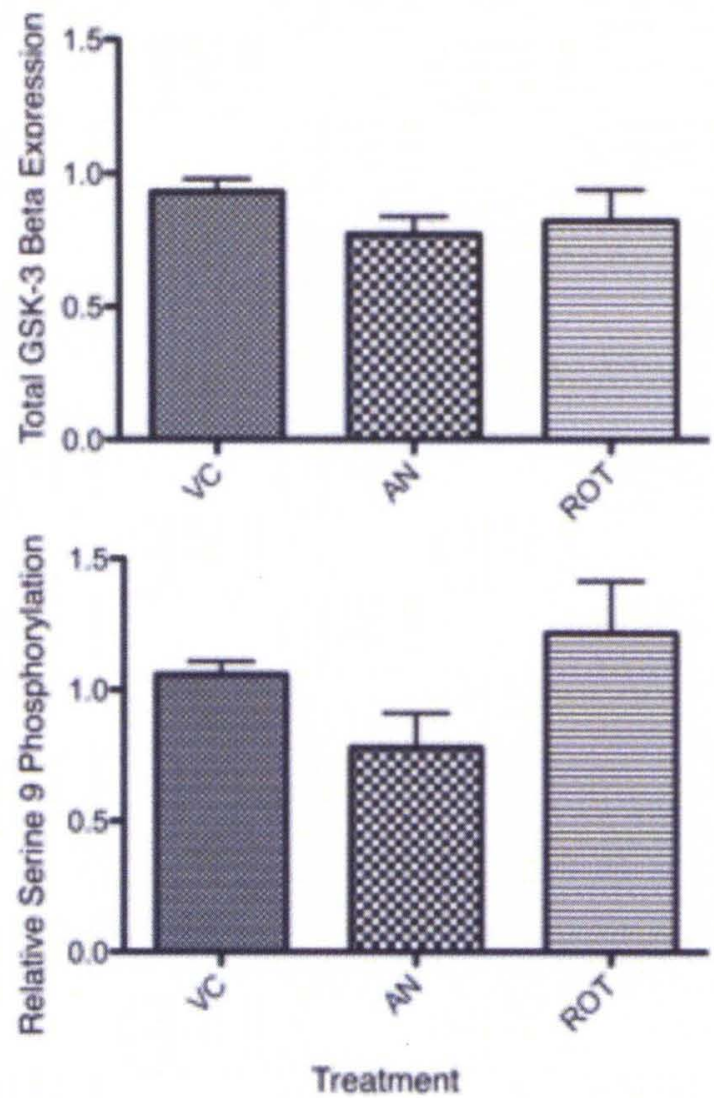
Figure 23. Western blot analysis of GSK-3 $\beta$ expression was performed as described in the text. $\beta$-actin was used as loading control. Lysates from 4 different experiments were run on the same blot $(A)$ with letters $A-D$ representing a different experiment. In $\mathrm{A}$, lanes 1-5 are VC, VC, AN, AN, R. In B lanes 1-3 are VC, AN, R. In C, lanes1-3 are VC, VC, AN. In D, lanes 1-2 are VC, AN. VC $=$ vehicle $(\mathrm{DMSO})$ control, $\mathrm{AN}=75 \mu \mathrm{M}$ annonacin, $\mathrm{ROT}=1 \mu \mathrm{M}$ rotenone. Quantitative analysis of relative abundance is graphically represented in panel B. One-way analysis of variance (ANOVA) with Dunnett's post-hoc test revealed no significant changes in GSK-3 $\beta$ expression 4 hours after annonacin treatment. Bars represent relative expression from 4 independent experiments (mean \pm SEM) as determined by normalizing absorbance values for each blot to its respective beta-actin blot and then to vehicle control. Phosphorylation of GSK-

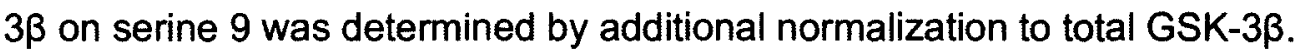




\section{CHAPTER IV}

\section{DISCUSSION}

\section{Extraction and isolation of annonacin from Asimina triloba fruit pulp}

The above results have (1) revealed the presence of annonacin in fruit pulp of the annonaceous tree, Asimina triloba, and (2) determined the amount of annonacin per gram of pulp. The presence of annonacin in fresh and frozen pawpaw fruit was verified by chromatographic and spectroscopic techniques. The extraction, isolation and chromatographic purification of annonacin from pawpaw fruit described herein is an effective method for procuring the material in suitable enough quantities so that both biological and chemical studies may be conducted. The fresh or frozen fruit is readily available in large quantities and the maceration/liquid-liquid partitioning protocol is time-effective and precludes the use and expense of freeze-drying equipment. Based on repeated extractions it was determined that annonacin represents $0.01 \%$ of pawpaw pulp by weight determination. This is higher in comparison to other sources of annonacin: $0.0004 \%$ Annona cherimolia seeds ${ }^{107}$ and $0.002 \%$ Annona muricata (soursop) pulp; ${ }^{10}$ presenting pawpaw fruit pulp as a new, easily accessible source of 
biomass for isolating substantial amounts of annonacin for use in biological studies.

The first stereoselective synthesis of annonacin involved multiple (24+) steps and yielded similar quantities of annonacin. ${ }^{90}$ A shorter synthetic route to annonacin was recently reported; ${ }^{108}$ however, this technique still involved multiple steps $\left(1^{+}\right)$and may not be optimal for obtaining large quantities. Therefore, the isolation technique reported here proved to be more efficient than original synthetic strategies for procuring annonacin in quantities suitable for small scale biological studies. Nevertheless, while natural product isolation is useful for small scale studies, development of a novel synthetic strategy with minimal steps is necessary to routinely procure quantities large enough to maintain multiple, ongoing biological studies.

The high concentration of annonacin in pawpaw pulp reported here is significant considering the neurotoxicity reported by Champy and colleagues in annonacin treated rats, ${ }^{5}$ which suggest that regular consumption of the annonaceous fruit, soursop, could lead to neurodegeneration. Specifically, Dr. Champy's results indicate that the amount of annonacin present in one soursop fruit is high enough such that regular consumption (i.e. one fruit per day per year) could lead to neurodegeneration. ${ }^{10}$ This is consistent with epidemiological reports of increased overall lifetime consumption of annonaceous products in atypical parkinsonian cases $(2 \mathrm{~g} / \mathrm{kg})$ compared to controls $(0.5 \mathrm{~g} / \mathrm{kg}) .^{40}$ Therefore, one would need to consume on average approximately 1 soursop fruit per day for 25.6 years to reach the aforementioned overall level of consumption. This same 
level of annonacin intake could be reached in 27.3 years by consuming an average of approximately 10 pawpaw fruits per day for 90 days per year (according to annual availability of ripe fruit). Though this is substantially more fruit to consume in one day, it is plausible considering the relatively small size of each pawpaw compared to soursop (100 versus $750 \mathrm{~g}$ of pulp, respectively). Fresh pawpaw is less likely to be consumed year-round, hence the difference in the number of days consumed per year between the 2 fruits. However, due to the increasing popularity of pawpaw, fruit products (e.g. frozen fruit pulp) are available for online purchase year-round, allowing for more regular consumption and in turn requiring fewer fruits per day and/or a shorter time period to reach the same amount of overall life-time consumption. Therefore, it is feasible for one to ingest high enough levels of annonacin by regularly consuming pawpaw fruit.

Due to its lipophilic nature, ${ }^{63}$ it is reasonable to assume that annonacin can cross biological membranes and interact with intracellular components. Champy and colleagues demonstrated that annonacin can cross the blood brain barrier after intravenous administration. ${ }^{5}$ Though this supports the hypothesis that annonacin could reach the brain after fruit consumption, it should be noted that the potentially toxic exposure levels discussed above are assumptions based on animal studies. Some studies have shown that intraperitoneal injection of acetogenins or oral consumption of crude pawpaw extract inhibits tumor growth and delay tumor genesis. ${ }^{42,109-111}$ Though these studies did not evaluate post-mortem tissue for the presence of acetogenins, the anticipated outcome of cancer cell death suggests the ability of these compounds to reach cellular 
targets. Contrarily, rats orally consuming pawpaw extract showed no trace of acetogenins in their blood via LC-MS/MS analysis even though the treated rats showed a delay in tumor growth compared to untreated controls. ${ }^{11}$ Considering these limited and conflicting reports, there is a need for detailed pharmacological studies to accurately determine the bioavailability of annonacin and other acetogenins after oral ingestion in order to truly evaluate the risk of fruit or extract consumption.

In vitro toxicity of annonacin and Asimina triloba organic fruit extract

Acute annonacin treatment was toxic to cortical neurons $(\mathrm{P} 0)$ at low micromolar concentrations while treatment with the ACG-free extract did not affect neuronal viability, indicating that the neurotoxicity of annonacin was not an artifact of the extraction process. Furthermore, annonacin was more toxic in the presence of CEX than when purified in terms of the amount of annonacin present in each treatment, suggesting that multiple acetogenins synergistically affect neuronal viability. The presence of bis-tetrahydrofuranyl acetogenins such as bullatacin was likely contributing to the neurotoxicity of $\mathrm{CEX}{ }^{1,63}$ On the other hand, cEX as a whole was not more potent than purified annonacin, exemplifying the complexity of interactions between numerous similar compounds and their cellular target(s). It is possible that the toxicity of cEX was primarily due to another acetogenin, such as bullatacin, which itself could be more toxic than annonacin. This would explain the difference in $L D_{50}$ values between purified 
annonacin and annonacin in the presence of CEX. Nonetheless, a synergistic effect of multiple acetogenins, including annonacin, cannot be ruled out since all acetogenins may share the same binding site. ${ }^{109}$ The difference in solvents used as the vehicle between $\mathrm{CEX}$ and annonacin treatments could explain why $\mathrm{CEX}$ was not wholly more toxic than annonacin alone since the cultures were more tolerable of EtOAc than DSMO. However, it is unlikely that there was a protective effect of EtOAc since it did not prevent rotenone toxicity.

Annonacin was less potent in cortical neurons than previously reported in mesencephalic and striatal neurons. ${ }^{37,63}$ Cortical neurons were utilized for toxicity experiments not only because they are generally less sensitive to insult than mesencephalic cultures, ${ }^{112}$ but primarily because they are affected in various neurodegenerative diseases. ${ }^{45,46,69}$ Annonacin, among other acetogenins, has been shown to inhibit mitochondrial complex-1,3, 34, 37, 63, 109, 113 which is vital for the production of ATP and a key target of oxidative stress due to the generation of reactive oxygen species (ROS). Furthermore, mitochondria act as calcium stores that help regulate the levels of intracellular calcium, which must be tightly controlled in order to maintain normal neuronal functioning. While increased oxidative stress may be detrimental to all neuronal types, substantia nigra neurons may be particularly vulnerable due to physiological properties distinct to their dopaminergic phenotype. For example, the catabolism of dopamine by monoamine oxidase results in the generation of ROS, adding to the oxidative burden of these cells. ${ }^{114}$ Moreover, the intrinsic pace-making activity of midbrain neurons may render them more susceptible to calcium excitotoxicity 
and increase the energy demand in order to maintain intracellular calcium homeostasis. ${ }^{115}$ Midbrain neurons are also much larger than cortical neurons with many more afferent synapses and corresponding energy requirements. ${ }^{116}$ These increases in the need for ATP production result in the generation of even more ROS making the DA cell even more vulnerable to oxidative stress and ATP depletion. Additionally, annonacin has recently been shown to cause an increase in intracellular calcium, ${ }^{117}$ which may be more detrimental to calciumsensitive dopaminergic cells than to cortical neurons. Together these factors may contribute to the increased vulnerability of dopaminergic neurons to mitochondrial toxins and explain the differences between the annonacin potency reported here and in previous studies. ${ }^{115,118}$

The important experimental difference of cell origins may also explain why, contrary to previous reports of annonacin sharing similar potency with rotenone ${ }^{56,63}$ rotenone was found to be more potent than annonacin in this model. Alternatively, one can speculate that the greater toxicity of rotenone may be due to its potential interactions with cellular targets other than mitochondrial complex-1, such as c-JUN N-terminal protein kinase (JNK), p38 mitogen activated protein kinases, phosphatase $2 \mathrm{~B}$ (calcineurin), and GSK3 $\beta$, among others. ${ }^{82,89,92,96,112}$ For example, Choi and colleagues have shown that the neurotoxicity of rotenone is not dependent upon its ability to inhibit complex-1. ${ }^{82}$ Additionally, it has been proposed that rotenone may bind at a different site of complex-1 than annonaceous acetogenins, which could account for differences in potencies. ${ }^{2,80}$ The combination of the increased sensitivity of midbrain 
neurons to oxidative stress and the ability of rotenone to act via other mechanisms could explain the descrepancies between annonacin potency here and prior reports as well as between annonacin and rotenone in this model. ${ }^{82,118-}$ 121

It was previously determined that, following the cell culture protocol described above in Chapter II, $80 \%$ or more of cells in the culture are neurons (unpublished data). Additionally, Ara-C was added to the cultures in order to inhibit the proliferation of non-neuronal cells; therefore, the reported toxicity was likely due to the loss of neuronal cells in the culture. Indeed, immunocytochemistry showed reduced MAP2 immunoreactivity in annonacintreated cultures after 48 hours, indicating toxicity to neuronal cells as MAP2 is a neuron-specific marker. To date, As. triloba toxicity has only been evidenced in cancer cell lines, and roughly addressed in cancerous murine models. ${ }^{8}$ This finding of in vitro cortical neurotoxicity corroborates previous reports of annonacin neurotoxicity to nigral neurons ${ }^{5,37,55,56}$ broadening the significance of annonacin-induced toxicity as it relates to neurodegeneration. The neurotoxicity results are particularly interesting considering the cortical neurodegeneration seen in a number of diseases including AD, FTD and corticobasal degeneration. $46,48,52,69$ 
In vitro effects of annonacin on microtubule associated protein tau

The microtubule associated protein tau plays a number of important roles involved in maintaining proper neuronal morphology and function. ${ }^{122}$ Tau is particularly important for regulating microtubule (MT) dynamics, which is crucial for neuronal viability. The ability of tau to interact with microtubules is affected by its phosphorylation status, with hyperphosphorylation resulting in a decreased affinity for MTs. ${ }^{123-126}$ Likewise, tau may be involved in MT stability and dynamic instability with its specific action depending on the isoform, therefore the ratio of $3 R$ to $4 R$ tau is also vital for neuronal functioning. ${ }^{127,128}$

Annonacin treatment of cortical neurons resulted in decreased levels of total tau (DA9). The annonacin induced decrease in tau protein expression is interesting as it was previously shown to cause an increase in both phospho- and total tau; however, this was attributed to a decrease in tau degradation rather than increased expression since tau messenger ribonucleic acid (mRNA) was decreased after annonacin treatment. ${ }^{37}$ The finding of decreased tau expression in conjunction with annonacin neurotoxicity is also interesting considering the ongoing debate regarding the role of tau in neurodegenerative pathogenesis. While the association of tau aggregation with neurotoxicity has been demonstrated, ${ }^{127,}{ }^{129-131}$ others propose that the formation of tau aggregates is the cells attempt to protect itself from toxic, soluble tau species. ${ }^{132,133}$ Likewise, though hyperphosphorylation of tau is undoubtedly an important factor contributing to neuronal dysfunction in tauopathy, the mechanism by which this is explained remains a topic of debate. Some suggest tau hyperphosphorylation 
may result in a loss of normal functioning due to an inability to properly bind and regulate microtubules. ${ }^{134-136}$ The observation that paclitaxel, a microtubule stabilizing agent, prevented tau-mediated toxicity supports this hypothesis. ${ }^{137}$ Contrarily, others show not only is there a lack of evident neurodegeneration or neuronal impairment in tau knockout studies, but suggest that reducing tau may be neuroprotective ${ }^{122,138}$ (and references therein). On the other hand, some studies suggest that tau abnormalities, and hence microtubule dysfunction, may disrupt mitochondria leading to oxidative stress and cell death. ${ }^{83,129,133}$ As this project was intended to evaluate the effect of annonacin on tau phosphorylation, the precise mechanistic and temporal relationships between tau reduction and cell death cannot be concluded. However, this finding supports the tau "loss of function" hypothesis, and the early time-point ( 4 hours) suggests the loss of tau occurs early in the process of annonacin neurotoxicity.

Though it is plausible that the neurotoxic effects of annonacin demonstrated here may be a result of direct action on tau and/ or microtubules, this explanation is unlikely as it was previously shown that annonacin toxicity persisted in the presence of taxol, which stabilized microtubules and prevented the somatic redistribution of tau. ${ }^{37}$ This suggests that annonacin is not directly impairing microtubules or causing a toxic loss of function in tau. Alternatively, the noticeable changes in tau could be a downstream effect of annonacin induced complex-1 inhibition, as previously reported..$^{5,37,56,63}$ In support of this mechanism of action is the observation that mitochondrial inhibition and oxidative stress effects tau phosphorylation and reports of impaired mitochondrial 
dynamics leading to neurodegeneration ${ }^{137,139,140}$ (and references therein). Fluorescent-labeled synthetic acetogenins have been shown to localize in mitochondria, ${ }^{141}$ further supporting a direct effect on complex-1 with changes in tau being secondary. Certainly, tau is an important protein for proper neuronal functioning and its dysregulation could be detrimental to the cell; however, the results presented here cannot determine whether the decrease in tau is a cause or consequence of impaired neuronal functioning.

At the outset of this project, it was hypothesized that annonacin would result in increased tau phosphorylation; therefore, its effect on GSK3 $\beta$ was considered due its ability to phosphorylate tau at a number of biologically relevant sites and implication in tau pathology. ${ }^{87-89}$ As expected based on its effects on tau, annonacin did not induce a significant change in total or phosphoGSK3 $\beta$ expression. Though not in support of the initial hypothesis, this finding does support the hypothesis that any annonacin-induced changes in tau are likely secondary to complex-1 inhibition. 


\section{CHAPTER V}

\section{STRENGTHS AND LIMITATIONS}

Though variability in fruit ripeness was not considered, this project capitalized on the availability of As. triloba fruit pulp as it is typically consumed (i.e. ripe fruit or commercially supplied frozen fruit pulp), and utilized efficient extraction and isolation methods along with multiple analytical techniques to determine the presence and quantification of annonacin. While this method of procuring annonacin was efficient for the purposes of this study, the development of a novel, large-scale synthesis should be employed for obtaining quantities suitable for maintaining multiple, ongoing biological testing. In addition to the potential difficulties in acquiring large amounts of biomass for acetogenin extraction and annonacin isolation, another limitation to procurement via natural product isolation is the variability of quality and quantity of the final product. A new synthetic strategy would provide for a more standardized process for obtaining consistent amounts of pure material.

This study revealed the presence of annonacin in As. triloba fruit pulp and substantiated the neurotoxicity of annonacin as well as the crude, acetogenincontaining extract in a different model system than previous studies. The crude, acetogenin-containing extract more closely represents the composition of actual 
consumed fruit and plant products. Hence, the finding of cEX neurotoxicity suggests a synergistic effect among acetogenins and provides insight into the neurotoxic potential of the fruit, which is important when considering potential deleterious effects of using As. triloba products chronically for the treatment of cancer.

The in vitro, acute treatment design of this project precludes any conclusions regarding chronic, in vivo toxicity; however, the use of primary neuronal cultures provides a reliable system for elucidating potential mechanisms of action occurring at the cellular level that should be investigated further. Additionally, the use of cortical neurons expands upon the current annonacin literature, which, with regard to neurotoxicity, has previously been confined to mesencephalic and striatal cultures. Likewise, although nothing can be concluded regarding bioavailability of orally consumed fruit from this study, it was previously demonstrated that annonacin crosses the blood brain barrier, ${ }^{5,6}$ therefore the neurotoxic effects of annonacin noted here could be exerted in vivo as well. As this project was designed to confirm previous findings of annonacin induced tau pathology; various other potential mechanisms of action and the mode of tau pathology were not considered. Considering the discrepancies found here with previous reports of annoancin's effect on tau, re-examination of its other noted effects (i.e. complex-1 inhibition) may be warranted to confirm prior assumptions of its mechanism of action. Additionally, while this is the first report of an annonacin-tetraacetate derivative, this project did not explore the effects of annonacin acetylation or other structural modifications on its 
neurotoxicity, which may provide valuable insight into its specific binding sites on cellular targets. 


\section{CHAPTER VI}

\section{CONCLUSIONS AND FUTURE CONSIDERATIONS}

In summary, these results established the presence of annonacin in As. triloba fruit pulp, determined the cortical neurotoxicity of annonacin as well as crude acetogenin-containing fruit extract, and revealed an early decrease in the microtubule associated protein tau in response to annonacin treatment. These findings corroborate previous reports of annonacin neurotoxicity ${ }^{5,37,55,56}$ and broaden the potential relevance of annonacin to neurodegenerative diseases with cortical pathology.

Consumption of Pawpaw in the United States could eventually be more widespread than that of other annonaceous fruits considering As. triloba is the only edible annonaceous fruit that is not confined to tropical areas, grows throughout the Eastern United States, is available to consumers all year round (e.g. frozen pulp, jam, etc.), is being pushed as an alternative cash-crop to tobacco in some states, and is touted for its potential use in alternative medicine with Paw-Paw Cell-Reg ${ }^{\top M}$ (an annonacin-containing commercial supplement made from pawpaw twig extracts), being marketed as beneficial for overall health (www.naturessunshine.com) and as a safe complement to cancer 
therapy. ${ }^{8,11,26,142}$ Therefore, future studies must corroborate the finding of $A s$. triloba fruit extract neurotoxicity discussed herein and elaborate on this and other reports of annonacin induced tau pathology.

The two primary directions for the future of As. triloba implicated by the findings presented here are 1) in vivo testing of chronic, oral fruit consumption to determine the bioavailability and more closely mimic human exposure in order to better understand the risks associated with consumption of annonaceous fruits, and 2) further elucidating mechanisms of annonacin action and effects on tau in order for it to be developed as a potentially novel model neurotoxin specific to tauopathy.

Although not directly translatable to human consumption, when considered with previous findings, the results reported here warrant further investigation regarding the toxic potential of pawpaw fruit and tree products. There are a few reports that acetogenin-containing pawpaw extract is safe and tolerable after of oral ingestion as determined by changes in weight of mice and beagle dogs; however these studies did not determine the presence of acetogenins in specific tissues after consumption. ${ }^{8,42}$ Champy and colleagues have demonstrated the presence of annonacin in the cortices of rats after chronic intravenous infusion. ${ }^{5}$ Similar studies should be done after chronic oral ingestion to determine if this translates risk to fruit consumption. Likewise, it would be insightful for one or multiple studies employing the same methodologies of administration and histological examination to consider both the therapeutic (i.e. tumor growth inhibition or delay) and neurotoxic effects (i.e. midbrain, striatal and 
cortical cell loss and tau pathology) of long-term in vivo exposure to acetogenins in order to truly model the risks/ benefits of these compounds. Pawpaw consumption should also be included in epidemiological studies investigating risk factors for neurodegeneration, and its use in alternative medicine further scrutinized in order to resolve conflicting epidemiological reports. ${ }^{40,143}$

The moderate lipophilicity of annonacin and other acetogenins likely contributes to its ability to cross biological membranes, but may prevent it from accessing intracellular targets that are not localized near the cell membrane. While studies have suggested how the different acetogenin components (i.e tetrahydrofuran ring placement, number of hydroxyl groups, hydrocarbon chain length, terminal lactone moiety) effect bioactivity, the majority of these have focused on their effects on specificity and potencies in various cancer cell lines. ${ }^{1,}$ 109, 144-147 It would be interesting to note the effects of structural modifications on acetogenin neurotoxicity. Utilizing fluorescently labeled annonaceous acetogenins as probes, such as Kojima and colleagues have recently synthesized, in combination with time-lapse imaging studies will be valuable in further understanding the direct mechanism(s) of action of these compounds. ${ }^{141}$

Recent studies have suggested that acetogenins may act as calcium chelators, causing increased intracellular calcium and initiating cell death mechanisms. $^{32,117}$ Maintaining calcium homeostasis is vital for neuronal signaling, and its dysregulation may be directly involved in neurodegenerative mechanisms. ${ }^{148-151}$ Considering this and its implications in the vulnerability of substantia nigra neurons as noted in Chapter IV, future studies should elaborate 
on the potential for acetogenins to interact with calcium or calcium modulators as a primary mechanism of action leading to impaired mitochondrial dynamics and tau pathology. ${ }^{117,144,150}$ Similarly, in vivo neurophysiological recordings during annonacin treatment could corroborate changes in neuronal calcium flux and provide a better understanding of how annonacin is immediately influencing neuronal activity. ${ }^{119}$ Ultimately, a better understanding of acetogenin mechanisms and specificity could lead to development of a novel class of neurotoxins for use in modeling specific diseases such as PSP and related tauopathies or acetogenin derivatives that may be safe and useful in the treatment of certain cancers. 


\section{REFERENCES}

1. Bermejo A, Figadere B, Zafra-Polo MC, Barrachina I, Estornell E, Cortes D. Acetogenins from Annonaceae: recent progress in isolation, synthesis and mechanisms of action. Nat Prod Rep 2005;22:269-303.

2. Degli Esposti M, Ghelli A, Ratta M, Cortes D, Estornell E. Natural substances (acetogenins) from the family Annonaceae are powerful inhibitors of mitochondrial NADH dehydrogenase (Complex I). Biochem $\mathrm{J}$ 1994;301 ( Pt 1):161-167.

3. Gonzalez-Coloma A, Guadano A, de Ines C, Martinez-Diaz R, Cortes D. Selective action of acetogenin mitochondrial complex $\mathrm{I}$ inhibitors. Z Naturforsch C 2002;57:1028-1034.

4. $\mathrm{Xu} Z \mathrm{Z}$, Wei $\mathrm{XY}$, Xie HH, Yang RZ. Inhibitory activities of three annonaceous acetogenins on $\mathrm{NADH}$ oxidase of chicken liver mitochondria. Biol Pharm Bull 2003;26:729-732.

5. Champy P, Hoglinger GU, Feger J, et al. Annonacin, a lipophilic inhibitor of mitochondrial complex $\mathrm{I}$, induces nigral and striatal neurodegeneration in rats: possible relevance for atypical parkinsonism in Guadeloupe. $J$ Neurochem 2004;88:63-69.

6. Lannuzel A, Hoglinger GU, Champy P, Michel PP, Hirsch EC, Ruberg M. Is atypical parkinsonism in the Caribbean caused by the consumption of Annonaceae? J Neural Transm Suppl 2006:153-157.

7. Liaw CC, Wu TY, Chang FR, Wu YC. Historic perspectives on Annonaceous acetogenins from the chemical bench to preclinical trials. Planta Med 2010;76:1390-1404.

8. McLaughlin JL. Paw paw and cancer: annonaceous acetogenins from discovery to commercial products. J Nat Prod 2008;71:1311-1321. 
9. Champy P, Guerineau V, Laprevote O. MALDI-TOF MS profiling of annonaceous acetogenins in Annona muricata products for human consumption. Molecules 2009;14:5235-5246.

10. Champy P, Melot A, Guerineau Eng V, et al. Quantification of acetogenins in Annona muricata linked to atypical parkinsonism in guadeloupe. Mov Disord 2005;20:1629-1633.

11. Cuendet M, Moon RC, Keller WJ, Peaden PA, Pezzuto JM. Dietary Administration of Asimina triloba (Paw Paw) Extract Increases Tumor Latency in N-Methyl-N-nitrosourea-Treated Rats. Pharmaceutical Biology 2008;46:3-7.

12. Ratnayake S, Rupprecht JK, Potter WM, McLaughlin JL. Evaluation of various parts of the paw paw tree, Asimina triloba (Annonaceae), as commercial sources of the pesticidal annonaceous acetogenins. J Econ Entomol 1992;85:2353-2356.

13. Cortes DR, Rios JL, Villar A, Valverde S. Cherimolin and dihydrocherimolin: two new bis-tetrahydrofuranic $y$-lactones possessing antimicrobial activity. Tetrahedron Letters 1984;25:3199-3202.

14. Chang FR, Wu YC. Novel cytotoxic annonaceous acetogenins from Annona muricata. J Nat Prod 2001;64:925-931.

15. Layne DR. The pawpaw [Asimina triloba (1.) dunal]: a new fruit crop for Kentucky and the United States. Horticulture Science 1996;31:777-784.

16. Pomper KWL, D.R. The North American pawpaw: botany and horticulture. Horticulture Review 2005;31:351-384.

17. Pomper KW, Lowe JD, Crabtree SB, Keller W. Identification of annonaceous acetogenins in the ripe fruit of the North American pawpaw (Asimina triloba). J Agric Food Chem 2009;57:8339-8343.

18. Zhao G, Hui Y, Rupprecht JK, McLaughlin JL, Wood KV. Additional bioactive compounds and trilobacin, a novel highly cytotoxic acetogenin, from the bark of Asimina triloba. J Nat Prod 1992;55:347-356. 
19. Alves RdSLLP, Pinheiro SPL, Amelia DBM. Two new adjacent bistetrahydrofuran annonaceous acetogenins from seeds of Annona cornifolia. Planta Medica 2009;75:80-83.

20. Rupprecht JKC, Chang CJ, Cassady JM, McLaughlin JL, Mikolajczak KL, Weisleder D. Asimicin, a new cytotoxic and pesticidal acetogenin from the pawpaw, Asimina triloba (Annonaceae). Heterocycles 1986;24:1197-1201.

21. Hui YH, Rupprecty JK, Liu YM, Anderson JE, Smith DL, Chang CJ, McLaughlin JL. Bullatacin and bullatacinone: two highly potent bioactive acetogenins from Annona bullata. J Nat Prod 1989;52:463-477.

22. Pettit GR, Riesen R, Leet JE, Polonsky J, Smith CR, Schmidt JM, Dufresne C, Schaufelberger D, Moretti C. Isolation and structure of rooliniastatin 2: a new cell growth inhibitory acetogenin from Rollinia mucosa. Heterocycles 1989;28:213-217.

23. Cortes DM, S.H.; Dupont, B.; Daoust, D. Acetogenins of the Annonaceae. Part 20. Bioactive acetogenins from seeds of Annona cherimolia. Phytochemistry 1993;32:1475-1482.

24. Gu ZM, Fang XP, Reiser MJ, Hui YH, Miesbauer LR, Smith D, Wood KV, McLaughlin JL. New cytotoxic annonaceous acetogenins:bullatanocin and cis- trans-vullatanocinone, from Annona bullata (Annonaceae). Tetrahedron 1993;49:747-754.

25. Kim E-J, Tian F, Woo M-H. Asitrocin, (2,4)-cis-and trans-Asitrocinones: Novel Bioactive Mono-tetrahydrofuran Acetogenins from Asimina triloba Seeds. J Nat Prod 2000;63:1503-1506.

26. Coothankandaswamy $\mathrm{V}$, Liu $\mathrm{Y}, \mathrm{Mao} \mathrm{SC}$, et al. The alternative medicine pawpaw and its acetogenin constituents suppress tumor angiogenesis via the HIF-1NEGF pathway. J Nat Prod 2010;73:956-961.

27. Woo MH, Chung SO, Kim DH. cis-Annonacin and (2,4)-cis-and transisoannonacins: cytotoxic monotetrahydrofuran annonaceous acetogenins from the seeds of Annona cherimolia. Arch Pharm Res 1999;22:524-528. 
28. Zhao GX, Rieser MJ, Hui YH, Miesbauer LR, Smith DL, McLaughlin JL. Biologically active acetogenins from stem bark of Asimina triloba. Phytochemistry 1993;33:1065-1073.

29. McCloud TG, Smith DL, Chang CJ, Cassady JM. Annonacin, a novel biologically active polyketide from Annona densicoma. Experientia 1987;43:947-949.

30. Fang XP, Rupprecht JK, Alkofahi A, Hui YH, Liu YM, Smith D, Wood KV, McLaughlin JL. Gigantetrocin and gigantriocin: two novel bioactive annonaceous acetogenins from Goniothalamus giganteus. Heterocycles 1991;32:11-17.

31. Woo $\mathrm{M}-\mathrm{H}$, Chung S-O, Kim D-H. Asitrilobins $\mathrm{C}$ and $\mathrm{D}$ : two new cytotoxic mono-tetrahudrofuran annonaceous acetogenins from Asimina triloba seeds. Bioorganic and Medicinal Chemistry 2000;8:285-290.

32. Liaw $\mathrm{CC}$, Yang $\mathrm{YL}$, Chen $\mathrm{M}$, et al. Mono-tetrahydrofuran annonaceous acetogenins from Annona squamosa as cytotoxic agents and calcium ion chelators. J Nat Prod 2008;71:764-771.

33. Laprevote O, Girard C, Das BC, Ciortes D, Andrem C. Acetigenins from Annonaceae. 16. Formation of gas-phase lithium complexes from acetogenins and their analysis by fast atom bombardment mass spectometry. Tetrahedron Letters 1992;33:5237-5240.

34. Zafra-Polo MC, Figadere B, Gallardo T, Tormo JR, Cortes D. Natural acetogenins from Annonaceae, synthesis and mechanisms of action. Phytochemistry 1998;48:1087-1117.

35. He K, Shi G, Zhao GX, et al. Three new adjacent bis-tetrahydrofuran acetogenins with four hydroxyl groups from Asimina triloba. J Nat Prod 1996;59:1029-1034.

36. Woo MH, Kim DH, McLaughlin JL. Asitrilobins A and B: cytotoxic monoTHF annonaceous acetogenins from the seeds of Asimina triloba. Phytochemistry 1999;50:1033-1040. 
37. Escobar-Khondiker M, Hollerhage M, Muriel MP, et al. Annonacin, a natural mitochondrial complex I inhibitor, causes tau pathology in cultured neurons. J Neurosci 2007;27:7827-7837.

38. Caparros-Lefebvre D, Elbaz A. Possible relation of atypical parkinsonism in the French West Indies with consumption of tropical plants: a casecontrol study. Caribbean Parkinsonism Study Group. Lancet 1999;354:281-286.

39. Caparros-Lefebvre D, Sergeant N, Lees A, et al. Guadeloupean parkinsonism: a cluster of progressive supranuclear palsy-like tauopathy. Brain 2002;125:801-811.

40. Lannuzel A, Hoglinger GU, Verhaeghe S, et al. Atypical parkinsonism in Guadeloupe: a common risk factor for two closely related phenotypes? Brain 2007;130:816-827.

41. Hoglinger GU, Michel PP, Champy P, et al. Experimental evidence for a toxic etiology of tropical parkinsonism. Mov Disord 2005;20:118-119.

42. Ahammadsahib KI, Hollingworth RM, McGovren JP, Hui YH, McLaughlin JL. Mode of action of bullatacin: a potent antitumor and pesticidal annonaceous acetogenin. Life Sci 1993;53:1113-1120.

43. Avalos J, Rupprecht JK, McLaughlin JL, Rodriguez E. Guinea pig maximization test of the bark extract from pawpaw, Asimina triloba (Annonaceae). Contact Dermatitis 1993;29:33-35.

44. D'Ver AS. Ascending Oral Dosing of Paw Paw Extract in Male Beagle Dogs. Doylestown, PA: White Eagle Toxicology Laboratories, 2001 September 25, 2001.

45. Robert M, Mathuranath PS. Tau and tauopathies. Neurol India 2007;55:11-16.

46. Gilman S, ed. Neurobiology of Disease. Burlington, MA: Elsevier, 2007.

47. Delacourte A, Buee L. Tau pathology: a marker of neurodegenerative disorders. Curr Opin Neurol 2000;13:371-376.

48. Bouchard M, Suchowersky O. Tauopathies: one disease or many? Can J Neurol Sci 2011;38:547-556. 
49. Magherini A, Litvan I. Cognitive and behavioral aspects of PSP since Steele, Richardson and Olszewski's description of PSP 40 years ago and Albert's delineation of the subcortical dementia 30 years ago. Neurocase 2005;11:250-262.

50. Santacruz P, Uttl B, Litvan I, Grafman J. Progressive supranuclear palsy: a survey of the disease course. Neurology 1998;50:1637-1647.

51. Litvan I. Update on progressive supranuclear palsy. Curr Neurol Neurosci Rep 2004;4:296-302.

52. Dickson DW, Rademakers R, Hutton ML. Progressive supranuclear palsy: pathology and genetics. Brain Pathol 2007;17:74-82.

53. Ludolph AC, Kassubek J, Landwehrmeyer BG, et al. Tauopathies with parkinsonism: clinical spectrum, neuropathologic basis, biological markers, and treatment options. Eur J Neurol 2009;16:297-309.

54. Koshimura I, Imai H, Hidano T, et al. Dimethoxyphenylethylamine and tetrahydropapaverine are toxic to the nigrostriatal system. Brain Res 1997;773:108-116.

55. Lannuzel A, Michel PP, Caparros-Lefebvre D, Abaul J, Hocquemiller R, Ruberg M. Toxicity of Annonaceae for dopaminergic neurons: potential role in atypical parkinsonism in Guadeloupe. Mov Disord 2002;17:84-90.

56. Lannuzel A, Michel PP, Hoglinger GU, et al. The mitochondrial complex I inhibitor annonacin is toxic to mesencephalic dopaminergic neurons by impairment of energy metabolism. Neuroscience 2003;121:287-296.

57. Betarbet R, Canet-Aviles RM, Sherer TB, et al. Intersecting pathways to neurodegeneration in Parkinson's disease: effects of the pesticide rotenone on DJ-1, alpha-synuclein, and the ubiquitin-proteasome system. Neurobiol Dis 2006;22:404-420.

58. Rojo Al, Montero C, Salazar M, et al. Persistent penetration of MPTP through the nasal route induces Parkinson's disease in mice. Eur $\mathrm{J}$ Neurosci 2006;24:1874-1884. 
59. Langston JW, Ballard P, Tetrud JW, Irwin I. Chronic Parkinsonism in humans due to a product of meperidine-analog synthesis. Science 1983;219:979-980.

60. Costa C, Belcastro V, Tozzi A, et al. Electrophysiology and pharmacology of striatal neuronal dysfunction induced by mitochondrial complex 1 inhibition. J Neurosci 2008;28:8040-8052.

61. Storch A, Ludolph AC, Schwarz J. Dopamine transporter: involvement in selective dopaminergic neurotoxicity and degeneration. J Neural Transm 2004;111:1267-1286.

62. Hoglinger GU, Feger J, Prigent A, et al. Chronic systemic complex I inhibition induces a hypokinetic multisystem degeneration in rats. $J$ Neurochem 2003;84:491-502.

63. Hollerhage $M$, Matusch $A$, Champy $P$, et al. Natural lipophilic inhibitors of mitochondrial complex $\mathrm{I}$ are candidate toxins for sporadic neurodegenerative tau pathologies. Exp Neurol 2009;220:133-142.

64. Delacourte A, Buee L. Normal and pathological Tau proteins as factors for microtubule assembly. Int Rev Cytol 1997;171:167-224.

65. Fuster-Matanzo A, de Barreda EG, Dawson HN, Vitek MP, Avila J, Hernandez F. Function of tau protein in adult newborn neurons. FEBS Lett 2009;583:3063-3068.

66. Panda D, Samuel JC, Massie M, Feinstein SC, Wilson L. Differential regulation of microtubule dynamics by three- and four-repeat tau: implications for the onset of neurodegenerative disease. Proc Natl Acad Sci U S A 2003;100:9548-9553.

67. Baker M, Litvan I, Houlden $\mathrm{H}$, et al. Association of an extended haplotype in the tau gene with progressive supranuclear palsy. Hum Mol Genet 1999;8:711-715.

68. Wang JZ, Liu F. Microtubule-associated protein tau in development, degeneration and protection of neurons. Prog Neurobiol 2008;85:148-175.

69. Iqbal K, Liu F, Gong CX, Grundke-lqbal I. Tau in Alzheimer disease and related tauopathies. Curr Alzheimer Res 2009;7:656-664. 
70. Hutton M, Lendon CL, Rizzu P, et al. Association of missense and 5'splice-site mutations in tau with the inherited dementia FTDP-17. Nature 1998;393:702-705.

71. Hoglinger GU, Melhem NM, Dickson DW, et al. Identification of common variants influencing risk of the tauopathy progressive supranuclear palsy. Nat Genet 2011;43:699-705.

72. Albers DS, Beal MF. Mitochondrial dysfunction in progressive supranuclear palsy. Neurochem Int 2002;40:559-564.

73. Di Filippo M, Chiasserini D, Tozzi A, Picconi B, Calabresi P. Mitochondria and the link between neuroinflammation and neurodegeneration. $J$ Alzheimers Dis 2010;20 Suppl 2:S369-379.

74. Park LC, Albers DS, Xu H, Lindsay JG, Beal MF, Gibson GE. Mitochondrial impairment in the cerebellum of the patients with progressive supranuclear palsy. J Neurosci Res 2001;66:1028-1034.

75. Swerdlow RH, Golbe LI, Parks JK, et al. Mitochondrial dysfunction in cybrid lines expressing mitochondrial genes from patients with progressive supranuclear palsy. J Neurochem 2000;75:1681-1684.

76. Schapira AH. Complex I: Inhibitors, inhibition and neurodegeneration. Exp Neurol 2010.

77. Hoglinger GU, Lannuzel A, Khondiker ME, et al. The mitochondrial complex I inhibitor rotenone triggers a cerebral tauopathy. J Neurochem 2005;95:930-939.

78. McCormack AL, Mak SK, Shenasa M, Langston WJ, Forno LS, Di Monte DA. Pathologic modifications of alpha-synuclein in 1-methyl-4-phenyl1,2,3,6-tetrahydropyridine (MPTP)-treated squirrel monkeys. J Neuropathol Exp Neurol 2008;67:793-802.

79. Sherer TB, Kim JH, Betarbet R, Greenamyre JT. Subcutaneous rotenone exposure causes highly selective dopaminergic degeneration and alphasynuclein aggregation. Exp Neurol 2003;179:9-16.

80. Degli Esposti M. Inhibitors of NADH-ubiquinone reductase: an overview. Biochim Biophys Acta 1998;1364:222-235. 
81. Sherer TB, Richardson JR, Testa CM, et al. Mechanism of toxicity of pesticides acting at complex I: relevance to environmental etiologies of Parkinson's disease. J Neurochem 2007;100:1469-1479.

82. Choi WS, Kruse SE, Palmiter RD, Xia Z. Mitochondrial complex I inhibition is not required for dopaminergic neuron death induced by rotenone, MPP+, or paraquat. Proc Natl Acad Sci U S A 2008;105:15136-15141.

83. Cartelli D, Ronchi C, Maggioni MG, Rodighiero S, Giavini E, Cappelletti G. Microtubule dysfunction precedes transport impairment and mitochondria damage in MPP+ -induced neurodegeneration. $\mathrm{J}$ Neurochem 2010;115:247-258.

84. Ren $Y$, Liu W, Jiang $H$, Jiang $Q$, Feng J. Selective vulnerability of dopaminergic neurons to microtubule depolymerization. J Biol Chem 2005;280:34105-34112.

85. Michel $G$, Mercken $M$, Murayama $M$, et al. Characterization of tau phosphorylation in glycogen synthase kinase-3beta and cyclin dependent kinase-5 activator (p23) transfected cells. Biochim Biophys Acta 1998;1380:177-182.

86. Takashima A, Honda $\mathrm{T}$, Yasutake $\mathrm{K}$, et al. Activation of tau protein kinase I/glycogen synthase kinase-3beta by amyloid beta peptide (25-35) enhances phosphorylation of tau in hippocampal neurons. Neurosci Res 1998;31:317-323.

87. Shahani N, Brandt R. Functions and malfunctions of the tau proteins. Cell Mol Life Sci 2002;59:1668-1680.

88. Ferrer I, Barrachina M, Puig B. Glycogen synthase kinase-3 is associated with neuronal and glial hyperphosphorylated tau deposits in Alzheimer's disease, Pick's disease, progressive supranuclear palsy and corticobasal degeneration. Acta Neuropathol 2002;104:583-591.

89. Chen YY, Chen G, Fan Z, Luo J, Ke ZJ. GSK3beta and endoplasmic reticulum stress mediate rotenone-induced death of SK-N-MC neuroblastoma cells. Biochem Pharmacol 2008;76:128-138. 
90. Hu TS, Yu Q, Wu YL, Wu Y. Enantioselective syntheses of monotetrahydrofuran Annonaceous acetogenins tonkinecin and annonacin starting from carbohydrates. J Org Chem 2001;66:853-861.

91. Hetman M, Kanning K, Cavanaugh JE, Xia Z. Neuroprotection by brainderived neurotrophic factor is mediated by extracellular signal-regulated kinase and phosphatidylinositol 3-kinase. J Biol Chem 1999;274:2256922580 .

92. Belcastro V, Tozzi A, Tantucci $M$, et al. A2A adenosine receptor antagonists protect the striatum against rotenone-induced neurotoxicity. Exp Neurol 2009;217:231-234.

93. Borland MK, Trimmer PA, Rubinstein JD, et al. Chronic, low-dose rotenone reproduces Lewy neurites found in early stages of Parkinson's disease, reduces mitochondrial movement and slowly kills differentiated SH-SY5Y neural cells. Mol Neurodegener 2008;3:21.

94. Brown TP, Rumsby PC, Capleton AC, Rushton L, Levy LS. Pesticides and Parkinson's disease--is there a link? Environ Health Perspect 2006;114:156-164.

95. Drechsel DA, Patel M. Role of reactive oxygen species in the neurotoxicity of environmental agents implicated in Parkinson's disease. Free Radic Biol Med 2008;44:1873-1886.

96. Gill MB, Perez-Polo JR. Bax shuttling after rotenone treatment of neuronal primary cultures: effects on cell death phenotypes. J Neurosci Res 2009;87:2047-2065.

97. Ying R, Liang HL, Whelan HT, Eells JT, Wong-Riley MT. Pretreatment with near-infrared light via light-emitting diode provides added benefit against rotenone- and MPP+-induced neurotoxicity. Brain Res 2008;1243:167-173.

98. Mosmann T. Rapid colorimetric assay for cellular growth and survival: application to proliferation and cytotoxicity assays. J Immunol Methods 1983;65:55-63. 
99. Datki Z, Juhasz A, Galfi M, et al. Method for measuring neurotoxicity of aggregating polypeptides with the MTT assay on differentiated neuroblastoma cells. Brain Res Bull 2003;62:223-229.

100. Hansen MB, Nielsen SE, Berg K. Re-examination and further development of a precise and rapid dye method for measuring cell growth/cell kill. J Immunol Methods 1989;119:203-210.

101. Xia Z, Dickens M, Raingeaud J, Davis RJ, Greenberg ME. Opposing effects of ERK and JNK-p38 MAP kinases on apoptosis. Science 1995;270:1326-1331.

102. Still WC, Kahn M, Mitra Abhijit. Rapid chromatographic technique for preparative separations with moderate resolution. J Org Chem 1978;43:2923-2925.

103. Caloprisco EF, J-D.; Faure, R.; Demarne, F-E. Unsual lactones from Cananga odorata. Journal of Agricultural and Food Chemistry 2002;50:7880.

104. Ruest LB, C.; Dodier, M.; Dube, L.; St-Martin, D. Ryanoids and related compounds. Isolation and characterization of four minor ryanoids from the plant Ryania speciosa Vahl: 8,9-didehydroroyanodine, 10-Oacetylryanodol, 3-O-acetylryanodol, 3-O-benzoylryanodol, and a first natural 4-deoxyryanoid: 4-deoxy-8ax-hydroxy-10-0-methyl-10 epiryanodine (4-deoxyesterA). Canadian Journal of Chemistry 1999;77:12-15.

105. Zerkowski JA, Solaiman DKY. Polyhydroxy fatty acids derived from sophorolipids. Journal of the American Oil Chemists' Society 2007;84:463471.

106. Donnelly DMX, O'Reily J, Chiaroni A, Polonsky J. Crystal structure and absolute configuration of a new sesquiterpenoid metabolite of Fomes annosus, 7a,8B,11-trihydroxydrimane. Journal of the Chemical Society, Perkin Transactions 1: Organic and Bio-Organic Chemistry (1972-1999) 1980;10:2196-2199. 
107. Kim DH, Son JK, Woo MH. Annomocherin, annonacin and annomontacin: a novel and two known bioactive mono-tetrahydrofuran annonaceous acetogenins from Annona cherimolia seeds. Arch Pharm Res 2001;24:300-306.

108. Oasa $M$, Hattori $Y$, Konno $H$, Makabe $H$. Synthesis of annonacin isolated from Annona densicoma. Biosci Biotechnol Biochem 2010;74:1274-1275.

109. Alali FQ, Liu XX, McLaughlin JL. Annonaceous acetogenins: recent progress. J Nat Prod 1999;62:504-540.

110. Rupprecht JK, Hui YH, McLaughlin JL. Annonaceous acetogenins: a review. J Nat Prod 1990;53:237-278.

111. McLaughlin JL, Benson GB, Turgeon TA, Forsythe JW. Use of Standardized Mixtures of Paw Paw Extract (Asimina triloba) in Cancer Patients: Case Studies. In: Kronenberg RCaF, ed. Botanical Medicine: From Bench to Bedside: Mary Ann Liebert, 2009.

112. Klintworth H, Newhouse K, Li T, Choi WS, Faigle R, Xia Z. Activation of CJun $\mathrm{N}$-terminal protein kinase is a common mechanism underlying paraquat- and rotenone-induced dopaminergic cell apoptosis. Toxicol Sci 2007;97:149-162.

113. Lannuzel A, Ruberg M, Michel PP. Atypical parkinsonism in the Caribbean island of Guadeloupe: etiological role of the mitochondrial complex I inhibitor annonacin. Mov Disord 2008;23:2122-2128.

114. Gonzalez-Hernandez T, Cruz-Muros I, Afonso-Oramas D, SalasHernandez J, Castro-Hernandez J. Vulnerability of mesostriatal dopaminergic neurons in Parkinson's disease. Front Neuroanat 2010;4:140.

115. Chan CS, Gertler TS, Surmeier DJ. A molecular basis for the increased vulnerability of substantia nigra dopamine neurons in aging and Parkinson's disease. Mov Disord 2010;25 Suppl 1:S63-70.

116. Surmeier DJ, Guzman JN, Sanchez-Padilla J. Calcium, cellular aging, and selective neuronal vulnerability in Parkinson's disease. Cell Calcium 2010;47:175-182. 
117. Liaw CC, Liao WY, Chen CS, et al. The calcium-chelating capability of tetrahydrofuranic moieties modulates the cytotoxicity of annonaceous acetogenins. Angew Chem Int Ed Engl 2011;50:7885-7891.

118. Bonsi P, Cuomo D, Martella G, et al. Mitochondrial toxins in Basal Ganglia disorders: from animal models to therapeutic strategies. Curr Neuropharmacol 2006;4:69-75.

119. Surmeier DJ, Guzman JN, Sanchez-Padilla J, Schumacker PT. The role of calcium and mitochondrial oxidant stress in the loss of substantia nigra pars compacta dopaminergic neurons in Parkinson's disease. Neuroscience 2011.

120. Freestone PS, Chung KK, Guatteo E, Mercuri NB, Nicholson LF, Lipski J. Acute action of rotenone on nigral dopaminergic neurons--involvement of reactive oxygen species and disruption of $\mathrm{Ca} 2+$ homeostasis. Eur $\mathrm{J}$ Neurosci 2009;30:1849-1859.

121. Yadava N, Nicholls DG. Spare respiratory capacity rather than oxidative stress regulates glutamate excitotoxicity after partial respiratory inhibition of mitochondrial complex I with rotenone. The Journal of neuroscience : the official journal of the Society for Neuroscience 2007;27:7310-7317.

122. Morris M, Maeda S, Vossel K, Mucke L. The many faces of tau. Neuron 2011;70:410-426.

123. Buee L, Bussiere T, Buee-Scherrer V, Delacourte A, Hof PR. Tau protein isoforms, phosphorylation and role in neurodegenerative disorders. Brain Res Brain Res Rev 2000;33:95-130.

124. Li B, Chohan MO, Grundke-lqbal I, Iqbal K. Disruption of microtubule network by Alzheimer abnormally hyperphosphorylated tau. Acta neuropathologica 2007;113:501-511.

125. Liu F, Li B, Tung EJ, Grundke-lqbal I, lqbal K, Gong CX. Site-specific effects of tau phosphorylation on its microtubule assembly activity and self-aggregation. Eur J Neurosci 2007;26:3429-3436. 
126. Steinhilb ML, Dias-Santagata D, Fulga TA, Felch DL, Feany MB. Tau phosphorylation sites work in concert to promote neurotoxicity in vivo. Mol Biol Cell 2007;18:5060-5068.

127. Bandyopadhyay B, Li G, Yin H, Kuret J. Tau aggregation and toxicity in a cell culture model of tauopathy. J Biol Chem 2007;282:16454-16464.

128. Levy SF, Leboeuf AC, Massie MR, Jordan MA, Wilson L, Feinstein SC. Three- and four-repeat tau regulate the dynamic instability of two distinct microtubule subpopulations in qualitatively different manners. Implications for neurodegeneration. J Biol Chem 2005;280:13520-13528.

129. Quintanilla RA, Dolan PJ, Jin YN, Johnson GV. Truncated tau and Abeta cooperatively impair mitochondria in primary neurons. Neurobiol Aging 2011.

130. Rankin CA, Gamblin TC. Assessing the toxicity of tau aggregation. J Alzheimers Dis 2008;14:411-416.

131. Rankin CA, Sun Q, Gamblin TC. Pre-assembled tau filaments phosphorylated by GSK-3 $\beta$ form large tangle-like structures. Neurobiol Dis 2008;31:368-377.

132. Fox LM, William CM, Adamowicz DH, et al. Soluble tau Species, Not Neurofibrillary Aggregates, Disrupt Neural System Integration in a tau Transgenic Model. J Neuropathol Exp Neurol 2011;70:588-595.

133. Lasagna-Reeves CA, Castillo-Carranza DL, Sengupta U, Clos AL, Jackson GR, Kayed R. Tau oligomers impair memory and induce synaptic and mitochondrial dysfunction in wild-type mice. Mol Neurodegener 2011;6:39.

134. Dawson HN, Cantillana V, Jansen M, et al. Loss of tau elicits axonal degeneration in a mouse model of Alzheimer's disease. Neuroscience 2010;169:516-531.

135. Feinstein SC, Wilson L. Inability of tau to properly regulate neuronal microtubule dynamics: a loss-of-function mechanism by which tau might mediate neuronal cell death. Biochim Biophys Acta 2005;1739:268-279. 
136. Trojanowski JQ, Lee VM. Pathological tau: a loss of normal function or a gain in toxicity? Nat Neurosci 2005;8:1136-1137.

137. Zempel $H$, Thies E, Mandelkow E, Mandelkow EM. Abeta oligomers cause localized $\mathrm{Ca}(2+)$ elevation, missorting of endogenous Tau into dendrites, Tau phosphorylation, and destruction of microtubules and spines. J Neurosci 2010;30:11938-11950.

138. Roberson ED, Halabisky B, Yoo JW, et al. Amyloid-beta/Fyn-induced synaptic, network, and cognitive impairments depend on tau levels in multiple mouse models of Alzheimer's disease. J Neurosci 2011;31:700711.

139. Fukui $\mathrm{H}$, Moraes $\mathrm{CT}$. The mitochondrial impairment, oxidative stress and neurodegeneration connection: reality or just an attractive hypothesis? Trends Neurosci 2008;31:251-256.

140. Schon EA, Przedborski S. Mitochondria: the next (neurode)generation. Neuron 2011;70:1033-1053.

141. Kojima $\mathrm{N}$, Morioka $\mathrm{T}$, Urabe $\mathrm{D}$, et al. Convergent synthesis of fluorescence-labeled probes of Annonaceous acetogenins and visualization of their cell distribution. Bioorganic \& medicinal chemistry 2010;18:8630-8641.

142. Wang LQ, Li $Y$, Min BS, et al. Cytotoxic mono-tetrahydrofuran ring acetogenins from leaves of Annona montana. Planta Med 2001;67:847852.

143. Vidal JS, Vidailhet $M$, Derkinderen $P$, de Gaillarbois TD, Tzourio $C$, Alperovitch A. Risk factors for progressive supranuclear palsy: a casecontrol study in France. J Neurol Neurosurg Psychiatry 2009;80:12711274.

144. Kojima N, Tanaka T. Medicinal chemistry of Annonaceous acetogenins: design, synthesis, and biological evaluation of novel analogues. Molecules 2009;14:3621-3661.

145. Royo I, DePedro N, Estornell E, Cortes D, Pelaez F, Tormo JR. In vitro antitumor SAR of threo/cis/threo/cis/erythro bis-THF acetogenins: 
correlations with their inhibition of mitochondrial Complex I. Oncol Res 2003;13:521-528.

146. Xiao $Q$, Liu $Y$, Qiu $Y$, et al. Design, synthesis of symmetrical bivalent mimetics of annonaceous acetogenins and their cytotoxicities. Bioorganic \& medicinal chemistry letters 2011;21:3613-3615.

147. Xiao Q, Liu $Y$, Qiu $Y$, et al. Potent antitumor mimetics of annonaceous acetogenins embedded with an aromatic moiety in the left hydrocarbon chain part. J Med Chem 2011;54:525-533.

148. Supnet C, Bezprozvanny I. The dysregulation of intracellular calcium in Alzheimer disease. Cell Calcium 2010;47:183-189.

149. Supnet C, Bezprozvanny I. Neuronal calcium signaling, mitochondrial dysfunction, and Alzheimer's disease. Journal of Alzheimer's disease : JAD 2010;20 Suppl 2:S487-498.

150. Salminen A, Kaarniranta K, Haapasalo A, Soininen H, Hiltunen M. AMPactivated protein kinase: a potential player in Alzheimer's disease. Journal of neurochemistry $2011 ; 118: 460-474$.

151. Mukherjee A, Soto $C$. Role of calcineurin in neurodegeneration produced by misfolded proteins and endoplasmic reticulum stress. Curr Opin Cell Biol 2011;23:223-230. 


\section{APPENDIX A:}

\section{LIST OF ABBREVIATIONS}

\begin{tabular}{ll} 
3R & 3 repeat \\
4R & 4 repeat \\
ACG & acetogenin \\
ACS & American Chemical Society \\
AD & Alzheimer's disease \\
An. & Annona \\
AN & annonacin \\
AN-AC & annonacin tetraacetate \\
ANOVA & analysis of variance \\
APD & atypical parkinsonian disorders \\
ANPP-EX & pure annoncin isolated from As. triloba fruit. \\
As. & Asimina \\
ANsmP & annonacin sample derived from An. muricata \\
ATP & adenosine triphosphate \\
BBB & blood-brain barrier \\
BME & basal medium Eagle \\
C & cis \\
\hline
\end{tabular}




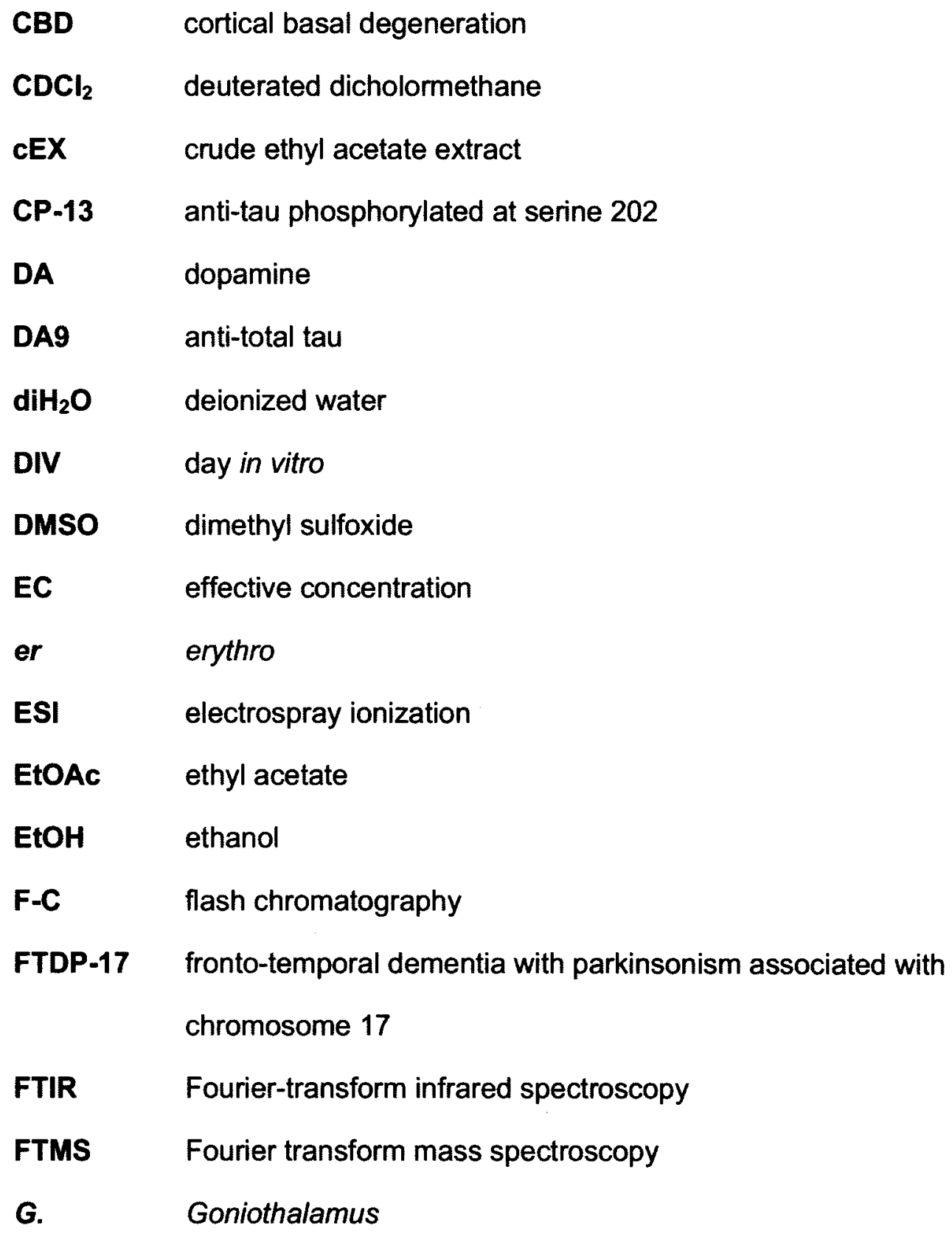

FTDP-17 fronto-temporal dementia with parkinsonism associated with chromosome 17

FTIR Fourier-transform infrared spectroscopy

FTMS Fourier transform mass spectroscopy

G. Goniothalamus

GABA $\quad$-aminobutyric acid

Gd Guadeloupian

GSK-3 $\beta$ glycogen synthase kinase

HRMS High Resolution Mass Spectral

IC inhibitory concentration 


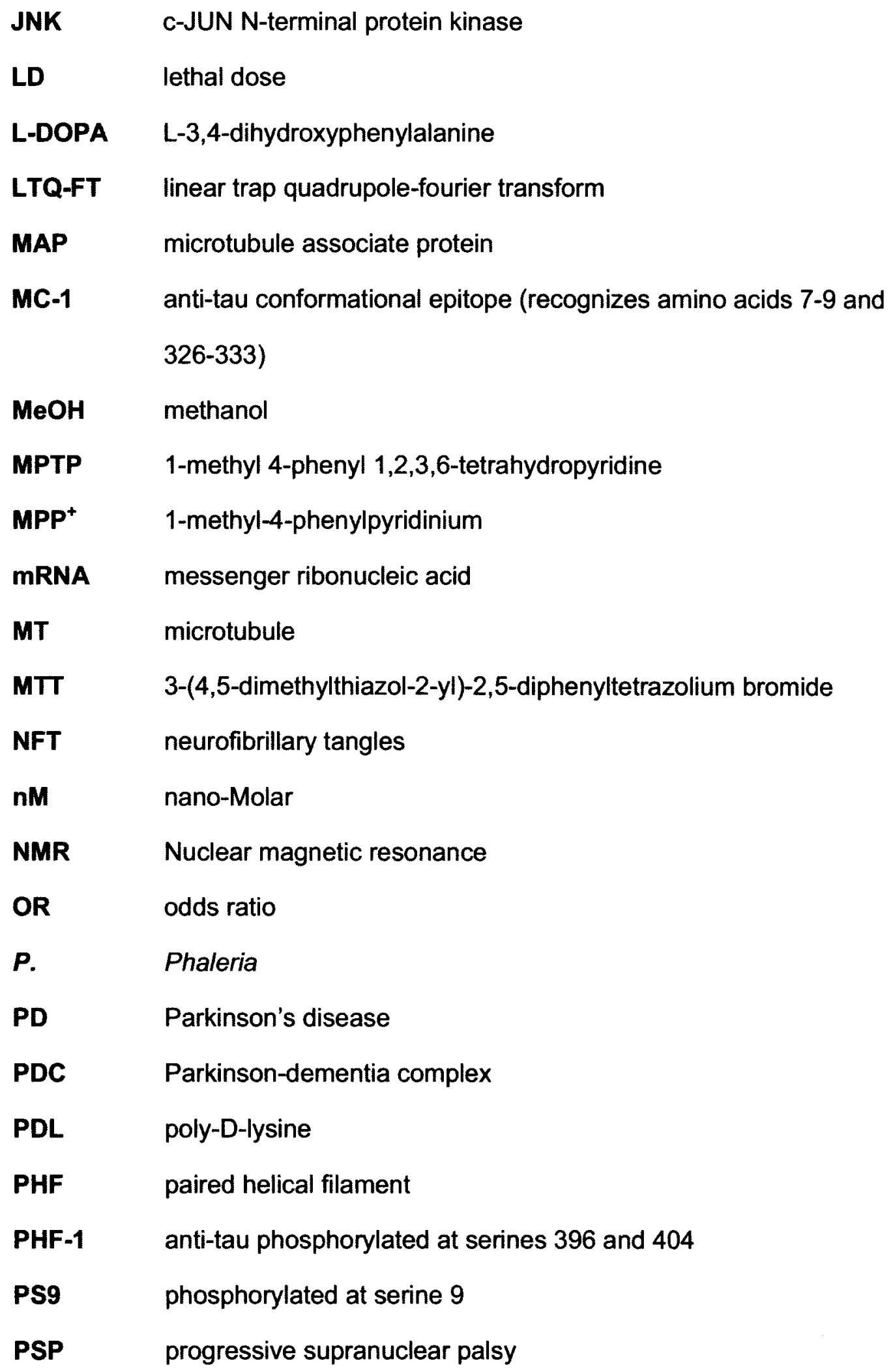




\begin{tabular}{|c|c|}
\hline $\mathbf{P Q}$ & paraquat \\
\hline $\boldsymbol{R}$. & Rollinia \\
\hline ROS & reactive oxygen species \\
\hline ROT, R & rotenone \\
\hline $\mathbf{r t}$ & room temperature \\
\hline SK-N-MC & human neuroblastoma cell line \\
\hline$t$ & trans \\
\hline th & threo \\
\hline TH & tyrosine hydroxylase \\
\hline THF & tetrahydrofuran \\
\hline $\mathrm{TIQ}$ & tetrahydroisoquinolone \\
\hline TLC & thin layer chromatography \\
\hline$\mu g$ & micro-gram \\
\hline$\mu \mathrm{m}$ & micro-meter \\
\hline$\mu \mathbf{M}$ & micro-Molar \\
\hline vC & vehicle control \\
\hline
\end{tabular}




\section{APPENDIX B:}

\section{EXTRACTION \& ISOLATION PROTOCOL}

\section{Extraction of Asimina triloba fruit pulp:}

1) Weigh total amount of fruit pulp (thawed previously) to be extracted

2) Homogenize pulp with $\mathrm{MeOH}$

a) $700-800 \mathrm{~mL}$ of $\mathrm{MeOH} / 1 \mathrm{~kg}$ of pulp

b) Record total final volume of all pulp/MeOH homogenate

3) Let homogenate steep overnight in fridge

4) Vacuum filter homogenate

a) Cut fast filter paper to fit filters, use 2 layers of filter paper/ funnel

b) Soak filter papers with $\mathrm{MeOH}$ before adding homogenate

c) Add 1/2 homogenate to each filter funnel

d) Filter until cake forms and wash with $50 \% \mathrm{MeOH}$ (in diH2O) $400 \mathrm{~mL} 50 \% \mathrm{MeOH} / 800 \mathrm{~mL}$ homogenate

e) Continue filtering until completely dry filter-cakes form

f) Record weight of filter cake(s) and total vol. of $\mathrm{MeOH}$ extracts

5) Liquid-liquid partitioning with ethyl acetate (EtOAc)

a) Partition $\mathrm{MeOH}$ extracts with $3 \times 200 \mathrm{~mL}$ ACS grade EtOAc/ $700 \mathrm{~mL}$ of $\mathrm{MeOH}$ extracts

b) In large separatory funnel add:

$-\mathrm{MeOH}$ extracts $(700 \mathrm{~mL})$

$-200 \mathrm{~mL}$ EtOAc

$-100 \mathrm{~mL}$ brine soln

$-50-100 \mathrm{~g} \mathrm{NaCl}$

$-100 \mathrm{~mL}$ diH2O (if needed to dissolve $\mathrm{NaCl}$ )

c) Agitate funnel to be sure contents are mixed well

d) Allow layers to separate for at least $30 \mathrm{~min}$. or until 2 distinct layers have formed (record total separation time) 
e) Empty aqueous (MeOH) layer into large Erlenmyer flask then collect organic (EtOAc) layer in another flask \& record volume of EtOAc extract

f) Add aqueous layer back into sep. funnel and add another $200 \mathrm{~mL}$ EtOAc

g) Repeat steps d. \& e. to have a total of $3 \times 200 \mathrm{~mL}$ EtOAc partitions

h) Wash sep. funnel(s) with small amt. of EtOAc \& add to collected extracts

i) Record total amount of EtOAc extracts and note color

6) Dry EtOAc extracts with anhydrous sodium sulfate $\left(\mathrm{Na}_{2} \mathrm{SO}_{4}\right)$ overnight under refridgeration

7) Concentrate EtOAc extracts in recovery flask on rotovap

a) Filter extracts into recovery flask

b) Wash $\mathrm{Na}_{2} \mathrm{SO}_{4}$ with EtOAc and filter wash into recovery flask with extracts

c) Rotovap to dryness \& repeat as needed until all extracts are concentrated

d) Record consistency \& color of concentrated crude extracts

8) Remove remaining solvent with high vacuum pump for 3 hours -overnight

a) Record final weight of dried extract and note consistency and color

\section{Isolation of annonacin from fruit extracts:}

Use gravity silica gel (Merck, Silica Gel $60 \mathrm{~F}_{254}$ ) packed to $250 \mathrm{~mm}$ in a $25 \mathrm{~mm}$ wide column. Volumes used are per $\sim 500 \mathrm{mg}$ of crude extract. Load crude extract in EtOAc adding small amounts of $\mathrm{MeOH}$ as needed to fully dissolve contents.

1) Gradient solvent system for 1st column chromatography:

a) Hexane : EtOAc 5:1 (500ml)

b) Hexane : EtOAc 1:1 (200ml)

c) Hexane : EtOAc 1:2 (200ml)

d) $100 \%$ EtOAc

e) $5 \% \mathrm{MeOH}$ in EtOAc $(500 \mathrm{ml})$

2) Gradient solvent system for $2^{\text {nd }}$ (and $3^{\text {rd }}$, if needed) column chromatography:

a) Hexane : EtOAc $1: 1(200 \mathrm{ml})$

b) Hexane : EtOAc 1:2 (300ml)

c) $5 \% \mathrm{MeOH}$ in EtOAc $(300 \mathrm{ml})$ 


\section{CURRICULUM VITAE}

\section{Lisa Fryman Potts}

Department of Anatomical Sciences and Neurobiology

University of Louisville

\section{Education}

University of Louisville

Ph.D. candidate in Anatomical Sciences and Neurobiology

Masters of Science in Anatomical Science and Neurobiology

Centre College

2005

Bachelors of Science in Psychobiology

\section{Professional Experience}

UNIVERSITY OF LOUISVILLE, Louisville, KY

2006 - present

Graduate Student

Supervised by Dr. Irene Litvan

\section{Abstracts and Meeting Presentations}

Potts LF, Luzzio FA, Hetman M, Litvan I. Annonacin isolated from Asimina triloba fruit pulp is toxic to rat primary cortical neurons. American Chemical Society, Medicinal Chemistry, August 25, 2010. Boston, MA. Society for Neuroscience, November 17, 2010. San Diego, CA. 
Potts LF, Luzzio FA, Litvan I, Bogdanov B. Isolation of annonacin from the fruit pulp of Asimina triloba. American Chemical Society, March 21, 2010, San Francisco, CA.

Potts LF, Ross O, Rademakers R, Dickson D, Wszolek Z, Farrer M, Hein D, Litvan I. Polymorphic genes of detoxification and mitochondrial enzymes as risk factors for progressive supranuclear palsy. Parkisnon's Study Group 23rd Annual Symposium, October 11, 2009, Baltimore, MD. Research!Louisville, University of Louisville, October 13, 2009, Louisville, KY.

Potts LF, Cunningham CR, Cambon A, Lees P, Adamson J, Cannon A, Hutton M, Uitti R, Wszolek Z, Juncos J, Litvan I. Pilot Case-Control Study of the Genetic and Environmental Risk Factors for PSP. University of Louisville Neuroscience Day. April 12, 2007, Louisville, KY. American Neurological Association. October 8, 2007, Washington, DC. Society for Neuroscience 37th Annual Meeting. November 5, 2007, San Diego, CA. American Neurological Association. October 8, 2007, Washington, DC. University of Louisville Neuroscience Day. April 12, 2007, Louisville, KY.

\section{Publications}

Lisa F. Potts, M.S.; Frederick A. Luzzio, Ph.D; Scott C Smith, M.S.; Michal Hetman, M.D., Ph.D; Pierre Champy, Pharm D., Ph.D.; Irene Litvan, M.D. Annonacin in Asimina triloba fruit: Implication for neurotoxicity. In Press. Neurotoxicology

Lisa F. Potts, Alex C. Cambon, Owen A. Ross, Rosa Rademakers, Dennis W. Dickson, Ryan J. Uitti, Zbigniew K. Wszolek, Shesh N. Rai, Matthew J. Farrer, David W. Hein, and Irene Litvan. Polymorphic Genes of Detoxification and Mitochondrial Enzymes and Risk for Progressive Supranuclear Palsy. Submitted. BMC Medical Genetics 